Barbara Ebert

\title{
Chlorellavirus-Proteine: \\ I. Die Hüllprotein-Genfamilie \\ II. Ein primitiver Kaliumkanal
}

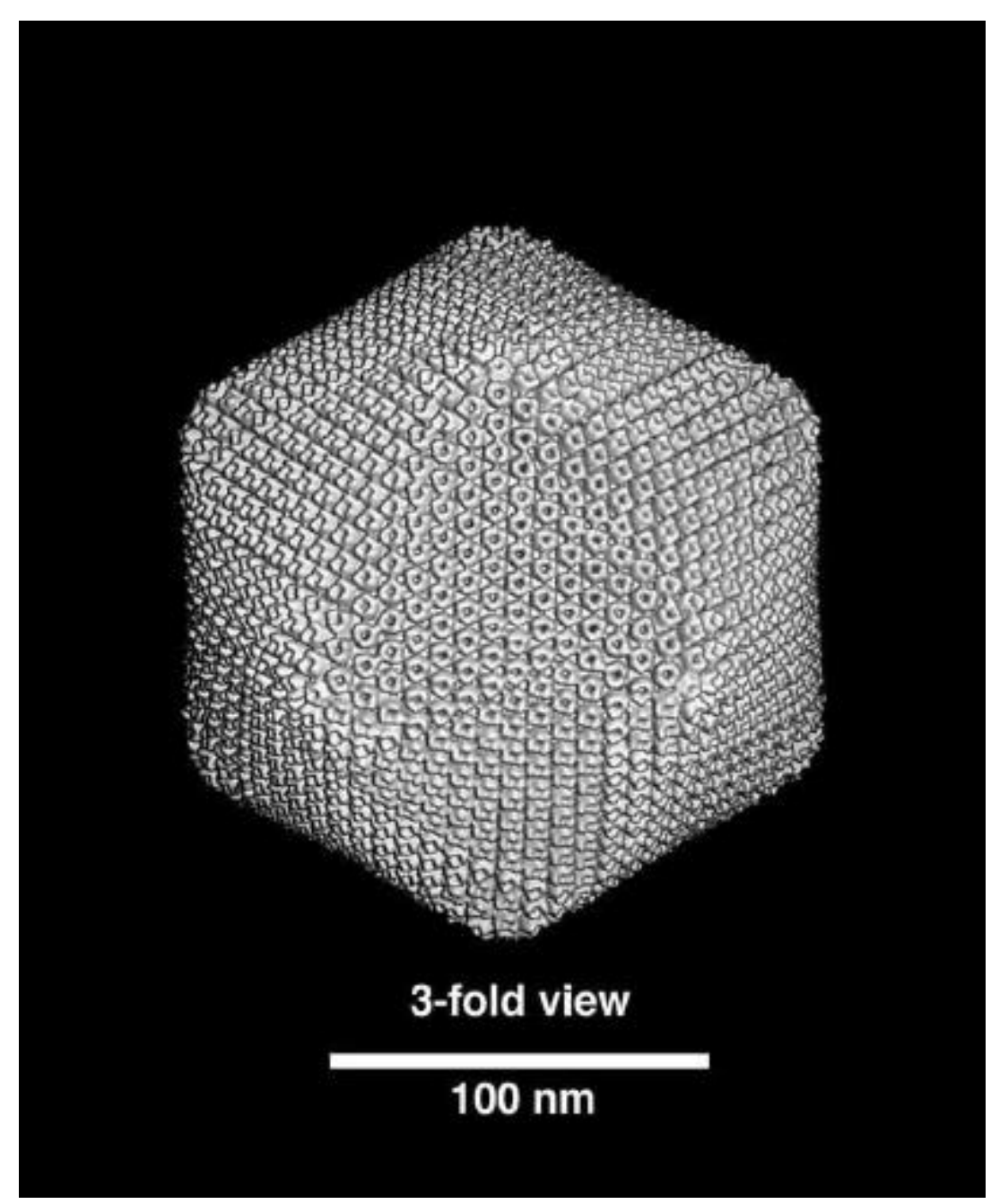




\title{
Chlorellavirus-Proteine:
}

\section{Die Hüllprotein-Genfamilie IV. Ein primitiver Kaliumkanal}

\author{
Dissertation \\ zur Erlangung des Doktorgrades \\ der Mathematisch-Naturwissenschaftlichen Fakultäten \\ der Georg-August-Universität zu Göttingen
}

vorgelegt von

Barbara Ebert

aus Braunschweig

Göttingen 1999 
D7

Referent: Prof. Dr. D. Gradmann

Korreferent: PD. Dr. G. Thiel

Tag der mündlichen Prüfung: 25.1.2000 


\section{INHALTSVERZEICHNIS}

1 EINLEITUNG 1

1.1 Viren 1

1.2 Chlorellaviren $\quad 2$

1.2.1 Taxonomische Einordnung der Chlorellaviren 4

1.2.2 Das PBCV-1 Genomprojekt 4

$\begin{array}{lll}1.2 .3 & \text { Zielsetzung } & 6\end{array}$

2 DAS HAUPTHÜLLPROTEIN-GEN VON CHLORELLAVIRUS CVG-1 IST TEIL EINER GENFAMILIE $\quad 7$

$\begin{array}{lll}2.1 & \text { Virale Hüllproteine und Wirtsspezifität } & 7\end{array}$

$\begin{array}{ll}2.2 & \text { Ergebnisse und Diskussion } \\ & 11\end{array}$

2.2.1 Genfragmente mit Ähnlichkeit zum viralen Hauptprotein 11

$\begin{array}{ll}\text { 2.2.2 Isolation der vollständigen Gensequenzen } & 12\end{array}$

2.2.3 Sequenzanalysen der offenen Leserahmen 13

$\begin{array}{ll}\text { 2.2.4 Sequenzvergleiche mit Proteinen aus anderen Chlorellaviren } & 16\end{array}$

$\begin{array}{lll}2.2 .5 & \text { Schlußfolgerungen } & 18\end{array}$

3 EIN KALIUMKANAL-GEN IN CHLORELLAVIRUS PBCV-1 19

3.1 Kaliumkanäle und Virus-codierte Ionenkanäle 19

$\begin{array}{lll}3.2 & \text { Ergebnisse } & 24\end{array}$

$\begin{array}{lll}\text { 3.2.1 Analyse der Primärstruktur von Kcv } & 24\end{array}$

3.2.2 Kcv-Homologe in anderen Viren? 27

$\begin{array}{ll}3.2 .3 & \text { Phylogenetische Analysen } \\ 3.2 .4 & 30\end{array}$

3.2.4 Nachweis einer Kcv-induzierten Leitfähigkeit in Xenopus Oocyten 32

3.2.5 Konstruktion einer nicht-funktionalen Mutante 44

3.3 Diskussion $\quad \mathbf{4 5}$

3.3.1 Gemeinsamkeiten von Kcv mit anderen Kanälen 45

3.3.2 Die Kcv-induzierte Leitfähigkeit 48

3.3.3 Die Rolle von Kcv im viralen Lebenszyklus 52

3.3.4 Weiterführende Experimente 54

3.4 Zusammenfassung $\quad \mathbf{5 5}$ 
4 Material \& Methoden $\quad 56$

4.1 EDV 56

4.2 Chemikalien $\quad 56$

4.2.1 Reaktionssysteme (Kits) 56

4.3 Organismen \& Plasmide

4.3.1 Escherichia coli (E. coli) 57

$\begin{array}{ll}\text { 4.3.2 } & \text { Bakteriophagen } \\ \text { 4.3.3 } & 57\end{array}$

$\begin{array}{lll}4.3 .3 & \text { Plasmide } & 57\end{array}$

$\begin{array}{lll}4.4 & \text { Oligonucleotide } & 58\end{array}$

$\begin{array}{ll}4.5 & \text { Kultivierung von } E \text {. coli }\end{array}$

$\begin{array}{lll}\text { 4.5.1 E. coli Stamm DH5 } \alpha \mathrm{F}^{\prime} & 60\end{array}$

4.5.2 E. coli Stamm XL1-Blue MRA 61

4.6 Polymerasekettenreaktion (PCR) 61

4.6.1 Amplifikation von Fragmenten aus genomischer DNA 61

4.6.2 Amplifikation von Plasmidinserts als Sondenmatritze 62

4.6.3 Analyse von Plasmiden aus Bakterienkolonien 62

$\begin{array}{lll}\text { 4.6.4 Sequenzierungsreaktionen } & 63\end{array}$

4.6.5 In vitro Mutagenese von ORF A250R 64

4.7 Reinigung und Konzentrierung von Nucleinsäuren $\quad 65$

$\begin{array}{lll}\text { 4.7.1 Phenol-Chloroform-Extraktion } & 65\end{array}$

$\begin{array}{lll}\text { 4.7.2 Schleudersäulen-Chromatographie } & 65\end{array}$

$\begin{array}{lll}4.7 .3 & 66\end{array}$

$\begin{array}{lll}\text { 4.7.4 Fällung } & 66\end{array}$

$\begin{array}{lll}\text { 4.7.5 Konzentrationsbestimmung } & 67\end{array}$

4.7.6 Isolation von DNA-Fragmenten aus Agarose-Gelen 67

4.8 Erstellen einer Genbibliothek von Chlorellavirus CVG-1 67

4.8.1 Partielle Restriktion mit Sau 3AI 67

$\begin{array}{lll}\text { 4.8.2 Fraktionierung im Saccharosegradienten } & 68\end{array}$

$\begin{array}{lll}4.8 .3 & \text { Größenselektion } & 68\end{array}$

$\begin{array}{lll}\text { 4.8.4 Ligation in EMBL3 } & 68\end{array}$

$\begin{array}{lll}4.8 .5 & \text { In vitro Verpackung } & 68\end{array}$

$\begin{array}{lll}\text { 4.8.6 Titerbestimmung } & 69\end{array}$

$\begin{array}{lll}4.9 & \text { Durchmustern der Genbibliothek } & \mathbf{7 0}\end{array}$

$\begin{array}{lll}\text { 4.9.1 Radioaktiv markierte Sonden } & 70\end{array}$

$\begin{array}{lll}\text { 4.9.2 Plattieren } & 71\end{array}$

4.9.3 Übertragen der Phagen-DNA auf Nylonmembranen 71

4.9.4 Hybridisierung mit $\alpha^{32}$ P-markierten Sonden 72

$\begin{array}{lll}\text { 4.9.5 Isolation positiver Plaques } & 72\end{array}$

4.9.6 Amplifikation positiver Phagenklone 72

$\begin{array}{lll}\text { 4.10 DNA-Extraktion aus Phagen } & \mathbf{7 3}\end{array}$

$\begin{array}{lll}\text { 4.10.1 Infektion der Wirtsbakterien } & 73\end{array}$

$\begin{array}{lll}\text { 4.10.2 Isolation der Phagenpartikel } & 73\end{array}$

$\begin{array}{ll}4.10 .3 & \text { DNA-Extraktion }\end{array}$ 
$\begin{array}{lll}\text { 4.11 } & \text { Restriktionsanalysen } & \mathbf{7 4}\end{array}$

$\begin{array}{lll}\text { 4.11.1 Plasmid DNA } & 74\end{array}$

$\begin{array}{lll}\text { 4.11.2 Phagen-DNA } & 75\end{array}$

$\begin{array}{lll}4.12 & \text { Gelelektrophorese } & 75\end{array}$

4.13 Southern Blot $\quad \mathbf{7 6}$

$\begin{array}{lll}\text { 4.13.1 Gelvorbehandlung } & 76\end{array}$

$\begin{array}{lll}\text { 4.13.2 Übertragung der DNA } & 76\end{array}$

4.13.3 Biotin-markierte Sonden 77

4.13.4 Hybridisierung mit Biotin-markierten Sonden 77

$\begin{array}{lll}4.14 & \text { Ligation von DNA-Fragmenten } & 78\end{array}$

$\begin{array}{lll}4.15 & \text { Transformation von } E \text {. coli } & 78\end{array}$

$\begin{array}{lll}4.16 & \text { Plasmidisolierung } & 79\end{array}$

$\begin{array}{lll}4.17 & \mathbf{7 9}\end{array}$

$\begin{array}{lll}4.18 & \text { Computergestützte Sequenzanalysen } & 79\end{array}$

$\begin{array}{ll}4.19 & \text { Analysen von voltage clamp-Daten }\end{array}$

5 LITERATURVERZEICHNIS $\quad 81$

$\begin{array}{lll}5.1 & \text { Artikel \& Bücher } & 81\end{array}$

$\begin{array}{lll}5.2 & \text { Web-Adressen } & 90\end{array}$

Anhang A: Abkürzungen für Aminosäuren und Nucleotide $\quad 90$

Anhang B: Nuclein- und Aminosäuresequenzen der Hüllprotein-Genfamilie $\quad 91$

Danksagung

Lebenslauf

Abbildung Titelseite: Dreidimensionale Rekonstruktion eines ChlorellavirusCapsids. Mit freundlicher Genehmigung von J.L. Van Etten der Homepage "World of Chlorella Viruses" entnommen (5.2). 


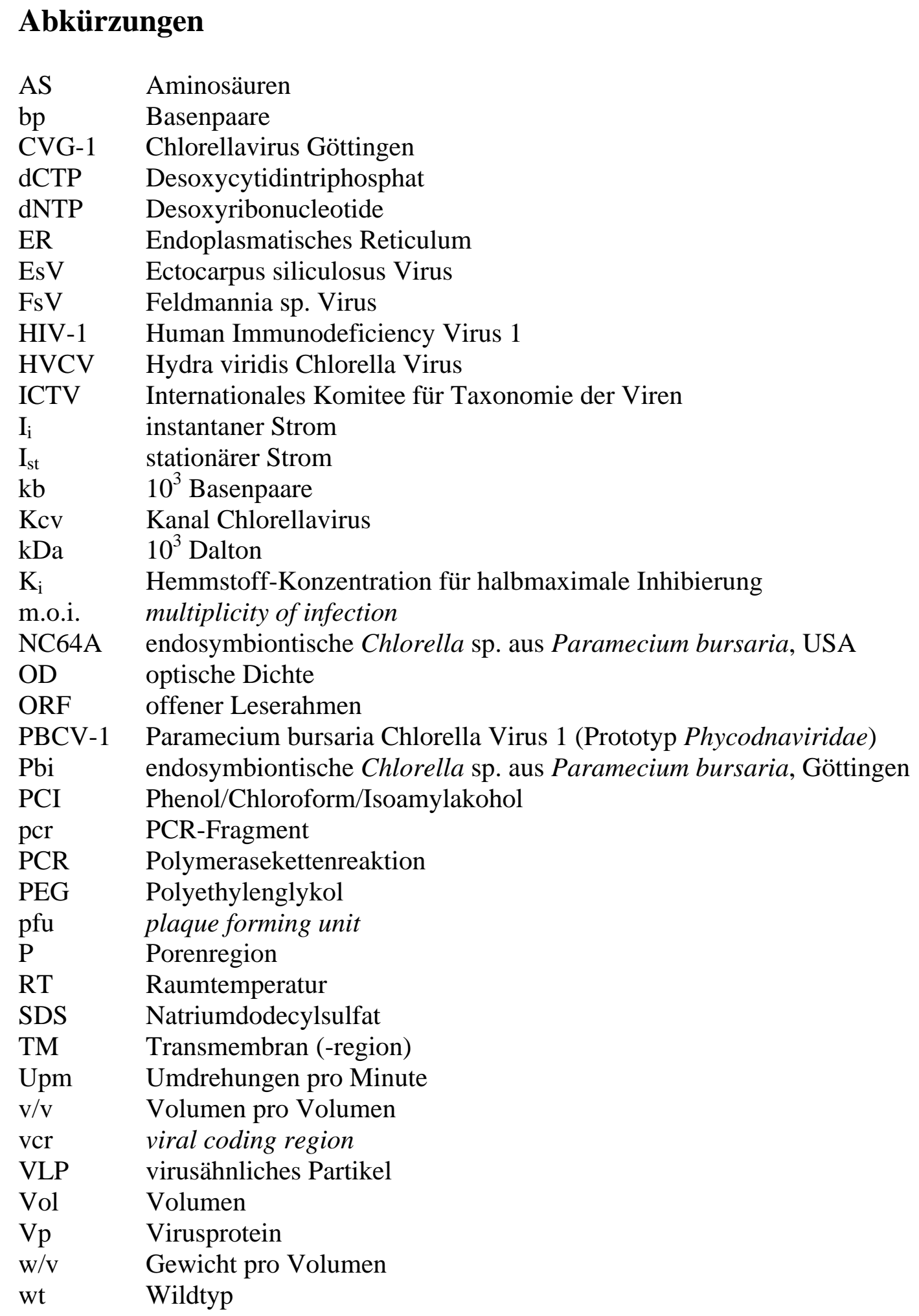




\section{EINLEITUNG}

\subsection{Viren}

Viren sind infektiöse Partikel ohne eigenen Stoffwechsel, die für ihre Vermehrung auf eine Wirtszelle angewiesen sind. Die Erbsubstanz der Viren besteht aus DNA oder RNA, die in einer Proteinhülle, dem Capsid verpackt ist. Das Viruspartikel heißt Virion. Besitzt es mehr als eine Hülle, so wird die äußerste Hüllschicht separat benannt und die innere mit der Nucleinsäure zusammen als Nucleocapsid bezeichnet.

Der Grad der Abhängigkeit des Virus vom Wirtsorganismus variiert mit der Größe des Genoms und der Anzahl der codierten Proteine. Das mit 190 kb sehr große Genom der Vacciniaviren codiert beispielsweise für eine DNA-Polymerase und eine Ribonucleotid-Reduktase - Enzyme, die zur weitgehend wirtsunabhängigen DNAReplikation des Virus beitragen. Die meisten Viren sind dagegen zur Replikation vollständig auf den Wirt angewiesen.

Viren sind so vielfältig wie die Organismen, die sie infizieren. Virustaxonomie ist deshalb sehr komplex und umfaßt Krankheitssymptome, Wirtsorganismen (Tiere, Pflanzen, Pilze, Bakterien), Morphologie, Genomstruktur, Proteinzusammensetzung und diagnostische Merkmale wie Antigeneigenschaften und Gewebespezifität. Das Internationale Komitee für Taxonomie der Viren (ICTV) geht davon aus, daß etwa 500-1000 Merkmale benutzt werden müßten, um eine Virusart umfassend zu beschreiben (für eine Übersicht des taxonomischen Systems s. Francki et al. 1991, aktuelle Informationen gibt die Homepage des ICTV, 5.2). Das taxonomische System beschränkte sich bisher auf die Ebenen Art, Gattung, Subfamilie und Familie. Jedoch werden mit neuen Methoden zunehmend Verwandtschaftsbeziehungen zwischen Virusfamilien mit unterschiedlichster Wirtsspezifität und Pathogenität aufgedeckt, so daß inzwischen die Einführung familienübergreifender Ordnungen diskutiert wird. Beispielsweise deuten Übereinstimmungen in Capsidarchitektur und Struktur der Hüllproteine von Bakteriophage PRD1 und Adenovirus Typ2 auf einen gemeinsamen evolutionären Ursprung dieser Viren hin (Benson et al. 1999). 


\subsection{Chlorellaviren}

Berichte über virusähnliche Partikel (VLP) in elektronenmikroskopischen Aufnahmen von Algen finden sich in der Literatur seit den späten fünfziger Jahren. Eine Infektion gesunder Algenkulturen mit isolierten VLPs gelang in der Regel nicht, da das Partikelvorkommen insgesamt sehr gering war und die Wirtsalgenspezies oftmals nicht in Kultur vorlagen. Chlorellaviren (Abbildung 1A, B) gehören zu den wenigen bisher isolierten Algenviren, die sich im Labor vermehren lassen (Kawakami \& Kawakami 1978, Meints et al. 1981, Van Etten et al. 1982). Ihr Wirt, die einzellige Grünalge Chlorella sp., lebt als Endosymbiont in Paramecium bursaria, einem Pantoffeltierchen. Die Alge kann aus dem Symbioseverband isoliert werden und ist dann - im Gegensatz zu vielen anderen Exsymbionten - im Labor kultivierbar. Analog zu Methoden der bakteriellen Virologie können sie sogar auf Agarose-haltigen Medien ausplattiert werden und bilden dort einen dichten „Algenrasen“. Virusinfektionen erscheinen auf den Platten als helle Lysehöfe (Plaques). Solche Plattentests können z.B. eingesetzt werden, um verschiedenen Wirtsalgen- und Virusisolate auf ihre Kompatibilität zu prüfen oder die Wirkung von Inhibitoren zu testen, die dem Medium zugesetzt werden.

Chlorellaviren wurden bereits in allen Teilen der Welt isoliert (Zhang et al. 1988; Yamada et al. 1993; Van Etten \& Meints 1999) und sind trotz ihrer weiten Verbreitung ein Sonderfall unter den pflanzenpathogenen Viren. Sie gehören zu der sehr kleinen Gruppe der DNA-Pflanzenviren und sind mit einem Capsiddurchmesser von ca. $150 \mathrm{~nm}$ und einer Genomgröße von über $300 \mathrm{~kb}$ ungewöhnlich groß. Ihr ikosaedrisches Capsid besteht aus einer äußeren Glykoproteinschicht und einer internen Membran (Übersicht in Van Etten \& Meints 1999).

Der Infektionsmechanismus der Chlorellaviren ist unter Pflanzenviren bisher einmalig: Die Wand der Wirtszelle wird durch ein viruseigenes Enzym lokal aufgelöst und die DNA in die Zelle entlassen (Abbildung 1C). Das Capsid bleibt an der Zelloberfläche zurück (Meints et al. 1984). Normalerweise infizieren Pflanzenviren ihren Wirt über tierische Vektoren oder Läsionen der Blattoberfläche - Zellen mit intakter Zellwand werden nicht infiziert. Das Viruspartikel wird durch Endocytose als komplettes Capsid von der Wirtszelle aufgenommen. 
A

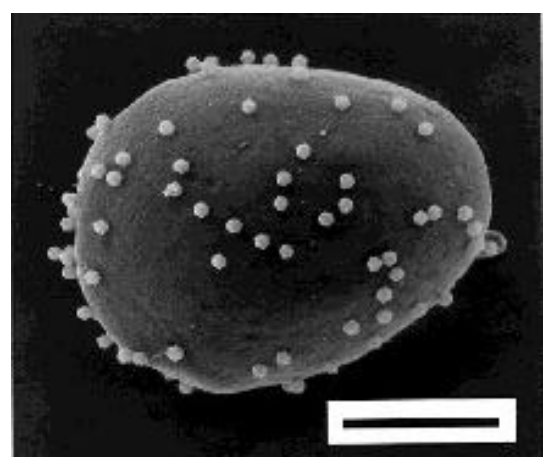

B

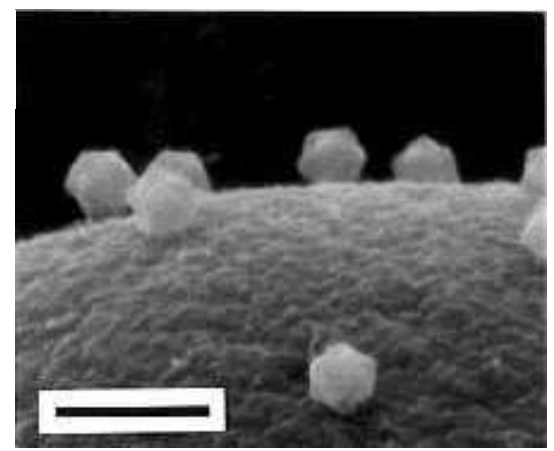

C

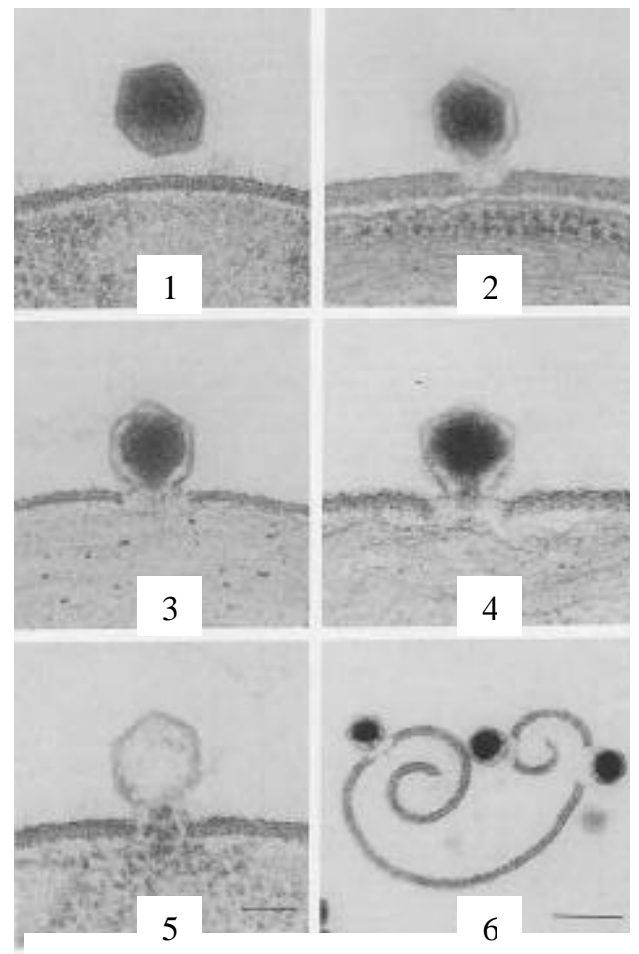

Abbildung 1: Chlorellaviren

(A) Eine Chlorella-Zelle mit angehefteten Viruspartikeln. Balken entspricht $1 \mu \mathrm{m}$.

(B) Chlorellaviren auf der Zelloberfläche. Balken entspricht $10 \mathrm{~nm}$. (C) Ein Chlorellavirus dringt in eine Wirtszelle ein: Ein Viruspartikel nähert sich der Zelloberfläche (1); nach Anheften beginnt die lokale Lyse der Zellwand $(2+3)$; die virale DNA wird in den Wirt entlassen (4); ein leeres Capsid bleibt an der Zelloberfläche zurück (5). Auch isolierte Zellwände werden lysiert, allerdings entlassen die Viren dann keine DNA (6). Die isolierten Zellwände rollen sich einwärts, das Anheften der Viruspartikel findet stets an der Außenseite statt (Meints et al. 1984). Die Aufnahmen wurden mit freundlicher Genehmigung der Homepage „World of Chlorella Viruses" von J.L. Van Etten entnommen (5.2).

Die Freisetzung des Genoms (uncoating) erfolgt in der Zelle. Die Strategie der Chlorellaviren - aktive Auflösung der Zellwand, und uncoating außerhalb der Zelle - ist dagegen nur von einigen Bakteriophagen bekannt.

Die DNA der Chlorellaviren ist methyliert (Van Etten et al. 1985). Die Modifikation der Nucleotide ist keine Funktion der Wirtszelle, sondern wird von viruseigenen, sequenzspezifischen Methyltransferasen katalysiert (Xia et al. 1986a, Zhang et. al. 1992). Interessanterweise besitzen Chlorellaviren dazu Restriktionsendonucleasen mit komplementären Erkennungssequenzen (Xia et al. 1986b, Zhang et. al. 1992), wie sie bisher nur aus Bakterien bekannt waren. Die biologische Funktion dieser Restriktions/Modifikationssysteme ist jedoch nicht aufgeklärt (Van Etten \& Meints 1999). 


\subsubsection{Taxonomische Einordnung der Chlorellaviren}

Die einzigen Pflanzenviren mit ähnlich großem Genom sind ebenfalls Algenviren: Ectocarpus siliculosus Virus (EsV, Müller et al. 1990) und Feldmannia sp. Virus (FsV, Henry \& Meints 1992) befallen filamentöse marine Braunalgen. Ihr Capsiddurchmesser beträgt wie bei Chlorellaviren ca. $150 \mathrm{~nm}$. Ebenso sind Glykoproteine und methylierte Basen im Genom beschrieben worden (Übersicht in Müller et al. 1998 und Van Etten \& Meints 1999). EsV vermehrt sich nur in den Sporangien, so daß die Virusinfektion für den Wirt nicht tödlich ist. EsV-ähnliche Viruspartikel finden sich im Großteil der freilebenden Ectocarpus-Arten (Müller et al. 1992; Sengco et al. 1996). Anders als Chlorellaviren ist EsV nicht streng wirtsspezifisch, sondern infiziert auch eine Reihe anderer Braunalgen als Ectocarpus (Müller 1992; Müller \& Parodi 1993). Diese Befunde sind besonders in ökologischer Hinsicht interessant, da EsV als Vektor für horizontalen Gentransfer dienen könnte (Van Etten \& Meints 1999). Taxonomisch werden EsV und FsV zusammen mit den Chlorellaviren in die Familie Phycodnaviridae eingeordnet (Van Etten 1995, Van Etten \& Meints 1999).

Die nächsten Verwandten der Phycodnaviridae sind nach phylogenetischer Einordnung der DNA-Polymerase-Gene die Herpesviridae (Chen \& Suttle 1996). Die Familie Iridoviridae (z.B. Frog virus 3) hat eine Reihe von Strukturmerkmalen, wie ikosaedrische Form, interne Lipidschicht, DNA-Genom und methylierte Basen, mit Chlorellaviren gemeinsam (Übersich in Willis 1985).

\subsubsection{Das PBCV-1 Genomprojekt}

Der Prototyp der Familie Phydcodnaviridae ist Chlorellavirus PBCV-1. Das Genom von PBCV-1 ist seit 1997 vollständig sequenziert (Li et al. 1995; Lu et al. 1995; Kutish et al. 1996; Lu et al. 1996; Li et al. 1997). Es enthält 701 offene Leserahmen (ORFs), von denen etwa 100 ORFs Ähnlichkeit mit Proteinen bekannter Funktion haben (Übersicht über ORFs und codierte Proteine in Van Etten \& Meints 1999). Für 20 ORFs ist nachgewiesen, daß die codierten Enzyme funktional sind (Tabelle 1). 
Tabelle 1: Funktionale Enzyme codiert von Chlorellavirus PBCV-1 (nach Van Etten \& Meints 1999)

$\begin{array}{llll}\text { A544R } & \text { DNA-Ligase } & \text { A517L } & \text { Cytosin-DNA-Methylase (AIII) } \\ \text { A583L } & \text { DNA-Topoisomerase II } & \text { A530R } & \text { Cytosin-DNA-Methylase (AIV) } \\ \text { A50L } & \text { T4 Endonuclease V } & \text { A581R } & \text { Adenin-DNA-Methylase (AI) } \\ \text { A169R } & \text { Aspartat-Transcarbamylase } & \text { A579L } & \text { Restriktionsendonuclease (AI) } \\ \text { A103R } & \text { RNA-Guanyltransferase } & \text { A98R } & \text { Hyaluronan-Synthase } \\ \text { A248R } & \text { Phosphorylase B-Kinase } & \text { A100R } & \text { Glucosaminsynthase } \\ \text { A181R } & \text { Chitinase } & \text { A690L } & \text { UDP-Glucose-Dehydrogenase } \\ \text { A292L } & \text { Chitosanase } & \text { A270R } & \text { Ornithin-Decarboxylase } \\ \text { A251R } & \text { Adenin-DNA-Methylase (AII) } & \text { A237L } & \text { Homospermidin-Synthase } \\ \text { A252R } & \text { Restriktionsendonuclease (AII) } & \text { A284L } & \text { Amidase }\end{array}$

Besonders auffällig ist, daß einige ORFs Sequenzen aus Prokaryoten oder Phagen ähneln, während andere eindeutig eukaryotischen Ursprungs sind - ein Hinweis auf häufigen Gentransfer während der Evolution der Viren (Van Etten \& Meints 1999). Eine weiterer interessanter Aspekt ist die Vielfalt der Enzyme, für die das Virus codiert - Enzyme für Nucleotid-Biosynthese, Protein- und DNA-Modifikation, Phosphorylierung, Zellwandabbau und Kohlehydratmetabolismus, um nur einige zu nennen. Diese Enzyme sind, neben der Frage nach der biologischen Funktion im viralen Lebenszyklus, z.T. auch für die kommerzielle Anwendung nutzbar. So sind beispielsweise die Restriktionsendonucleasen und Methyltransferasen bereits im Handel erhältlich.

Eine Vielzahl von Projekten ist nötig um die Funktion weiterer Gene aufzuklären. Sie sind ein wertvolles Werkzeug, um die komplexe Biologie dieser Viren zu erforschen, deren Replikation einen außergewöhnlichen Grad an Selbständigkeit erreicht zu haben scheint. Das Genom von Chlorellavirus PBCV-1 hat immerhin 1/4 der Länge des kleinsten bisher sequenzierten Bakteriengenoms, des obligaten Parasiten Rickettsia prowazekii (Andersson et al. 1998). Das Rickettsia-Genom enthält 834 Proteincodierende Gene - lediglich 133 mehr als die Anzahl der ORFs im Genom von PBCV-1. 


\subsubsection{Zielsetzung}

Bisher wurden rund 60 Vertreter der Gattung Chlorellavirus charakterisiert, die entweder Chlorella-Stamm NC64A oder Chlorella Pbi infizieren und anhand dieser Wirtsspezifität gruppiert werden (Van Etten \& Meints 1999, s. auch 2.1). Diese strenge Wirtsspezifität ist eines der wichtigsten taxonomischen Merkmale der Chlorellaviren. Morphologie und Genomstruktur der Chlorella NC64A- und Chlorella Pbi-infizierenden Virusisolate ähneln sich sehr (Becker 1991). Ein Ziel der Arbeit war es, die Charakterisierung des Pbi-Virus CVG-1 von Becker (1991) durch genetische Analysen zu ergänzen und das Haupthüllproteingen von CVG-1 zu isolieren. Sequenzvergleiche mit dem korrespondierenden Gen von PBCV-1 sollten zu Aussagen hinsichtlich der Verwandtschaftsbeziehungen zwischen den beiden Virustypen führen. Da das Capsid der Chlorellaviren höchst komplex ist und sich aus mehreren verschiedenen Proteinen zusammensetzt, sollten darüber hinaus weitere Strukturproteine identifiziert werden, die möglicherweise ebenfalls taxonomische Merkmale darstellen.

Der zweite Teil der Arbeit steht im Zusammenhang mit dem PBCV-1-Genomprojekt und dem Ziel, die Funktion der dort codierten Proteine zu erforschen. Ein besonders interessanter Kandidat dafür ist ein kurzer offener Leserahmen, dessen Sequenz Ähnlichkeiten mit der Porendomäne eukaryotischer Kaliumkanäle aufweist (3.1). Die Funktion eines solchen Kanals ist zum einen im Hinblick auf die virale Physiologie zu klären. Zum anderen sind virale Gene in der Regel zellulären Ursprungs und können - so sie nicht in jüngerer Zeit durch horizontalen Gentransfer erworben sind - evolutionär sehr alt sein. Daher könnte ein viraler Kaliumkanal auch zur Aufklärung der hochkonservierten Struktur von Kaliumkanälen einen Beitrag leisten. 


\section{DAS HAUPTHÜLLPROTEIN-GEN VON CHLORELLAVIRUS CVG-1 IST TEIL EINER GENFAMILIE}

\subsection{Virale Hüllproteine und Wirtsspezifität}

Hüllproteine sind entscheidende Faktoren der viralen Wirtserkennung. Sie interagieren in spezifischer Weise mit Strukturen der Zelloberfläche und vermitteln die Anheftung des Partikels. Erfolgt nach der Zellerkennung keine Abwehrreaktion des Wirts, dringt das Virus ein (Abbildung 1).

Chlorellavirus-Isolate sind sehr spezifisch in ihrer Wirtswahl und werden entsprechend gruppiert (Abbildung 2): Pbi-Viren infizieren den Chlorella-Stamm Pbi (isoliert aus Paramecium bursaria-Zellen, gesammelt in Göttingen), NC64A-Viren den Chlorella-Stamm NC64A (isoliert aus P. bursaria-Zellen gesammelt im USBundesstaat North Carolina) und die Gruppe der HVCV-Viren infiziert ChlorellaStämme, die aus dem Süßwasserpolypen Hydra viridis isoliert wurden.

Die exsymbiontischen Wirtszell-Stämme Chlorella Pbi und Chlorella NC64A unterscheiden sich in Chloroplasten-Morphologie (Abbildung 2) und Zellwandzusammensetzung. Beide Stämme sind zwar keiner freilebenden Chlorella-Art zuzuordnen, stehen aber der Chlorella vulgaris/sorokiniana-Gruppe nahe (Reisser \& Widowski 1992).

PBCV-1, ein Vertreter der NC64A-Viren, ist das bestuntersuchte Chlorellavirus und Prototyp der Phycodnaviridae (Übersicht in Van Etten \& Meints 1999). Über die vor allem in Europa isolierten Pbi-Viren ist dagegen nur wenig bekannt. Die einzig verfügbare genomische Sequenz eines Pbi-Virus war ein Fragment des DNAPolymerase-Gens (Chen \& Suttle 1996). In phylogenetischen Analysen von DNAPolymerase-Genen verschiedener Algenviren (Chen \& Suttle 1996) werden Pbi- und NC64A-Viren in separate, wenn auch nah verwandte Gruppen eingeordnet. Die Viren infizieren die Wirtsalgen der jeweils anderen Gruppe nicht, weil sie sich nicht an die Zellwand anheften können (Reisser et al. 1988). Dies mag mit der unterschiedlichen Zellwandzusammensetzung der Wirtsalgen zusammenhängen, die sich jedoch auch in Variationen der viralen Hüllproteine widerspiegeln muß. 


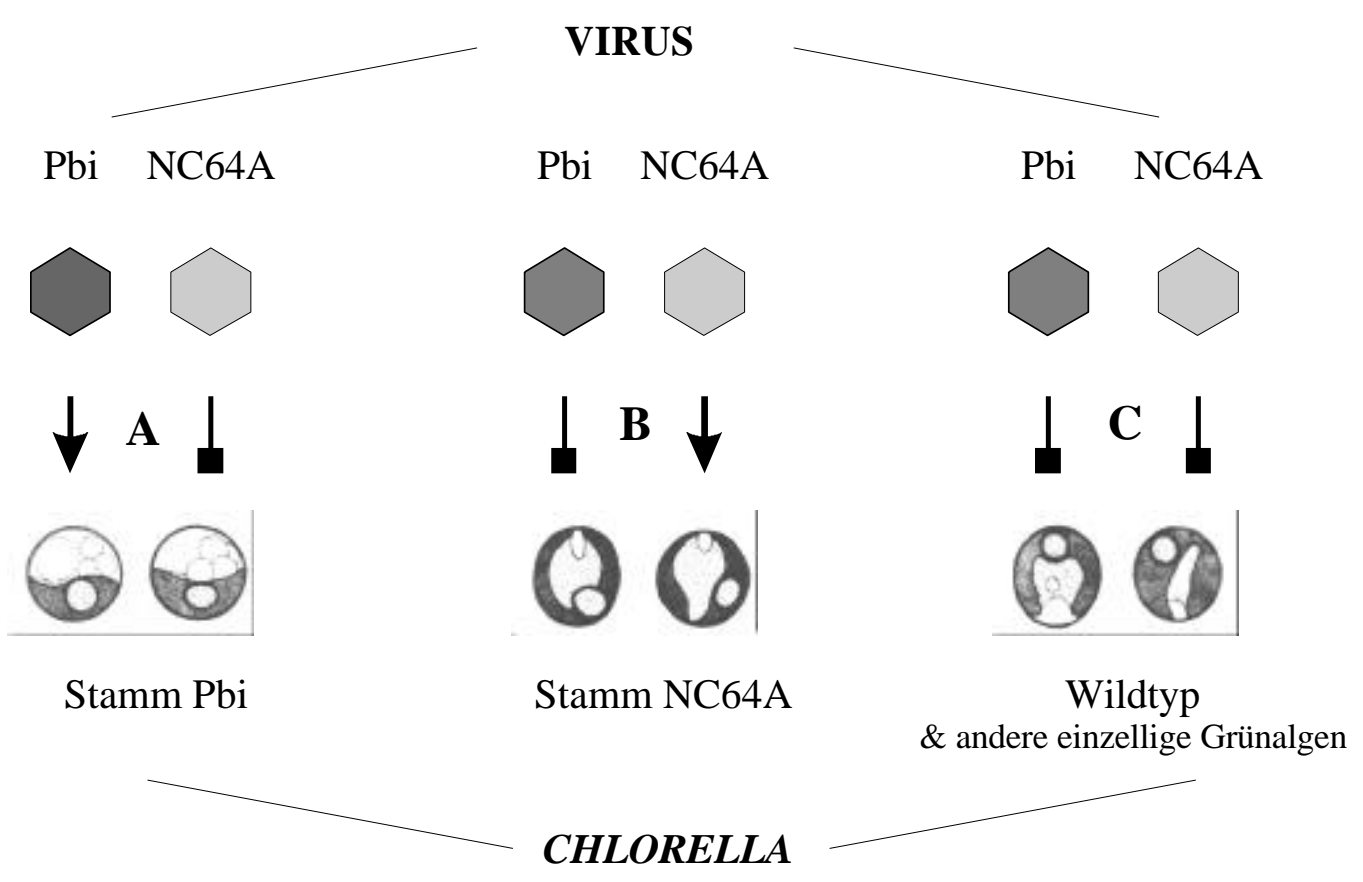

\section{Abbildung 2: Wirtsspezifität der Chlorellavirus-Gruppen Pbi und NC64A}

(A) Pbi-Viren infizieren Chlorella Pbi (Reisser 1984), aber nicht Chlorella NC64A. Beide Wirtsalgen wurden aus Symbiosen mit Paramecium bursaria isoliert. (B) NC64A-Viren infizieren Chlorella Pbi nicht. (C) Freilebende Chlorella-Arten und eine Reihe ebenfalls aus Symbiosen isolierter Chlorella-Stämme werden weder von Pbi- noch von NC64A-Viren infiziert (Reisser et al. 1986). Die schematische Darstellung der Chlorella-Zellen (aus Reisser \& Widowski 1992) läßt die unterschiedliche Chloroplastenmorphologie erkennen.

Einige der mehr als 50 Strukturproteine des Viruspartikels (des sog. Virions) sind glykosyliert und befinden sich in der äußersten Schicht des Capsids (Skrdla et al. 1984, Songsri et al. 1997). Die Oberfläche des Virions besteht vor allem aus dem glykosylierten Haupthüllprotein, das $40 \%$ des viralen Gesamtproteins ausmacht (Skrdla et al. 1984). Jedoch ist fraglich, ob das Haupthüllprotein auch beim Wirtserkennungsprozeß eine Rolle spielt: Mehrere Varianten von PBCV-1 können trotz unvollständiger Oligosaccharid-Seitenketten die Wirtsalge NC64A infizieren (Wang et al. 1993a). Das Schlüsselprotein für die Wirtserkennung ist wahrscheinlich eines der weniger stark repräsentierten Oberflächenproteine. 
Das Virus heftet sich stets mit einer Ecke an die Wirtszelle an und entläßt an dieser Stelle seine DNA in die Zelle (Abbildung 1C). Je nach Präparationstechnik zeigen elektronenmikroskopischen Aufnahmen von PBCV-1 auch haarähnliche Strukturen an einigen Ecken, bzw. eine Art Schwanz, wie er von Bakteriophagen bekannt ist (Van Etten et al. 1991). Cryoelektronenmikroskopische Bilder zeigen diese Strukturen nicht (Yan et al. 1999). Trotz Anwendung verschiedener Präparationstechniken wurden bei Pbi-Viren keine solchen Strukturen beobachtet (Becker 1991).

Eine dreidimensionale Rekonstruktion des PBCV-1 Capsids aus über 300 cryoelektronenmikroskopischen Aufnahmen (s. Titelblatt) zeigt, daß die Ecken des Ikosaeders von 12 Capsomeren mit Pentamer-Struktur und die seitlichen Flächen von 1680 Capsomeren aus Protein-Trimeren gebildet werden (Yan et al. 1999). Die Trimere setzen sich wahrscheinlich aus dem Haupthüllprotein zusammen, während die Pentamere - die auch in der Größe unterschiedlich sind - wahrscheinlich aus anderen Oberflächenproteinen bestehen (Yan et al. 1999). Songsri et al. (1997) identifizierte sieben solcher Oberflächenproteine in der äußeren Hülle von Chlorellavirus CVK2. Zwei Proteine ähnelten am N-Terminus dem Haupthüllprotein.

Nicht alle Viren besitzen glykosylierte Hüllproteine. Sie sind vor allem bei membranumhüllten Viren üblich (z.B. Influenzavirus), wo sie als spikes aus der Membran herausragen. Diese Glykoproteine besitzen zumeist eine hydrophobe Transmembrandomäne von etwa 20 Aminosäuren Länge (Schlesinger \& Schlesinger 1987). Das Haupthüllprotein von PBCV-1 besitzt eine 30 Aminosäuren lange hydrophobe Region am C-Terminus und ist außerdem mit der Fettsäure Myristylat verknüpft (Graves \& Meints 1992, Que et al. 1994). Beide Eigenschaften könnten zur Verbindung des Proteins mit der internen Lipidschicht des Virions beitragen.

Virale Glykoproteine besitzen die Fähigkeit, Zell-Zell-Fusionen bzw. Fusionen von Virushüllmembran und Wirtsmembranen herbeizuführen (Schlesinger \& Schlesinger 1987). So könnte auch der außergewöhnliche Infektionsmechanismus der Chlorellaviren erklärt werden (1.2). Becker (1991) vermutet, daß nach vollendeter Lyse der Zellwand die innere Lipidschicht des Virus mit dem Plasmalemma der Wirtszelle fusioniert. Auf ähnliche Art und Weise verläuft die Infektion des ikosaedrischen Bakteriophagen PRD1 (Tectiviridae), der ebenfalls eine interne Lipidschicht enthält. 
Wie PBCV-1 dockt PRD1 mit einer Ecke des Ikosaeders an die Wirtszelle an. An dieser Stelle wird anschließend die DNA entlassen und durch eine schwanzartige Ausstülpung, die von der internen Membran gebildet wird, in die Zelle injiziert (Bamford et al. 1995). Möglicherweise sind dabei Glykoproteine des Virions an der Vermittlung der Membranfusion beteiligt.

Im folgenden Abschnitt der Arbeit werden strukturelle Komponenten des Pbi-Virus CVG-1 auf genetischer Ebene untersucht, um die strukturelle Unterschiede zwischen NC64A- und Pbi-Viren zu beleuchten. Ziel war es, das Haupthüllprotein und verwandte Virionkomponenten zu isolieren und wenn möglich korrespondierende Gene der NC64A-Viren zu identifizieren. 


\subsection{Ergebnisse und Diskussion}

\subsubsection{Genfragmente mit Ähnlichkeit zum viralen Hauptprotein}

SDS-PAGE Proteingele zeigen, daß CVG-1 Partikel ca. 50 verschiedene Proteine enthalten, deren molekulare Massen im Bereich von 10-200 kDa liegen (Abbildung 3). Das häufigste Protein, Vp49, liegt als Dimer vor (Abbildung 3B) und ähnelt in seiner N-terminalen Sequenz dem Haupthüllprotein Vp54 von Chlorellavirus PBCV1 (Tabelle 2, Plugge et al. 1999). Nach Erhitzen liegt die Hauptproteinbande bei 49 kDa (Abbildung 3A), da das Dimer zerfällt.

Das für Vp49 codierende Gen sollte in einer Polymerasekettenreaktion mit Hilfe degenerierter Oligonucleotide isoliert werden (4.4). Das Aminosäuremotiv VAYGAQDVY am N-Terminus von Vp49 (Abbildung 4) wurde unter Berücksichtigung der Degeneration des genetischen Codes in Nucleinsäuresequenzen übersetzt. Ein zweites Motiv, NFNHPTKYL, wurde der Sequenz von Vp54 entnommen, dem Haupthüllprotein des Virusstammes PBCV-1 (Abbildung 4). Der zwischen den Primern liegende Abschnitt des Hüllproteingens wurde - nach der bekannten Sequenz von Vp54 - auf eine Länge von ca. 760 bp geschätzt.

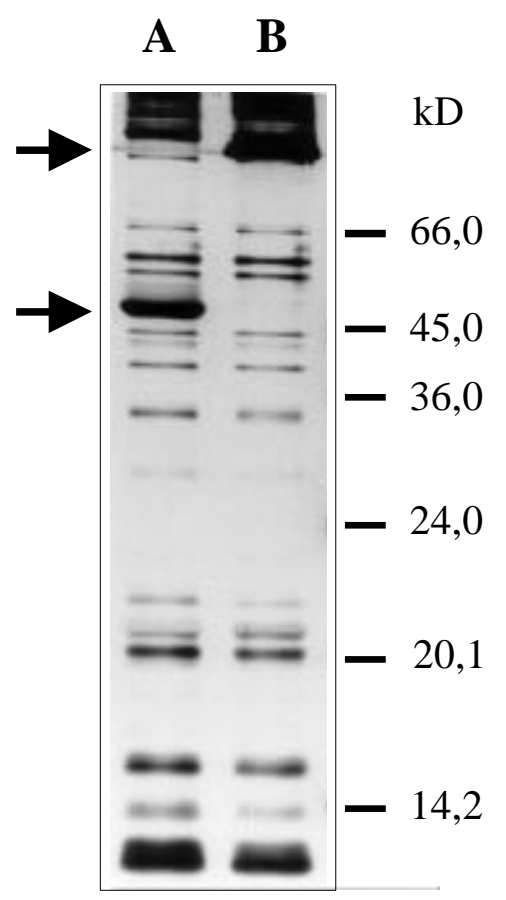

\section{Abbildung 3: Proteinmuster von CVG-1}

Elektrophoretische Auftrennung im 12,5\% SDS-Gel. Die Proteinpräparationen wurden vor dem Auftragen $5 \mathrm{~min}$ bei $100{ }^{\circ} \mathrm{C}$ (A) bzw. $60{ }^{\circ} \mathrm{C}$ (B) erhitzt. Pfeile markieren die Position der monomeren $(49 \mathrm{kDa})$ und dimeren $(95 \mathrm{kDa})$ Form des viralen Hauptproteins. Die Linien markieren die Protein-Größenstandards. Die Abbildung wurde aus Plugge et al. 1999 entnommen. 
In der Polymerasekettenreaktion wurden überraschenderweise nicht eines, sondern zwei Fragmente mit unterschiedlicher Größe amplifiziert. Nach Ligation der Fragmente in den Vektor pUC18 und anschließender Transformation wurden drei verschiedene Klone isoliert: pcr3 (800 bp), pcr7 (800 bp) und pcr8 (1100 bp). Ein Vergleich der translatierten Sequenzen der drei Klone ergab eine $60 \%$ ige Ähnlichkeit der Aminosäuresequenzen untereinander und eine ebenfalls signifikante Ähnlichkeit aller drei Klone mit dem Haupthüllprotein des Chlorellavirus Stamms PBCV-1. Statt des anvisierten einen waren also gleich drei potentielle Hüllproteingene amplifiziert worden.

\subsubsection{Isolation der vollständigen Gensequenzen}

Um die fehlenden 5'- und 3'-Bereiche der isolierten Genfragmente zu vervollständigen, wurde eine Genbibliothek von CVG-1 erstellt.

Sau 3AI-Fragmente genomischer DNA wurden, wie im Methodenteil beschrieben (4.8.1), aufgearbeitet und in den Bakteriophagen EMBL3 kloniert. Die so erhaltene Genbibliothek wurde in repräsentativer Dichte plattiert und mit radioaktiv markierten Sonden durchmustert. Als Sonden wurden die Klone pcr7 und pcr8 eingesetzt. Die nach Entwicklung der Autoradiogramme sichtbaren Signale konnten einzelnen Plaques zugeordnet werden. Die isolierten rekombinanten Phagen wurden in Southern Blot-Analysen erneut mit pcr7 hybridisiert, um die Anwesenheit der gesuchten Sequenzen zu bestätigen.

Die in den Southern Blot-Analysen identifizierten Restriktionsfragmente wurden ohne weitere Trennung zur Ligation mit dem Vektor pBluescript $\mathrm{KS}^{+}$eingesetzt (shotgun Verfahren) und sequenziert. Durch primer walking (4.17) wurden in diesen Fragmenten zwei vollständige Leserahmen (ORFs) identifiziert: vcr7 (1299 bp) enthielt die Sequenz von pcr7 und vcr8 (1566 bp) enthielt die Sequenz von pcr8. Für pcr3 wurde kein Phagensubklon isoliert. Die vollständigen Nuclein- und Aminosäuresequenzen der drei Gene sind in Anhang B verzeichnet. 


\title{
2.2.3 Sequenzanalysen der offenen Leserahmen
}

Der A/T-Gehalt der 50 bp vor den Start-Codons von vcr7 und vcr8 (76\% bzw. $78 \%$ ) ist deutlich höher als in den codierenden Regionen (42\%/ bzw. $51 \%$ ). Diese Gewichtung ist typisch für ORFs, die im Genom des Virusstamms PBCV-1 identifiziert wurden (Schuster et al. 1990, Lu et al. 1995). Markant ist auch eine Reihe von 10 bzw. 9 Adeninnucleotiden 30 bp aufwärts vom Start-Codon (s. Anhang B). Dieses Motiv spielt in den Promotorregionen von frühen Genen des shope fibroma Virus eine wichtige Rolle (Macaulay \& McFadden 1989) und findet sich ebenfalls in einer Reihe von PBCV-1 Genen (Graves \& Meints 1992).

Die Aminosäuresequenzen der ORFs vcr7 und vcr8 enthalten mehrere Erkennungssequenzen für Protein-glykosylierende Proteine (Abbildung 4), die hinsichtlich der bekannten Glykosylierung der Haupthüllproteine Vp54 und Vp49 von PBCV-1 und CVG-1 bedeutsam sein könnten. Normalerweise werden virale Glykoproteine durch Glykosyltransferasen des Wirts im Endoplasmatischen Reticulum (ER) oder GolgiApparat modifiziert (Schlesinger \& Schlesinger 1987). Die Glykanketten der Haupthüllproteine sind jedoch nicht $\mathrm{N}$-glykosidisch gebunden, wie es für ER-modifizierte Proteine typisch ist (Graves \& Meints 1992, Becker 1991). Tatsächlich codiert zumindest PBCV-1 offensichtlich für eigene glykosylierende Enzyme (Wang et al. 1993a, Van Etten \& Meints 1999). Bisher wurden im Genom von PBCV-1 zwei ORFs gefunden, die eine entfernte Ähnlichkeit mit bekannten Glykosyltransferasen aufweisen (Van Etten \& Meints 1999).

nächste Seite

\begin{abstract}
Abbildung 4: Aminosäuresequenzen der CVG-1 Leserahmen
Multiples Alignment mit korrespondierenden Genen aus PBCV-1. Bestimmte Abschnitte von $v c r 7$ und $a 430 l$ weichen deutlich stärker voneinander ab als der Rest der Sequenz (AS 310-330, AS 413-441 und AS 519-536). Vcr8 und a622l besitzen eine Domäne von ca. 100 Aminosäureresten (AS 92-196), die keine Ähnlichkeit mit den anderen Genen aufweist. Die Positionen der PCR-Primer sind unterstrichen. Fett gedruckte Buchstaben markieren konservierte Aminosäuremotive, die in allen sechs Genen anzutreffen sind. Erkennungssequenzen für Glykosylierung sind doppelt unterstrichen. Die Gene von PBCV-1 wurden der vollständigen genomischen Sequenz des Virus entnommen (Zugangsnummer GenBank PBU42580).
\end{abstract}


50

ver 8

a 6221

ver 7

a 4301

pcr3

a5581

$\operatorname{ver} 8$

a 6221

$\operatorname{ver} 7$

a 4301

pcr3

a5581

$\operatorname{ver} 8$

a 6221

$\operatorname{vcr} 7$

a 4301

per 3

a5581

$\operatorname{vcr} 8$

a 6221

$\operatorname{ver} 7$

a 4301

pcr 3

a5581

ver 8

a 6221

ver 7

a 4301

pcr 3

a5581

ver 8

a 6221

ver 7

a 4301

per 3

a5581

ver 8

a 6221

ver 7

a 4301

$\operatorname{ver} 8$

a 6221

ver 7

a 4301

ver 8

a 6221

ver 7

a 4301

MP GAISQLVSYGAQDVYLTGNPQITFFKAIYRRYTNFAMESIQQSMDGTTDFGKFPTCT I SRNGDLA MP GA ISQLVSYGAQDVYLTGNPQI TFFKAVYRRYTNFAMESIQQTFDGT TDFGKFP TVT I SRNGDLA MAGGLSQLVAYGAODVYLTGNPQITFFKTVYRRYTNFAVESIOQTINGSVGFGNKVSTQI SRNGDLI

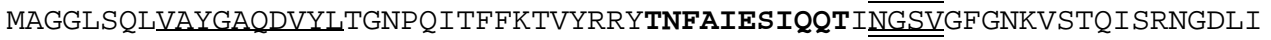
----------------SGEPAKT IWKSAHRKTKP FAVESI IQTLEGDVNYGGQATVKLSRSGDLI M-GGIMQLVSTGYQDVF LTGDP TRSLWKRIMARKTNFAIESIETVFD--VLYGSTSF INIKKAGDLL 100

GAIWIEVTLP SLLGYNITPTPP I SPGSSTLQNASNVMANTSLFTDTSGNYWQTRNGAA---YSNLVA GP IWIEVNLP SLLGYNITP TPAEG------

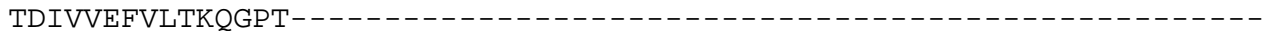

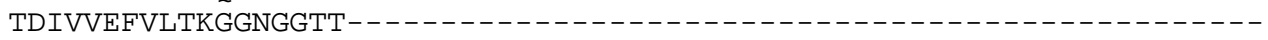

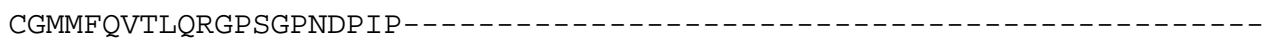

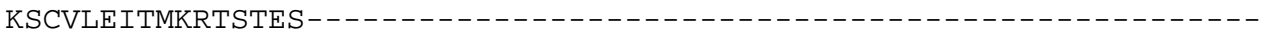

A--NLNGIYYASADTANMANTAAYSGNI I TWPYMTFTGNGMPNTPAISNVSIP TSNLRYVNGVGLAL AF SNVDYKYYANAVTSTYPPTA-LSNVVYSWPYM-ITGN----TGTRSTVAIPTANLRYVNGIGLAL

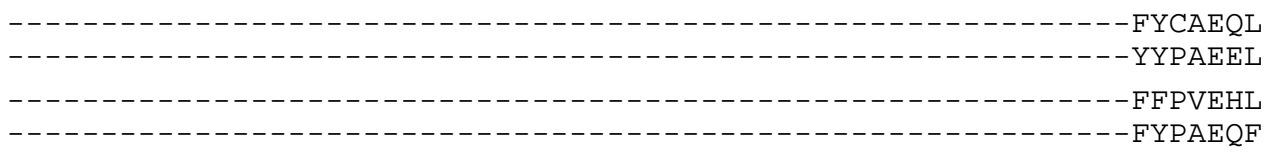

250

FNS IELQLGGQRIDK--HYSEWWD IWSELTETSEHLQGYNQMVGRYDPAYYNNNWDVTQARGGTYYI FNS IELELGGQRIDK--HYSEWWD IWTELTETAEKIQGYNTMVGRYDPAVYNAGWNISQAQGGTYYV LODVELEIGGORIDK--HYADWFRMYDS LFRMDNDRONYRRMTDFVN--------DEPATAVKRFYV LQDVELEIGGQRIDK--HYNDWFRTYDALFRMNDDRYNYRRMTDWVN--------NELVGAQKRFYV FHS IELRIGGQRIDW--IP HNWLRVYAQMYFNSKQTAAYTDMADF-G--------NENEGQQRTFFL IKSLTLLIGDQEVEKIQDFPTWSRVHDELFNDTEMRSANYRMLNF-RP-------DDPPGAIRTFYL

300

PLKFCYNLNP-GQYMPLVALSYHDLKLNFD INNYLNCVRCNYPVTSLTSMVGSNP LS ISNFKLYCDY PLKFCYNRNP - GLYMPLVALSYHQMKLNFNINNYLNCVKCNYPVTALT SKNGANP LS I TNMKLYTDF PLIFFFNQTP-GLALPLIALQYHEVKLYFT-------LASTVNGITAVEGGAAVTAVAPQMSVWVDY PLIFFFNQTP-GLALPLIALQYHEVKLYFT-------LASQVQGVNY $\underline{\underline{N G S S A}}$ I AGAAQP TMSVWVDY P IPFFFNQWDWGRALPLIALQYHEVELWINFT-----PANE IVG INPNF--------YPQI SLFVDY DLP LFFTRY-LSNS LPLVALQYHEVKLKIDFE-----PPYNIP GIDSTY--------MPQVRFYGDY

IFLDAPERIRMSE IQHEYLVTQLQWQGSEPVTAP SAP NGTTNRKFTLNFNHPVKCLI IAYQAAS--S

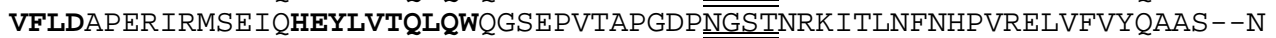
IFLDTQERTRFAQLP HEYLIEQLQF TGSETATP STTSQST--QNIRLNFNHP TKYLAWNE SNP SP LA IFLDTQERTRFAQLP HEYLIEQLQFTGSETATP SATTQAS --QN I RLNFNHPTKYLAWNFNNP T--N AFIDSPERIWFAQNP HEYLVTQLQYQKQS I IVDALTRDYKIPVVFLDKPERVYFAQTEHEYIIEQLQTFVTIPNMSNSVNTTMVDL-

450

YEQGDAVN--------GND IFNYQIP GDDDA--------EI IESMTLL I NGSERF SARP GAYFRLVQ YD-VDAVT--------GNNIFDYEIPANP TATPPYAGGGEVF TEVKLI I NGSDRF SGRP GAYFRLVQ YGQYTATANL--------TASSNVLYGDVPNTAVFNEALA I LD SSKLQLNGQDRFAARKGSYFNOVQ YGQYTALANIPGACSGAGTAAATVTTPDYGNTGTYNEQLAVLDSAKIQLNGQDRFATRKGSYFNKVQ

PYQHSLRTP SKS IYLYSFALEDIDSKQPNGSANFTRYDSAQLQMVLNPNLP SG--------------PYEHHVRVP SKSVYVYSFALEDADSRQP NGSANFTRYDSVQLQLTLNENLASG------------PFQTIGSLAP SGVYLYSFALKPAG-RQP SGTCNFSRIDNATLSLTYKTASVNAYAATATTAAALYAS

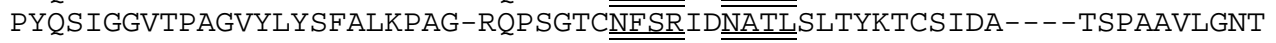
550

----------- RFQIYAPNYNI LRVAAGIGGLAFAN*

----------RVQIYAPNFNILRIAAGMGGLAFAN *

ETVTANTATSLTALNIYAKNYNVLRIMSGMGGLAYAN *

ETVTANTATLLTALNIYAKNYNVLRIMSGMGGLAYAN* 
Tabelle 2: N-Termini von Chlorellavirus-Hüllproteinen

\begin{tabular}{|c|c|c|c|c|c|c|c|}
\hline \multirow{3}{*}{ Virus } & \multirow{3}{*}{ N-Terminus des Proteins } & \multicolumn{4}{|c|}{ Gen/Klon } & \multirow{3}{*}{$\begin{array}{c}\text { N-terminale } \\
\text { Sequenzierung }\end{array}$} & \multirow{3}{*}{ Referenz } \\
\hline & & \multirow[t]{2}{*}{ Protein } & & \multicolumn{2}{|c|}{ molekulare Masse } & & \\
\hline & & & & $\underline{\text { SDS-Gel }}$ & berechnet & & \\
\hline PBCV-1 & AGGLSQLVAYGAQDVYLTGNPQ- & Vp54 & $a 430 l$ & $\overline{54 \mathrm{kDa}^{*}}$ & $\overline{48 \mathrm{kDa}}$ & ja & GenBank PBU42580 \\
\hline CVG-1 & AGGLSQLVAYGAQDVYLTGNPQ- & Vp49 & $v c r 7$ & $49 \mathrm{kDa}^{*}$ & $48 \mathrm{kDa}$ & ja & GenBank AF076921 \\
\hline CVT2 & MAGGLSQLVAYGAQDVYLTGNPQ- & Vp54 & $v p 54$ & $54 \mathrm{kDa}$ & $48 \mathrm{kDa}$ & o.A. & Genbank AB006978 \\
\hline CVK2 & MAGGLSQLVAY-------------- & Vp52 & mcpl & $52 \mathrm{kDa}$ & $48 \mathrm{kDa}$ & ja & GenBank AB018579 \\
\hline CVK2 & AGGLSQLVAY------------- & $\mathrm{Vp} 45$ & o.A. & $45 \mathrm{kDa}$ & o.A. & ja & Songsri et al. 1997 \\
\hline PBCV-1 & MPGAISQLVSYGAQDVYLTGNPQ- & $\mathrm{Vp} 58 * *$ & $a 622 l$ & $58 \mathrm{kDa}^{* *}$ & $58 \mathrm{kDa}$ & nein & GenBank PBU42580 \\
\hline CVG-1 & MP GAISQLVSYGAQDVYLTGNPQ- & $\mathrm{Vp} 58 * *$ & ver 8 & $58 \mathrm{kDa}^{* *}$ & $58 \mathrm{kDa}$ & nein & GenBank AF076922 \\
\hline CVK2 & AGIOMQLVSTG------------ & Vp41 & o.A & $42 \mathrm{kDa}$ & o.A. & ja & Songsri et al. 1997 \\
\hline PBCV-1 & MGGIMQLVSTGYQDVFLTGDP TRSLWK- & o.A. & $a 5581$ & o.A. & $45.5 \mathrm{kDa}$ & nein & GenBank PBU42580 \\
\hline CVG-1 & ----------------LSGEPAKT IWK & o.A. & pcr3 & o.A. & o.A. & nein & GenBank AF076923 \\
\hline
\end{tabular}

* Die angegebene molekulare Masse bezieht sich auf die monomeren Formen von Vp54 und Vp49 (die Proteine bilden Dimere). Das höhere apparente Molekulargewicht von Vp54 ist durch die Glykosylierung des Proteins bedingt. Das deglykosylierte Protein hat eine apparente Masse von ca. 48 kDa.

** Proteinbanden von $58 \mathrm{kDa}$ in Proteinpräparationen von CVG-1 und PBCV-1 


\subsubsection{Sequenzvergleiche mit Proteinen aus anderen Chlorellaviren}

Die Sequenzen von vcr7, vcr8 und pcr3 wurden vor allem mit Sequenzen von Virusstamm PBCV-1 verglichen, dem Prototyp der NC64A-Gruppe. Für die gruppenspezifische Bewertung der Sequenzähnlichkeiten wurden, soweit verfügbar, auch Gene aus anderen Chlorellaviren einbezogen Tabelle 2 und Tabelle 3).

\subsubsection{Vcr7 codiert für das Haupthüllprotein}

Die vergleichende Analyse der Sequenz von vcr7 legt den Schluß nahe, daß dieser offene Leserahmen für das Haupthüllprotein codiert: 1) Die translatierte Sequenz von vcr7 entspricht exakt der N-terminalen Aminosäuresequenz des viralen Hauptproteins Vp49 (Tabelle 2 und Abbildung 4). 2) Die für das vcr7-Protein berechnete molekulare Masse von $48 \mathrm{kDa}$ stimmt gut mit den molekularen Massen der Proteine überein, die für die Haupthüllprotein-Gene der NC64A-Viren PBCV-1 (Graves \& Meints 1992) und CVT2 (Nishida et al. 1998) angegeben werden (für eine Übersicht s. Tabelle 2). Der Unterschied zur molekularen Masse des isolierten Haupthüllproteins (49 kDa) kann durch Glykosylierung des Genprodukts erklärt werden (Graves \& Meints 1992, Plugge et al. 1999). 3) Das von ver7 codierte Protein und die Haupthüllproteine von PBCV-1 und CVT2 haben eine Aminosäure-Identität von $78 \%$. Interessanterweise unterscheiden sich die Haupthüllproteine der beiden NC64AViren PBCV-1 und CVT2 kaum (98 \% Aminosäure-Identität), obwohl sie weit entfernt voneinander in den USA und in Japan isoliert wurden (Tabelle 3A).

Die Ähnlichkeit der Proteinsequenzen aus den beiden NC64A-Viren einerseits und die Divergenz der Pbi-Virus Proteinsequenz andererseits unterstützen die Gruppierung der Chlorellaviren nach ihrer Wirtsspezifität. Eine phylogenetische Analyse von PCR-Fragmenten aus DNA-Polymerase-Genen (Chen \& Suttle 1996) bestätigt diese Beobachtung: Die Peptidsequenzen der NC64A-Viren sind zu $90 \%$ identisch, während die Sequenzen von PBCV-1 und dem Pbi-Virus CVA-1 lediglich zu $78 \%$ identisch sind (Tabelle 3B). 
Tabelle 3: Homologien von Proteinen zwischen den Chlorellavirusgruppen

\section{A Hüllprotein-Genfamilien}

\begin{tabular}{l|c|ccc} 
PBCV-1 & \multicolumn{3}{|c}{ CVG-1 (Pbi) } \\
$(\mathrm{NC64A})$ & $\begin{array}{c}\text { CV54 } \\
\text { vec48 }\end{array}$ & pcr7 \\
\hline \begin{tabular}{l|ccl} 
a430l $(\mathrm{Vp} 54)$ \\
a622l
\end{tabular} & $\mathbf{9 8}$ & $\mathbf{7 9}(85)$ & $35(48)$ & $44(63)$ \\
a558l & & & $\mathbf{7 1}(81)$ & \\
& & & & $\mathbf{3 6}(59)$
\end{tabular}

\section{B DNA-Polymerasegene}

\begin{tabular}{|c|c|c|}
\hline $\begin{array}{l}\text { PBCV-1 } \\
(\mathrm{NC64A)}\end{array}$ & $\begin{array}{c}\mathrm{NY}-2 \mathrm{~A}(\mathrm{NC} 64 \mathrm{~A}) \\
d p o b\end{array}$ & $\begin{array}{c}\text { CVA-1 (Pbi) } \\
\text { pol }\end{array}$ \\
\hline dpoa (a185r) & 91 (96) & $78(88)$ \\
\hline
\end{tabular}

Analysiert wurden translatierte offene Leserahmen aus insgesamt fünf Chlorellavirus-Isolaten: den NC64A-Viren PBCV-1, CVT2 und NY-2A, sowie den Pbi-Viren CVG-1 und CVA-1. Werte geben die Aminosäure-Identität bzw. -Ähnlichkeit (in Klammern) zwischen zwei Proteinen in Prozent an. (A) Vergleich der vollständigen Sequenzen der Hüllproteine (Zugangsnummern s. Tabelle 2). (B) Vergleich der konservierten Domänen der DNA-Polymerasen (umfaßt einen Ausschnitt von jeweils 230-235 Aminosäuren). Bezeichnung der DNA-Polymerasegene wie in Chen et al. 1996. Zugangsnummern: GenBank M86836 (dpoa), M86837 (dpob) und U32985 (pol).

\subsubsection{Eine Familie von Hüllproteingenen}

Mehrere Aminosäuremotive aus vcr7 sind in den Sequenzen von vcr8 und pcr3 konserviert (Abbildung 4). Die Aminosäure-Identität der Gesamtsequenzen beträgt etwa $40 \%$. Ganz ähnlich finden sich im Genom von PBCV-1 vier Leserahmen mit Ähnlichkeiten zum Haupthüllprotein-Gen a430l (Li et al. 1997). Die Haupthüllproteine des Pbi-Virus CVG-1 und des NC64A-Virus PBCV-1 scheinen also jeweils einer Genfamilie anzugehören. In der Tat läßt sich jeder der CVG-1 Sequenzen ein homologer PBCV-1 Leserahmen zuordnen.

Vcr8 codiert ein Protein von 521 Aminosäuren mit einer berechneten molekularen Masse von $58 \mathrm{kDa}$. Die Aminosäuresequenz ist zu $72 \%$ identisch mit der des Gens a622l von PBCV-1 (das, wie das Haupthüllprotein, in der späten Phase der Infektion exprimiert wird; M. Graves, pers. Mitteilung). Außerdem hat vcr8 signifikante Ähnlichkeit mit dem Haupthüllprotein. Allerdings ist das vcr8-Protein größer als das 
Haupthüllprotein und weist nur in den N- und C-terminalen Regionen Ähnlichkeiten mit Vp49 auf. Eine Region von 100 Aminosäureresten kann außer mit a622l mit keinem anderen Leserahmen in Übereinstimmung gebracht werden (Abbildung 4).

In den Proteinmustern von CVG-1 (Abbildung 3) und PBCV-1 (Skrdla et al. 1984) gibt es Proteinbanden von ca. $58 \mathrm{kDa}$, die möglicherweise Genprodukte von vcr8 bzw. a622l sind. Diese werden jedoch nicht als glykosylierte oder Oberflächenproteine markiert (Skrdla et al. 1984, Plugge et al. 1999).

Der Klon pcr3 enthält einen unvollständigen offenen Leserahmen, der eine moderate Ähnlichkeit mit Gen $a 558 l$ aus PBCV-1 aufweist (Abbildung 4). Der Wert von $36 \%$ für die Aminosäure-Identität (Tabelle 3A) zeigt, daß diese beiden Gene deutlicher divergieren als die beiden Paare vcr7/a430l und vcr8/a622l.

\section{$\underline{2.2 .5 \quad \text { Schlußfolgerungen }}$}

Die Ergebnisse dieser Arbeit etablieren folgende Gemeinsamkeiten zwischen dem Pbi-Virus CVG-1 und NC64A-Viren: 1) Die Größe des Haupthüllproteins von CVG-1, Vp49, und sein Auftreten als Dimer stimmen mit den entsprechenden Proteinen der NC64A-Gruppe überein. 2) Das korrespondierende Haupthüllproteingen ist Teil einer Genfamilie, die mindestens zwei weiteren Gene umfaßt. 3) Die Aminosäuresequenzen der drei hier identifizierten Leserahmen sind homolog zu entsprechenden Sequenzen in der Hüllprotein-Genfamilie des NC64A-Virusstammes PBCV-1.

Es ist auffällig, daß - mit einer Ausnahme - die bisher analysierten Aminosäuresequenzen von Pbi- und Nc64A-Viren eine konstante Divergenz von ca. $25 \%$ aufweisen. Berücksichtigt man die Tatsache, daß die Sequenzen der NC64A-Viren untereinander nahezu identisch sind, so bestätigt dieser Befund die ursprüngliche Gruppierung der Chlorellavirus-Isolate nach ihrer Wirtsspezifität. Die Entwicklung der Virusstämme verläuft offensichtlich schon seit längerer Zeit getrennt - wahrscheinlich parallel zur Entwicklung ihrer Wirtsalgen, den endosymbiontischen ChlorellaStämmen Pbi und NC64A. 


\section{EIN KALIUMKANAL-GEN IN CHLORELLAVIRUS PBCV-1}

\subsection{Kaliumkanäle und Virus-codierte Ionenkanäle}

Kaliumkanäle sind membranständige Transportproteine, die mit hoher Selektivität den Durchtritt von $\mathrm{K}^{+}$durch die Membran katalysieren. Sie sind in Tieren, Pflanzen, Pilzen und wahrscheinlich auch Prokaryoten an wichtigen Zellfunktionen wie Regulation des Membranpotentials, Signaltransduktion und Osmoregulation beteiligt (Hille 1992).

Alle bisher bekannten $\mathrm{K}^{+}$-Kanalproteine besitzen eine konservierte Domäne um ein TXXTXGY/FG-Motiv (Heginbotham et al. 1994), das die Kaliumselektivität determiniert. Diese Domäne wird als Pore $(\mathrm{P})$ bezeichnet. Sie befindet sich stets zwischen zwei Transmembrandomänen (TM). Im einfachsten Fall hat das Protein also den Aufbau TM1 - P - TM2 (Abbildung 5A). Diese Architektur haben die eukaryotischen Kir-Kanäle (Kubo et al. 1992) und einige prokaryotische Kanäle (Derst \& Karschin 1998). Weit verbreitet sind die Kv-Kanäle mit vier zusätzliche Transmembrandomänen (Shih \& Goldin 1997; Abbildung 5B, 6TM-Motiv). Zu diesem Strukturtyp gehören auch die ether-à-gogo (EAG) Kanäle (Kubo et al. 1992) und der pflanzliche Kaliumkanal KAT1 (Anderson et al. 1992).

Tandem-Kanäle besitzen zwei P-Domänen (Abbildung 5C). Im Cetk1.3-Kanal (Caenorhabditis elegans) ist das 2TM-Motiv verdoppelt (Goldstein et al. 1996). Bei Tok1 (Saccharomyces cerevisiae) ist ein 6TM-Motiv mit einem 2TM-Motiv verknüpft (Ketchum et al. 1995). Diese Anordnung der Primärstrukturen weist auf Gen-Duplikation hin. Eine ähnliche Entstehung wird für die $\mathrm{Na}^{+}$- und $\mathrm{Ca}^{2+}$-Kanäle angenommen, die aus vier aufeinanderfolgende 6TM-Motiven bestehen (Raganathan 1994).

Der Kanal in der Membran wird aus vier sog. $\alpha$-Untereinheiten gebildet (MacKinnon 1991, Doyle et al. 1998), die einem 2TM- bzw. 6-TM-Motiv entsprechen. Bei Tandemkanälen sind es entsprechend lediglich zwei Untereinheiten (Lesage et al. 1996).

Die Superfamilie der Kaliumkanäle läßt sich in artenübergreifende Subfamilien unterteilen, deren Verteter sich durch Schaltverhalten, Pharmakologie und Interaktion mit intrazellulären Liganden unterscheiden lassen. Eine Übersicht über Vertreter der verschiedenen Strukturgruppen gibt Tabelle 4. 
A

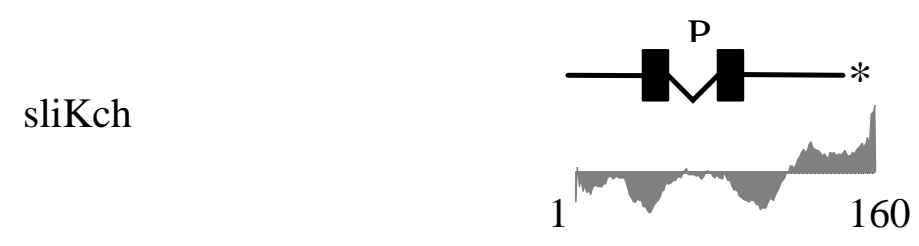

B

Shaker

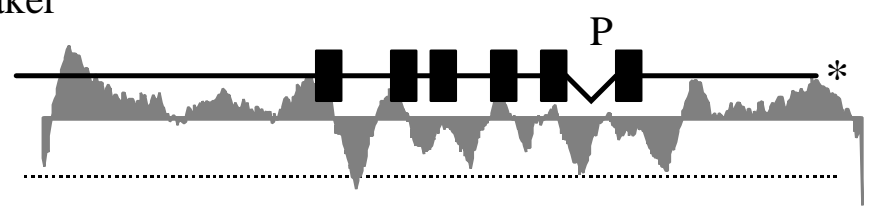

1

616

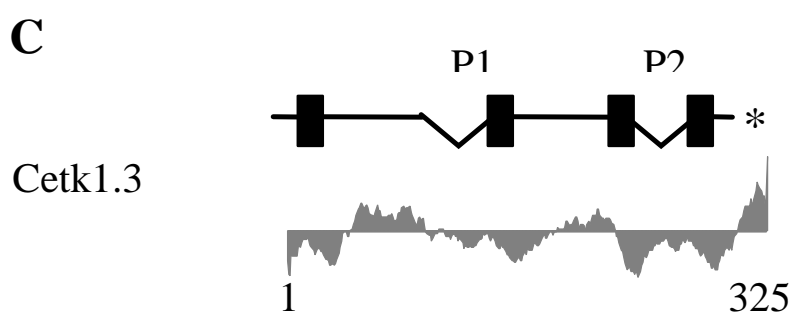

Tok1
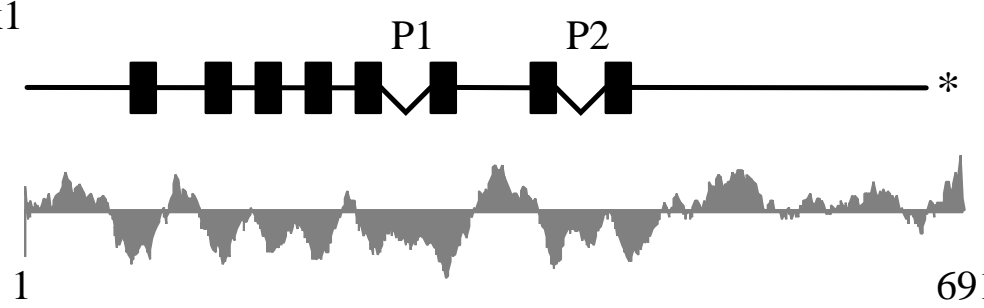

\footnotetext{
Abbildung 5: Strukturgruppen von Kaliumkanälen.

Kaliumkanäle können nach der Anzahl ihrer Transmembrandomänen in drei strukturelle Klassen eingeteilt werden. (A) 2TM-Typ (sliKch, Streptomyces lividans). Zu diesem Strukturtyp zählen auch die Kir-Kanäle. (B) 6TM-Typ (Shaker, Drosophila melanogaster). Die Porenregion P liegt zwischen dem 5. und 6. Transmembransegment. Zu diesem Strukturtyp zählen auch EAG-Kanäle und pflanzliche Einwärtsgleichrichter. (C) Tandem-Kanäle mit zwei Porendomänen. Oben: Cetk1.3-Kanal (Caenorhabditis elegans) mit 2x 2TM-Motiv. Unten: Tok1 (Saccharomyces cerevisiae) mit 6TM-Motiv + 2TM-Motiv. Unter dem Proteinprofil (schwarz) ist jeweils das zugehörige Hydropathie-Diagramm (grau) abgebildet.
} 
Das Auffinden von Kaliumkanal-Genen in den verschiedensten Organismen hat nicht zuletzt durch die Sequenzierung vollständiger Genome enormen Auftrieb erhalten. So wurden im Genom des Fadenwurms Caenorhabditis elegans allein in der ersten Hälfte der Sequenz Vertreter aus acht verschiedenen Kaliumkanal-Subfamilien identifiziert (Wei et al. 1996). Durch eine gezielte Suche nach Kaliumkanal-Genen in verschiedenen Bakteriengenomen (Derst \& Karschin 1998) wurden 20 homologe Leserahmen mit sechs bzw. zwei Transmembransegmenten identifiziert. Zwei prokaryotische Kaliumkanal-Gene waren bereits vor einiger Zeit in Escherichia coli (Milkman 1994) und Streptomyces lividans (Schrempf et al. 1995) gefunden und in letzterem Fall auch elektrophysiologisch charakterisiert worden. Mit dem S. lividans Kanal ist es gelungen, erstmalig ein Kaliumkanalprotein zu kristallisieren (Doyle et al. 1998). Die Röntgenstrukturanalyse dieses einfach gebauten Kanals mit zwei Transmembrandomänen (Abbildung 5) hat viel dazu beigetragen, die Kaliumselektivität auf molekularer Basis zu verstehen.

In Sequenzanalysen des $300 \mathrm{kbp}$ großen Genoms von Chlorellavirus PBCV-1 wurde ein kurzer offener Leserahmen (ORF) identifiziert, A250R, der das typische Kaliumkanal-Motiv TXXTXGY/FG (Heginbotham et al. 1994) aufweist. Virus-codierte Ionentransportproteine wurde zwar bereits in Influenzaviren (Pinto et al. 1992, Sunstrom et al. 1996) und dem Aidsvirus HIV-1 (Piller et al. 1996, Schubert et al. 1996) gefunden, doch hat keines dieser Proteine Sequenzähnlichkeiten mit zellulären Transportproteinen. Das Influenzavirus M2-Protein ist 97 Aminosäuren lang, besitzt nur eine Transmembrandomäne und bildet Tetramere, die durch Disulfidbrücken stabilisiert werden (Holsinger \& Lamb 1991, Sugrue \& Hay 1991). Die Tetramere fungieren in vitro als Ionenkanäle, die $\mathrm{K}^{+}, \mathrm{Na}^{+}$und andere Kationen, aber keine Anionen leiten (Pinto et al. 1992, Tosteson et al. 1994). Das 14 kDa Protein ist eines von drei Proteinen in der Hüllmembran des Viruspartikels (neben Hämagglutinin und Neuraminidase). Die Membran umgibt das Nucleocapsid des Virus, einen Komplex aus Proteinen und einzelsträngiger RNA, die die Erbinformation des Virus trägt. Während des Infektionsprozesses sorgt M2 für die Ansäuerung des Virusinneren, was dazu beiträgt, daß das Nucleocapsid in das Cytoplasma entlassen und die RNA in den Zellkern transportiert werden kann (Tosteson et al. 1994). 
Tabelle 4: Übersicht der Strukturtypen und Kaliumkanalfamilien

\begin{tabular}{|c|c|c|c|}
\hline Kanal & Beispiel & Organismus & Zugangsnummer \\
\hline $\begin{array}{l}\text { 2ТМ-Тур } \\
\text { Kir (inward rectifier) }\end{array}$ & $\begin{array}{l}\text { romK }=\text { Kir } 1.1 \\
\text { hgirk = Kir3.2 } \\
\mu \text { KATP1 }\end{array}$ & $\begin{array}{l}\text { Rattus norvegicus } \\
\text { Homo sapiens } \\
\text { R. norvegicus }\end{array}$ & $\begin{array}{l}\text { Swissprot P35560 } \\
\text { GenBank S78684 } \\
\text { GenBank D42145 }\end{array}$ \\
\hline $\begin{array}{l}\text { 2TM/PNBD* und 2TM } \\
\text { Kanalhomologe aus } \\
\text { Prokaryoten }\end{array}$ & $\begin{array}{l}\text { sliKch (KcsA) } \\
\text { draKchA } \\
\text { synKchA (ORF sll0536) } \\
\text { synKchB (ORF sll0993) }\end{array}$ & $\begin{array}{l}\text { Streptomyces lividans } \\
\text { Deinococcus radiodurans } \\
\text { Synechocystis sp. }\end{array}$ & $\begin{array}{l}\text { GenBank Z37969 } \\
\text { Inst. Gen. Res. (TIGR) } \\
\text { GenBank D64006 }\end{array}$ \\
\hline $\begin{array}{l}\text { Kanalhomolog aus } \\
\text { Algenvirus }\end{array}$ & $\mathrm{Kcv}$ & Chlorellavirus (PBCV-1) & GenBank AAC96618 \\
\hline $\begin{array}{l}6 \text { TМ-Тур } \\
\text { Kv (Shaker-Typ) }\end{array}$ & $\begin{array}{l}\text { Shaker (Kv1) } \\
\text { Shab (Kcv2) } \\
\text { nShaw (Kv3) }\end{array}$ & $\begin{array}{l}\text { Drosophila melanogaster } \\
\text { D. melanogaster } \\
\text { Caenorhabditis elegans }\end{array}$ & $\begin{array}{l}\text { PIR S00479 } \\
\text { GenBank M32659 } \\
\text { GenBank AF005246 }\end{array}$ \\
\hline KQT & KVLQT1 & H. sapiens & GenBank U40990 \\
\hline EAG (ether-à-gogo) & $\begin{array}{l}\text { EAG } \\
\text { EGL-2 } \\
\text { hERG }\end{array}$ & $\begin{array}{l}\text { D. melanogaster } \\
\text { C. elegans } \\
\text { H. sapiens }\end{array}$ & $\begin{array}{l}\text { Swissprot Q02280 } \\
\text { GenBank AAD28468 } \\
\text { PIR I38465 }\end{array}$ \\
\hline Slo & mSlo & H. sapiens & GenBank A48206 \\
\hline $\begin{array}{l}\text { CNG (Cyclic } \\
\text { nucleotide gated) }\end{array}$ & hRCNC2 & H. sapiens & GenBank U765320 \\
\hline $\begin{array}{l}\text { pflanzliche } \\
\text { Kaliumkanäle }\end{array}$ & $\begin{array}{l}\text { KAT1 } \\
\text { AKT1 } \\
\text { KST1 }\end{array}$ & $\begin{array}{l}\text { Arabidopsis thaliana } \\
\text { A. thaliana } \\
\text { Solanum tuberosum }\end{array}$ & $\begin{array}{l}\text { GenBank M86990 } \\
\text { GenBank U06745 } \\
\text { GenBank X79779 }\end{array}$ \\
\hline $\begin{array}{l}\text { 6TM Kanalhomologe } \\
\text { aus Prokaryoten }\end{array}$ & $\begin{array}{l}\text { ecoKch } \\
\text { mjaKchA (ORFMJ0139) }\end{array}$ & $\begin{array}{l}\text { Escherichia coli } \\
\text { Methanococcus janaschii }\end{array}$ & $\begin{array}{l}\text { GenBank AE000223 } \\
\text { GenBank U67471 }\end{array}$ \\
\hline $\begin{array}{l}\text { 6TM-Kanäle aus } \\
\text { Paramecium }\end{array}$ & $\begin{array}{l}\text { Pak1 } \\
\text { Pak2 }\end{array}$ & $\begin{array}{l}\text { Paramecium tetraaurelia } \\
\text { P. tetraaurelia }\end{array}$ & $\begin{array}{l}\text { GenBank U19907 } \\
\text { GenBank U19908 }\end{array}$ \\
\hline $\begin{array}{l}\text { Tandem-Kanäle } \\
\text { 6TM-Motiv + 2TM- } \\
\text { Motiv }\end{array}$ & $\begin{array}{l}\text { Tok1 } \\
\text { Trek1 }\end{array}$ & $\begin{array}{l}\text { Saccharomyces cerevisiae } \\
\text { Mus musculus (Maus) }\end{array}$ & $\begin{array}{l}\text { GenBank P40310 } \\
\text { GenBank U73488 }\end{array}$ \\
\hline $2 \times 2 \mathrm{TM}$ & $\begin{array}{l}\text { Cetk1 (ORF C24A3.1) } \\
\text { Cetk3 (ORF T12C9.3) }\end{array}$ & C. elegans & $\begin{array}{l}\text { GenBank U41104 } \\
\text { GenBank U41104 }\end{array}$ \\
\hline $\begin{array}{l}\text { virale Ionenkanäle } \\
1 \mathrm{TM}\end{array}$ & $\begin{array}{l}\text { M2 } \\
\text { NB } \\
\text { Vpu } \\
\text { Vpr }\end{array}$ & $\begin{array}{l}\text { Influenzavirus A } \\
\text { Influenzavirus B } \\
\text { HIV-1 } \\
\text { HIV-1 }\end{array}$ & $\begin{array}{l}\text { GenBank P03491 } \\
\text { GenBank P16194 } \\
\text { GenBank P35966 } \\
\text { GenBank P05926 }\end{array}$ \\
\hline $\begin{array}{l}1 \mathrm{TM} \mathrm{K}^{+} \text {-Kanal- } \\
\text { untereinheit }\end{array}$ & $\operatorname{minK}(\mathrm{IsK})$ & H. sapiens & GenBank M64922 \\
\hline
\end{tabular}

*putative $N A D^{+}$binding domain 
Bei der Replikation bestimmter Influenza-Viren hat das M2-Protein die weitere Aufgabe, in der späten Phase des Infektionszyklus die pH-induzierte Konformationsänderung des Hämagglutinins beim Transport durch das trans Golgi-Netzwerk zu verhindern (Tosteson et al. 1994). Über das Vpu Protein von HIV-1 ist weit weniger bekannt. Es wird angenommen, daß seine Ionenkanalaktivität die Entlassung der Viruspartikel aus der Wirtszelle fördert (Schubert et al. 1996).

Das Kaliumkanalmotiv, das ORF A250R besitzt, weist auf eine strukturelle und funktionelle Analogie des codierten Proteins mit Kaliumkanälen hin. Für die Aktivität eines Ionenkanals im Lebenszyklus von Chlorellavirus PBCV-1 spricht, daß die Replikation des Virus durch die Kanal-Blocker $\mathrm{Ba}^{2+}$ und Amantadin gehemmt wird (Plugge et al. 2000). In Northern Blot-Analysen wurden drei frühe und ein spätes mRNA-Transkript identifiziert, die mit A250R hybridisieren (M. Graves \& J.L. Van Etten, pers. Mitteilung). Die Klärung der genauen Rolle des A250R-Genproduktes im viralen Lebenszyklus ist die Aufgabe zukünftiger Versuche und wird sicherlich viel zum Verständnis der Biologie der Chlorellaviren beitragen.

Ziel dieser Arbeit war es, zunächst zu prüfen, ob das von ORF A250R codierte Protein eine Ionenkanalaktivität besitzt. In Anlehnung an die Nomenklatur für Kaliumkanäle wird das von A250R codierte Protein im folgenden Kcv (Kanal Chlorellavirus) genannt. 


\subsection{Ergebnisse}

\subsubsection{Analyse der Primärstruktur von Kcv}

ORF A250R codiert für ein kleines, 94 Aminosäurereste umfassendes Protein (Abbildung 6), das zu $55 \%$ aus unpolaren Aminosäuren besteht. Die berechnete molekulare Masse von Kcv beträgt 10,6 kDa. Die 50 bp vor dem Startcodon (Abbildung 6) haben mit $82 \%$ einen deutlich höheren A/T-Gehalt als der offene Leserahmen (60,3 \%). Dies ist typisch für Protein-codierende ORFs in PBCV-1 (Schuster et al. 1990, Lu et al. 1995).

Zur Identifizierung möglicher Transmembransegmente in der Primärstruktur von Kcv wurde zunächst eine Hydropathieanalyse durchgeführt. Das HydropathieDiagramm (Abbildung 7A) weist zwei breite Minima auf, die als Transmembranregionen interpretiert werden können. Um eine Lipiddoppelschicht zu durchspannen, sind mindestens 17 Aminosäurereste erforderlich (Engelman et al. 1986). Zwei potentielle Transmembranregionen von 22 bzw. 17 Aminosäureresten Länge werden auch aufgrund von Vergleichen mit einer Transmembranprotein-Datenbank vorhergesagt (4.18). Ihre Position stimmt mit den Hydropathie-Analysen überein und ist in Abbildung 6 angegeben.

Der Bereich zwischen den beiden potentiellen Transmembranregionen umfaßt 44 Aminosäuren und enthält eine Domäne von 26 Aminosäuren (AS 53-76), die $60 \%$ Ähnlichkeit und $37 \%$ Identität mit den P-Regionen einiger bekannter Kaliumkanaltypen aufweist (Abbildung 8). Größte Ähnlichkeit (65\%) besitzen im Vergleich mit der Kcv-Sequenz die erste Pore der Tandemkanäle Tok1 (Hefe) und Trek1 (Maus) sowie der prokaryotische Kanal ecoKch: An 16 von 26 verglichenen Positionen stehen Aminosäuren mit gleichen Eigenschaften (Abbildung 8). Gleichzeitig weisen Tok1 und ecoKch mit je $50 \%$ bzw. $46 \%$ auch die meisten identischen Aminosäuren auf. Die beiden Transmembranregionen von Kcv haben hingegen keine Sequenzübereinstimmung mit den entsprechenden Domänen anderer Kaliumkanalfamilien (Abbildung 9). 


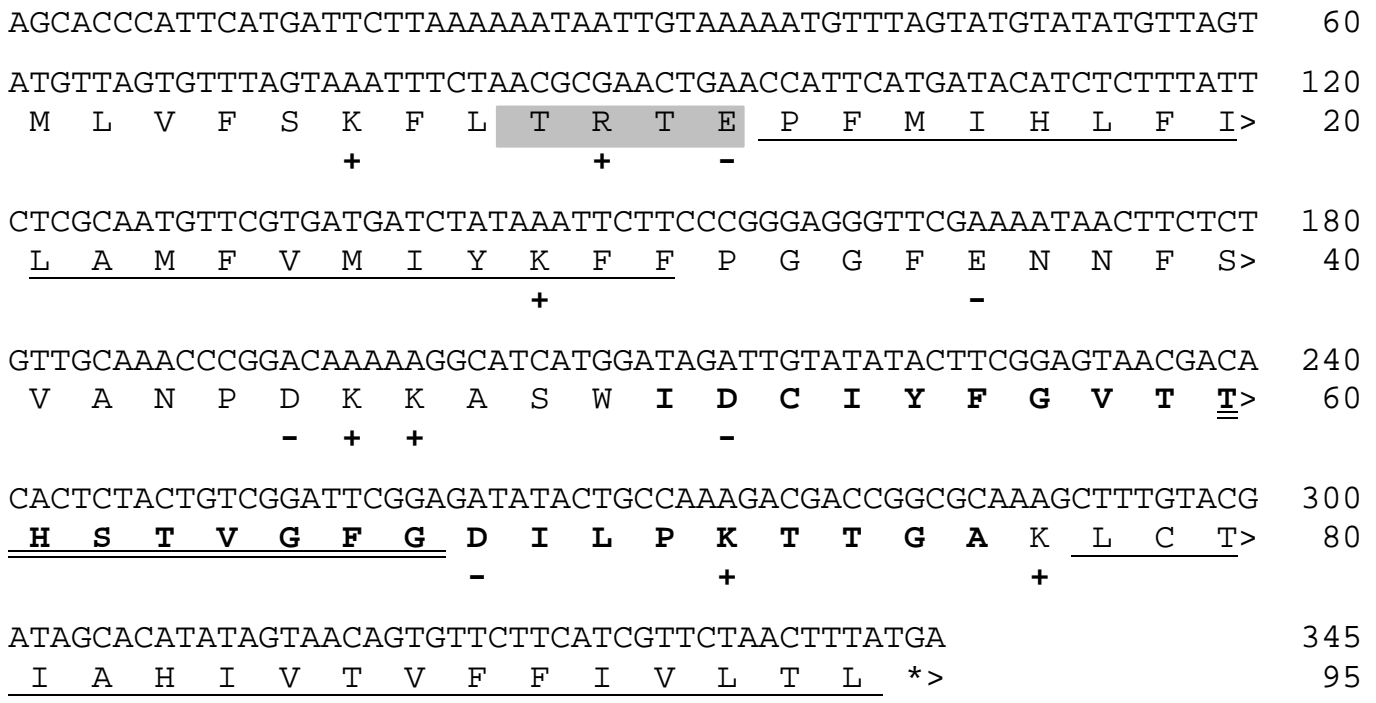

Abbildung 6: Nuclein- und Aminosäuresequenz von Kcv

Die Nucleinsäuresequenz (ORF A250R) wurde der vollständigen Sequenz des Genoms von PBCV-1 entnommen (Zugangsnummer GenBank U42580) und umfaßt zusätzlich $60 \mathrm{bp}$ des 5'-untranslatierten Bereiches. Die 50 bp vor dem Startcodon haben mit $82 \%$ einen deutlich höheren A/T-Gehalt als der offene Leserahmen $(60,3 \%)$. Unter der Nucleinsäuresequenz ist die korrespondierende Aminosäuresequenz wiedergegeben. Mögliche Transmembranregionen, die mit dem Programm TMpred (Hofmann \& Stoffel 1993) gefunden wurden, sind unterstrichen (AS 13-31 und AS 76-94). Die Porenregion (s. auch Abbildung 8) ist fett gedruckt, die Kaliumkanal-Konsensussequenz mit Selektivitätsfilter GFG ist doppelt unterstrichen. Eine mögliche Phosphorylierungsstelle für Proteinkinase ck2 am N-Terminus ist grau unterlegt. Positiv geladenen Aminosäurereste sind durch ein + , negative durch ein - gekennzeichnet.

Auffällig gut konserviert ist die Konsensussequenz ThsTvGFG mit dem Selektivitätsfilter-Motiv (Heginbotham et al. 1994). Wie bei den EAG-Kanälen ist auch bei Kcv das Tyrosin (Y) durch Phenylalanin (F) ersetzt (Abbildung 8). Auch in der zweiten Pore der Tandemkanäle aus C. elegans (Cetk1 und Cetk3, Abbildung 8) steht an dieser Position ein F. Überdies sind in diesen Kanälen auch die vier folgenden Aminosäurereste (DIL/VP) der Kcv-Sequenz sehr ähnlich, während diese Positionen in den beiden EAG-Kanälen deutlich anders besetzt sind. Das Fehlen der negativ geladenen Aminosäure Aspartat (D) in den EAG-Sequenzen ist dabei besonders auffällig, denn diese Aminosäure ist in einer Reihe von Kanälen konserviert (Abbildung 8). Bei dem pflanzlichen Kaliumkanal KST1 ist dieser Aspartatrest (D269) Teil des pH-Sensors (Hoth \& Hedrich 1999). 
A

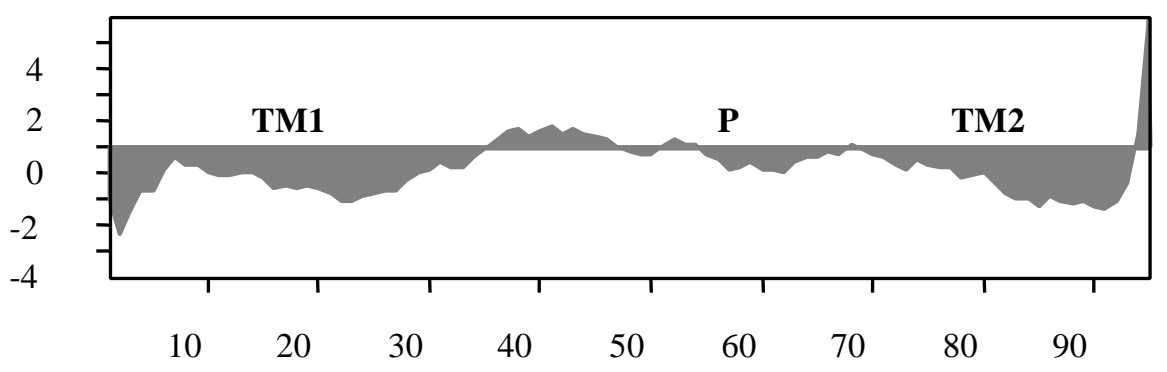

B

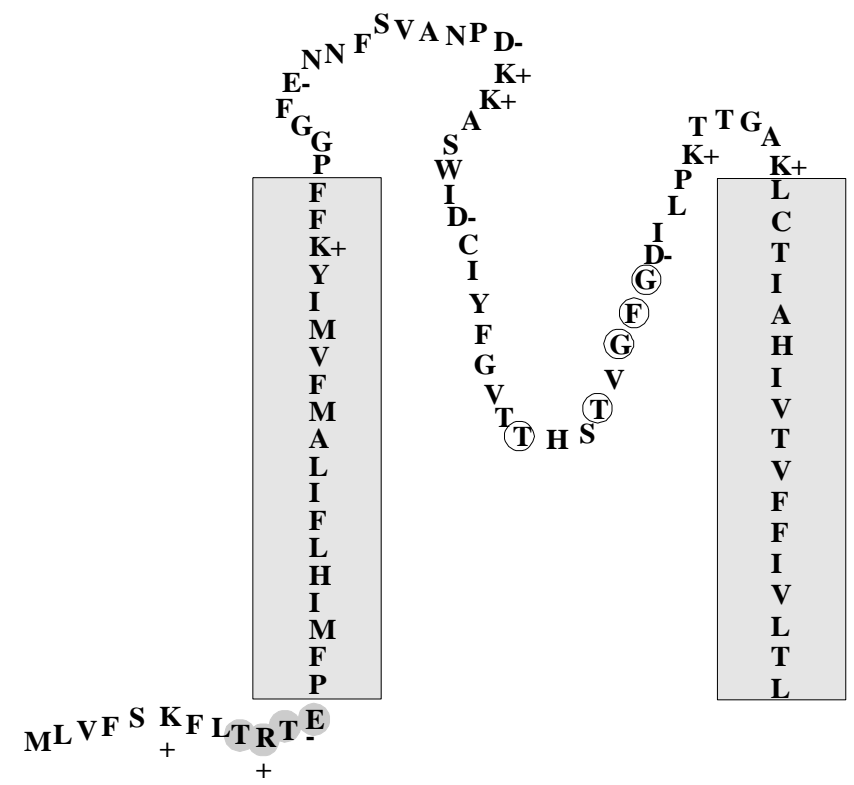

\section{Abbildung 7: Sekundärstruktur von Kcv}

(A) Hydropathie-Diagramm. Für je 19 AS wurde der durchschnittliche Hydropathiewert (Kyte \& Doolittle 1982) der Aminosäuren berechnet und gegen die Position im Protein aufgetragen. Negative Werte deuten auf hydrophobe, positive Werte auf hydrophile Regionen hin. Die zwei breiten Minima am N- und C-Terminus der Sequenz können als Transmembranregionen (TM) interpretiert werden. Der als Porenregion $(\mathrm{P})$ bezeichnete Bereich von Kcv, bei Kaliumkanälen eine membranständige Domäne, ist ebenfalls hydrophob. (B) Hypothetisches Modell der Kcv-Kanalstruktur (angelehnt an Becker et al. 1996 und Doyle et. al. 1998). Der N-Terminus umfaßt die AS 1-12 vor der ersten Transmembranregion (AS 13-31) und könnte sowohl membranassoziiert als auch cytoplasmatisch sein. Die mögliche Phosphorylierungsstelle ist grau unterlegt. Die Transmembranregionen (im Kasten) sind $\alpha$-Helices (nicht dargestellt). Der hydrophile Bereich vor der P-Domäne könnte in den extrazellulären Raum ragen. Die P-Region taucht in die Membran ein. Die Aminosäuren der Kaliumkanal-Konsensussequenz sind eingekreist. Der C-Terminus ist Teil der zweiten Transmembranregion. Positiv und negativ geladene AS sind durch + und - gekennzeichnet. 
In der Kcv-Porendomäne sind mit Y55 und F56 zwei weitere strukturell wichtige Aminosäuren konserviert. Röntgenstrukturanalysen des S. lividans Kanal-Homologs sliKch weisen auf die besondere Rolle zweier aromatischer Aminosäuren (Tryptophan, W) in äquivalenter Position hin (Doyle et al. 1998). In der TetramerAnordnung der Untereinheiten bilden diese Tryptophanreste mit den Tyrosinseitenketten (Y) des Selektivitätsfilters ein Netzwerk von aromatischen Aminosäuren, einer Manschette ähnlich. Diese Anordnung soll die Aminosäuren des Selektivitätsfilters nach außen ziehen und die Pore gerade so weit offenhalten, wie es für die Stabilisierung der durchtretenden Kaliumionen erforderlich ist (molecular springHypothese). Wie bei Kcv, sind bei vielen Kaliumkanaltypen diese Tryptophanreste durch die ebenfalls aromatischen Aminosäuren Tyrosin (Y) bzw. Phenylalanin (F) ersetzt (Abbildung 8).

Abbildung 7B zeigt ein hypothetische Modell von Kcv, angelehnt an die Kristallstruktur des 2TM-Kanals sliKch von Doyle et al. 1998. Die Anordnung der Aminosäuren in der P-Region folgt einer Darstellung von Becker et al. (1996). Kcv hat nur einen sehr kurzen N-Terminus von ca. 12 Aminosäuren. Der C-Teminus ist Teil der zweiten Transmembranregion. Der N-Terminus ist danach die einzig mögliche cytoplasmatische Domäne, könnte aber, da sie recht hydrophob ist, auch mit der Membran assoziiert sein. Kurz vor der ersten Transmembranregion befindet sich in dieser Domäne eine Erkennungssequenz (TRTE) für die zelluläre Proteinkinase ck2 (s. auch Abbildung 6).

\subsubsection{Kcv-Homologe in anderen Viren?}

Eine Reihe vollständig sequenzierter Virusgenome wurde gezielt nach Leserahmen mit struktureller Analogie zu Kcv durchsucht. Weder im Genom des Afrikanischen Schweinefiebervirus (das ähnliche strukturelle Merkmale wie Chlorellaviren hat) noch in einer Reihe membranumhüllter RNA-und DNA-Viren (Rhinovirus, Influenzavirus A, Mumpsvirus, Herpesvirus, Vacciniavirus) wurden solche Sequenzen gefunden. Darüber hinaus wurden auch keine potentiellen viralen Transmembranproteine gefunden, die die Kaliumkanalkonsensussequenz TXXTXGY/FG oder andere Analogien zu Ionenkanälen aufweisen. 


\begin{tabular}{|c|c|c|c|c|c|}
\hline Kev1 & IDCIYFGVTT & HSTVGFGDIL & PKTTGA & 76 & $\% \operatorname{sim}($ id) \\
\hline Kv-Kanäle & & & & & $58(35)$ \\
\hline Shaker & PDAFWWAVVT & MTTVGYGDMT & PVGFWG & 455 & $50(27)$ \\
\hline \multicolumn{6}{|c|}{ pflanzliche Kanäle } \\
\hline Kat1 & VTALYWSITT & LTTTGYGDFH & AENPRE & 273 & \\
\hline \multicolumn{6}{|c|}{ Tandem-K, 1. Pore } \\
\hline Tok1/1 & GNALYFCTVS & LLTVGLGDIL & PKSVGA & 155 & $65(50)$ \\
\hline Trek1/1 & GSSFFFAGTV & ITTIGFGNIS & PRTEGG & 155 & $65(39)$ \\
\hline \multicolumn{6}{|c|}{ Tandem-K, 2. Pore } \\
\hline Cetk1/2 & GTSLYFTLIS & FTTIGFGDIL & PSDYDF & 279 & $58(39)$ \\
\hline Cetk3/2 & MDAFYYSFIS & LTTIGFGDIV & PENHDY & 496 & $62(35)$ \\
\hline \multicolumn{6}{|c|}{ PAK Familie } \\
\hline Pak1 & LHSLYWSIIT & MTTIGYGDIT & $\mathbf{P Q N L R E}$ & 354 & $58(31)$ \\
\hline Pak2 & FNSLYWITIT & SMTVGYGDIV & PVTTPE & 340 & $62(42)$ \\
\hline \multicolumn{6}{|c|}{ EAG Familie } \\
\hline EAG & VTALYFTMTC & MTSVGFGNVA & AETDNE & 466 & $50(31)$ \\
\hline hERG & VTALYFTFSS & LTSVGFGNVS & PNTNSE & 637 & $62(31)$ \\
\hline \multicolumn{6}{|c|}{ prokaryotische Kanalgene } \\
\hline sliKch & PRALWWSVET & ATTVGYGDLY & PVTLWG & 88 & $62(35)$ \\
\hline \multirow[t]{2}{*}{ ecoKch } & MTAFYF SIET & MSTVGYGDIV & $\mathbf{P} \vee \mathbf{S} E S \mathbf{A}$ & 198 & $65(46)$ \\
\hline & & & & & $60(37)$ \\
\hline
\end{tabular}

Abbildung 8: Die Porenregion von Kcv im Vergleich mit typischen Vetretern anderer Kaliumkanalfamilien.

Gleiche oder strukturell ähnliche Aminosäuren sind fett gedruckt. Die Einordnung in strukturelle Gruppen erfolgte nach dem 11-Buchstaben-Alphabet der Aminosäuren (Brendel et al. 1992, s. Anhang A). Nach jeder Sequenz folgt die Position des letztgenannten Aminosäurerestes sowie die prozentuale Aminosäure-Ähnlichkeit und -Identität (in Klammern). In der letzten Zeile ist die durchschnittliche prozentuale Ähnlichkeit bzw. Identität angegeben.

Nächste Seite:

\footnotetext{
Abbildung 9: Die P-Regionen der Kaliumkanalfamilien sind sich ähnlicher als die TM-Domänen.

Multiples CLUSTAL W-Alignment. Für die Analyse wurden jeweils Fenster von 84110 Aminosäuren ausgewählt, die die konservierte P-Region und die flankierenden Transmembransequenzen umfassen. Man beachte, daß Ähnlichkeiten zwischen den Transmembransequenzen auf verwandte Kaliumkanäle beschränkt sind. Fettdruck: zwei aromatische Aminosäuren im N-terminalen Bereich der P-Region (molecular spring-Hypothese) und Kaliumkanal-Konsensussequenz TXXTXGY/FG. Die Zahlen beziffern die Position im Alignment.
} 
TM

1

$\mathrm{Kcv}$

HLF ILAMFVM IYKFFPGGFE NNFSVAN---

sliKch

TVLLVIVLLA GSYLAVLAER GA

mjaKchA

LLTICFIASC LIWIVESGVN

draKchA

LSGLLLGLLA FGSLGYR---

sysKchA

GVLFFVVTLV LATLGYI---

sysKchB

GAITLAGLFV VGTAWYR---

ecoKchA

FAFISFTTLL FYSTYGALYL SEGFN-

Shaker

FFLFIGVVLF SSAVYFAEAG S-

nShaw

FFLILGIVIF AALVYYAEKM EAN--

Pak1

HFCACLFHYF ALYEVDQGYT --HTWLHQQN IF

Pak2

LAAAHFSACI WFLVGSTGNP NDTSWIKAQN IE

EAG

EGL2

CFYMLVAHWL ACIWYSIGRS DA-----DNG IQYSWLWKLA NVTQSPYSYI WSNDTGPELV

hERG CAYVIVAHWL ACVWFWIGDS EVRLKMDNLA LPDGWLWKLS NDLRQHYNIP LSNKTT--LV

Cetk1.2 CTFALIAHWL ACIWYAIGN- ---MEQPHMD

SRIGWLHNLG DQIGKPYN-- ----SS--GL

Cetk3.2

Cetk1.1

VIWVIFCAVL FTFLE-

Cetk3.1

LLYIAFGGIL FSILE-

TTFQETLGIV PADMDKD---

Akt1

GDSERKRRHR HGNKRGDRGS

Kat1

hGIRK

CAACFYYLIA ARNSNPAKTW IGANVANFL-

romK

CAGCFNYLIA DRYPNPRKTW IGAVYPNFK-

$\mu \mathrm{KATP} 1$

VTWLFFGMIW WLIAYIRGDM DHIEDPS-WT

GSWFLFGLLW YVVAYVHKDL PEFYPPDNRT

CSWLLFAIMW WLVAFAHGDI YAYMEKGITE KSGLESA--

$P$

61

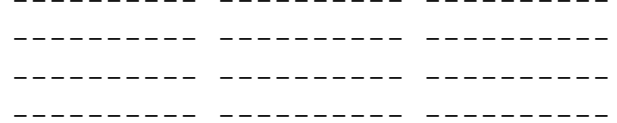

--PDKKASWI DCIYEGVTTH STVGEGDIIP KTTGA-KICT IAHIVT---- VEFIVLTI

$\mathrm{Kcv}$

sliKch

-PGAQLITYP RALWWSVETA TTVGYGDLYP VTLWG-RLVA VVVMVAGITS FGL-VTAALA

mjaKchA

---PAINNFF DAFYFTTISI TTVGYGDITP KTDAG-K--- LIIIFSVL-- -FFI------

draKchA

sysKchA

--LTEGWSWL DCLYMTEMVL TTVGFGEVHP LSPAG-KAFS ILLMLFGI-G LMLYLLTLL-

sysKchB

---CFGWTTT EAVYMVVITV FGVGYGEVRP LTTTAERVFT MGVILAGTTS AVYIVGAFV-

--YVEDWTWL DAFYMTTITL ATVGFGETHP LSPAS-RLFT ILLILMGLLT IGYM------

ecoKchA

---PRIESLM TAFYFSIETM STVGYGDIVP VSESA-RLFT ISVIISG-IT VFATSMTSIF

Shaker

-ENSFFKSIP DAFWWAVVTM TTVGYGDMTP VGFWG-KIVG SLCVIAGVLT IALPVPVIVS

nShaw

-PNNQFQSIP LGLWWAICTM TTVGYGDMTP HTSFG-RLVG SLCAVMGVLT IALPVPVIVS

Pak1

Pak2

-DEDLYTKYF NSLYWITITS MTVGYGDIVP VTTP-EKILV TVITFLVTGV FGYALG----

-NEQWFNQYL HSLYWSIITM TTIGYGDITP QNLR-ERVFA VGMALSAVGV FGYSIG----

EAG

EGL2

hERG

Cetk1.2

Cetk3.2

Cetk1.1

NGPSRKSMYV TALYFTMTCM TSVGFGNVAA ETDN-EKVFT ICMMIIAALL YATIFGHVTT GGPSRTSAYI SSLYYTMSCM STVGFGNIAS NTDN-EKIFG VCMMIISALL YAAIFGHMTT GGPSIKDKYV TALYFTFSSL TSVGFGNVSP NTNS-EKIFS ICVMLIGSLM YASIFGNVSA

Cetk3.1

Akt1

Kat1

hGIRK

romK

-----EWDFG TSLYFTLISF TTIGFGDILP SDYDF-MPIV GVLLLIGL-- -SLVSTVMTL -----DWSYM DAFYYSFISL TTIGFGDIVP ENHDY-IAIM LIYLGVGL-- -SVTTMCIDL ----IHWTFL GSIFYCMTVY TTIGYGNIVP GTGWG-RFAT ILYAFIGIPL TVLSLYCLGS ---EKMWTTS SALFFAATTM ATIGYGNIVP VTPLG-RLAC VLFALFGAPI AIITIGDLGK

$\mu \mathrm{KATP} 1$

-EESLWMRYV TSMYWSITTL TTVGYGDLHP VNTK-EMIFD IFYMLFNLGL TAYLIG----

-EASLWNRYV TALYWSITTL TTTGYGDFHA ENPR-EMLFD IFFMMFNLGL TAYLIG----

PCVTNLNGEV SAFLFSIETE TTIGYGYRVI TDKCPEGIIL LLIQSVLGSI VN-------PCVENINGMT SAFLFSLETQ VTIGYGFRFV TEQCATAIFL LIFQSILGVI IN-------VCVTNVRSFT SAFLFSIEVQ VTIGFGGRMM TEECPLAITV LILQNIVGLI IN-------- 


\subsubsection{Phylogenetische Analysen}

Die Aminosäuresequenz von Kcv wurde mit Hilfe des CLUSTAL W Programmes auf die Verwandtschaft zu anderen Kaliumkanalgruppen untersucht. Grundlage solcher Analysen ist ein multiples Alignment, in dem vergleichbare Sequenzabschnitte der Proteine gesucht und aneinander ausgerichtet werden. Die Qualität des Alignments ist entscheidend für die Verwandtschaftsanalyse, in der die Wahrscheinlichkeit eines Aminosäureaustausches an Einzelpositionen evaluiert wird. Wegen der Diversität, die trotz konservierter Strukturen in der Architektur von Kaliumkanälen besteht, gilt es, die vergleichbaren Bereiche der Proteine sorgfältig auszusuchen. So kann beispielsweise nicht die ganze, sechs Transmembranregionen umfassende Sequenz des Shaker-Kanals (Abbildung 5) mit Kcv verglichen werden, sondern nur der Abschnitt, der die letzten zwei Transmembranregionen mit der dazwischen liegenden Pore umfaßt. Weiterhin stellt sich das Problem, daß bei den unterschiedlichen Kanaltypen verschieden lange Sequenzabschnitte zwischen der P-Domäne und den beiden flankierenden Transmembransequenzen liegen können (Abbildung 9).

Ziel der Analyse ist es, die fraglichen Sequenzen in Relation zueinander zu gruppieren, d.h. das verwendete Programm ist nicht für die Einordnung einzelner Sequenzen mit entfernter Verwandtschaft konzipiert. In solchen Fällen ist zu erwarten, daß das Programm Zuordnungen vornimmt, die mit Änderung der Parameter oder verändertem Sequenzausschnitt variieren. Je mehr Sequenzen zum Vergleich eingesetzt werden, desto größer wird die Wahrscheinlichkeit, daß es zu einer willkürlichen Einordnung der fraglichen Sequenz in bestehende Gruppen kommt. Diese Probleme tauchten - nicht überraschend - auch bei der phylogenetischen Analyse von Kcv auf.

Eine stabilere Zuordnung von Kcv wurde durch die Beschränkung auf fünf repräsentative Kanal-Familien erreicht (Abbildung 10). Der Abstammungsbaum basiert auf Sequenzvergleichen zwischen eukaryotischen und prokaryotischen Kaliumkanalsequenzen (Derst \& Karschin 1998). In diesem Umfeld entspringt die Kcv-Sequenz einem eigenen, ursprünglichen Ast - ein Hinweis auf starke Sequenz-Divergenzen zwischen Kcv und den Vergleichskanälen (vor allem in TM1 und TM2) und eine evolutionär frühe Abspaltung des Kcv-Kanals. 


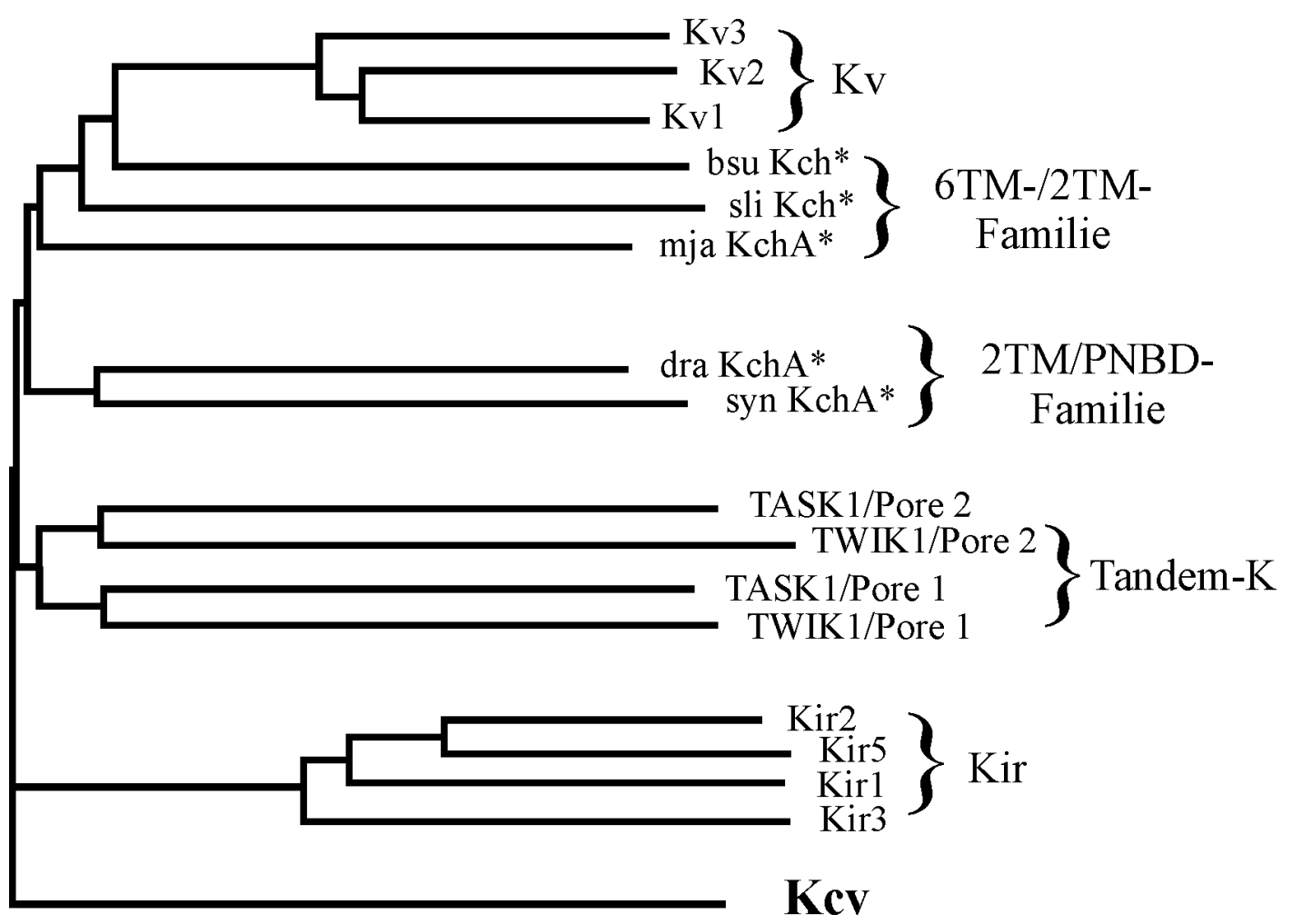

\section{Abbildung 10: Verwandtschaftsbeziehungen zwischen Kcv und Kaliumkanälen aus Pro- und Eukaryoten.}

Die Länge der horizontalen Äste ist ein Maß für die Sequenzabweichung zwischen den analysierten Proteinen. $\mathrm{Kcv}$ erscheint als eigener, ursprünglicher Ast und hat demnach geringe Ähnlichkeit mit den anderen Kaliumkanal-Familien.

Die Berechnungen erfolgten mit CLUSTAL/CLUSTREE Algorithmen (Saitou \& Nei 1987, Thompson et al. 1994). Prokaryotische Kanäle sind mit * gekennzeichnet.

Kv: Kaliumkanäle vom Shaker-Typ; 6TM-/2TM-Familie: prokaryotische Kaliumkanäle (Derst \& Karschin 1998); 6TM/PNBD-Familie: prokaryotische Kaliumkanäle mit NAD ${ }^{+}$-Bindungsstelle (Derst \& Karschin 1998); Tandem-K: Kaliumkanäle mit zwei Poren in Tandemanordnung; Kir: einwärtsgleichrichtende Kaliumkanäle mit zwei TM-Domänen. Subfamilien der Kv- und Kir-Kanäle sind durch Konsensussequenzen mehrererVertreter repräsentiert. Der phylogenetische Baum entstand durch freundliche Unterstützung von Dr. Christian Derst (Universität Marburg). 


\subsubsection{Nachweis einer Kcv-induzierten Leitfähigkeit in Xenopus Oocyten}

Um zu prüfen, ob Kcv tatsächlich ein funktioneller Kaliumkanal ist, wurde das Gen heterolog in Xenopus laevis Oocyten exprimiert. Diese Zellen haben eine sehr hohe Translationsfähigkeit und werden routinemäßig für die transiente und v.a. funktionelle Expression artfremder Proteine eingesetzt (s. einschlägige Lehrbücher, z.B. Numberger \& Draguhn 1996). In der Regel werden diese Proteine in den Oocyten korrekt posttranslational modifiziert und Kanäle werden in zelluläre Membranen eingebaut. Die Präparation der Oocyten, die Transkription des Plasmids, die Injektion der mRNA, und die elektrophysiologischen Messungen wurden in der Abteilung für Physiologie und Biochemie der Pflanzen der Universität Mailand durchgeführt.

ORF A250R wurde per Polymerasekettenreaktion (PCR) aus genomischer DNA des Virus PBCV-1 vervielfacht. Die in der Reaktion verwendeten Primer waren mit Erkennungssequenzen der Restriktionsendonucleasen Bam HI bzw. Xho I ausgestattet (4.4). Das 320 bp PCR-Produkt von A250R und der Oocyten-Expressionsvektor pSGEM wurden mit Bam HI und Xho I geschnitten und ihre überhängenden kompatiblen Enden durch eine Ligationsreaktion verknüpft. Das so konstruierte Plasmid pSKcv wurde in E. coli Zellen transformiert und dort vervielfältigt. Aus diesen Zellen wurden größere Mengen pSKcv Plasmid DNA isoliert und aufgereinigt, die dann linearisiert und als Matritze für die Synthese von RNA eingesetzt werden konnten. $\mathrm{Zu}$ Beginn der Experimente wurde den Oocyten -wie in Experimenten mit KAT1 (Véry et al. 1994) - 15 ng mRNA in einem Volumen von $40 \mathrm{nl}$ injiziert. Ab dem zweiten Tag nach Injektion nahm die Vitalität dieser Oocyten deutlich ab, am dritten bis vierten Tag waren $95 \%$ der Zellen tot. Daraufhin wurde die mRNA-Menge schrittweise bis auf $1 \mathrm{ng}$ herabgesetzt. Mit diesem Protokoll konnte in den injizierten Oocyten nach zwei bis drei Tagen Inkubationszeit die Expression von Kcv mit elektrophysiologischen Methoden nachgewiesen werden. Dazu wurde das konventionelle Voltage-clamp-Verfahren mit zwei Elektroden eingesetzt (4.19). Bei allen Messungen wurde parallel zur Stromdichte auch die Membranspannung der Oocyte aufgezeichnet. Bedingt durch die Größe dieser Zellen kann das tatsächliche Membranpotential z.T. deutlich von der angelegten Testspannung abweichen.

Oocyten, denen Kcv-mRNA injiziert wurde, werden als Kcv-Oocyten bezeichnet. Wasserkontrollen sind Oocyten, denen $40 \mathrm{nl} \mathrm{H}_{2} \mathrm{O}$ ohne mRNA injiziert wurde. 


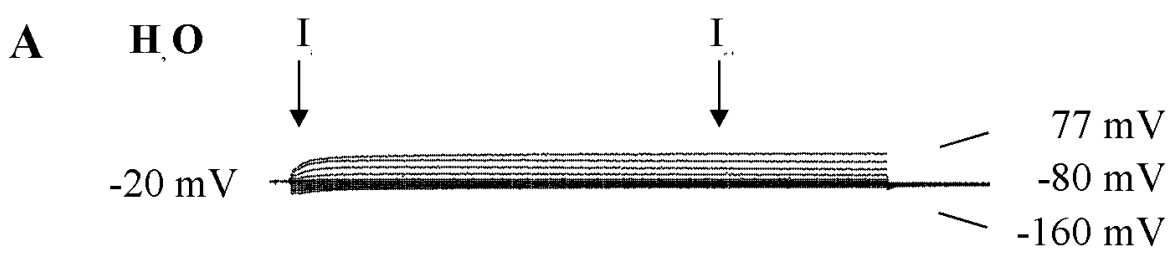

B Kev-mRNA
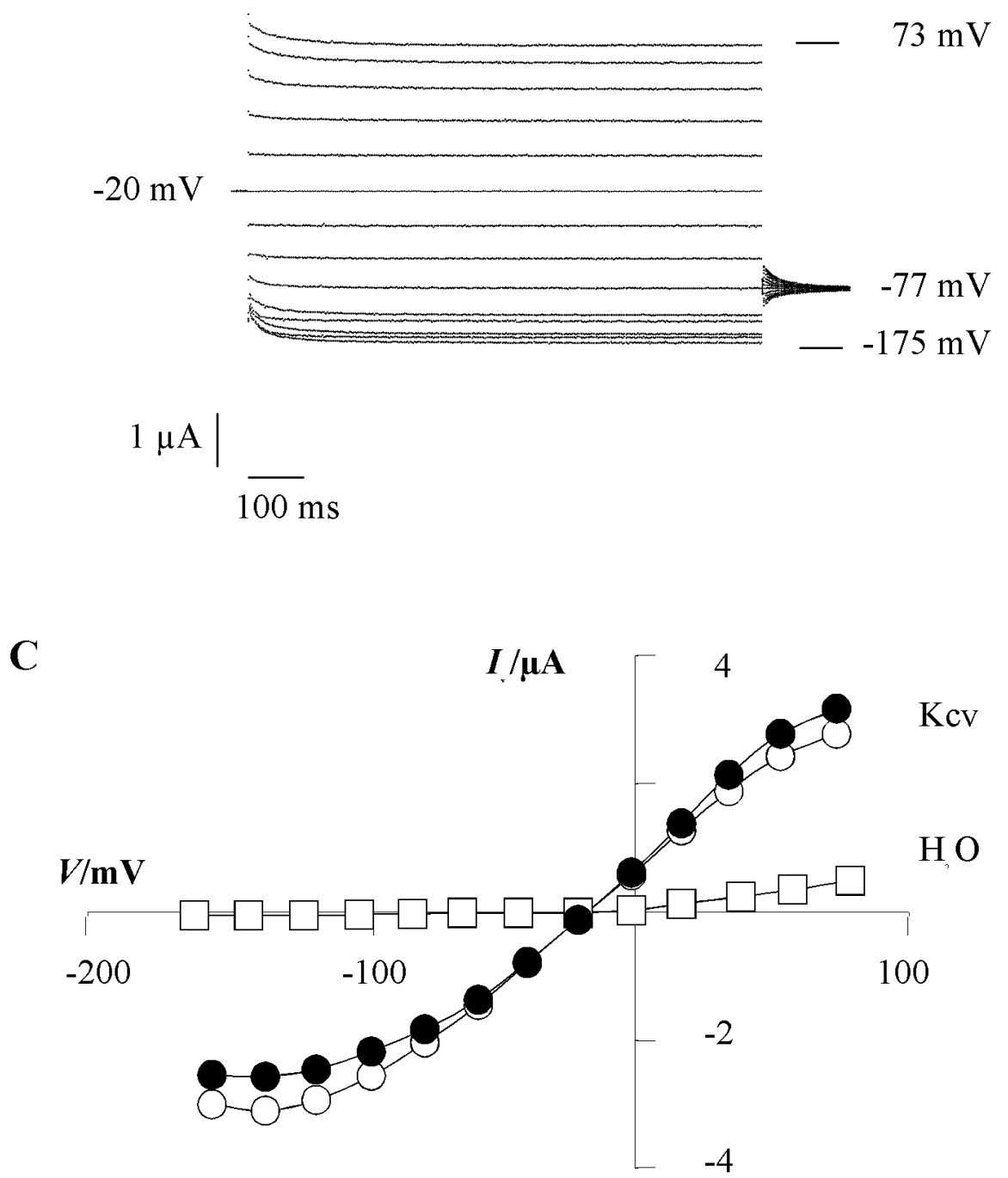

\footnotetext{
Abbildung 11: Heterologe Expression des Kaliumkanal-Gens Kev in Xenopus Oocyten.

(A, B) Ganzzellmessungen in $50 \mathrm{mM} \mathrm{KCl}$ von Wasserkontrollen und Kcv-Oocyten. Ausgehend vom Ruhepotential wurden in $20 \mathrm{mV}$-Schritten Spannungsstufen in den angegebenen $\mathrm{mV}$-Bereichen angelegt. Die $\mathrm{mV}$-Angaben bezeichnen die tatsächliche Membranspannung der Oocyte, die parallel zum Strom aufgezeichnet wurde. (C) Instantaner Strom $I_{i}\left(\right.$ nach $30 \mathrm{~ms}$, O) und stationärer Strom $I_{s t}$ (nach 700 ms, O) von Wasserkontrollen und Kcv-Oocyten als Funktion der Spannung.
} 


\subsubsection{Leitfähigkeit von Kcv-Oocyten}

Die Ströme aller Kcv-Oocyten waren in den Messungen deutlich von denen der Wasser-Kontrollen zu unterscheiden (Abbildung 11). Unbehandelte Oocyten haben eine geringe Leitfähigkeit für $\mathrm{K}^{+}$(Bauer et al. 1996) und $\mathrm{Cl}^{-}$(Dascal 1987), wobei die Leitfähigkeiten bei verschiedenen Zellpräparationen durchaus variieren können (Dascal 1987). Die hier gemessenen Wasserkontrollen hatten in $50 \mathrm{mM} \mathrm{KCl}$ ebenfalls nur eine geringe Leitfähigkeit (Abbildung 11A). Oocyten, denen Kcv-mRNA injiziert worden war, hatten dagegen reproduzierbar eine größere Leitfähigkeit (Abbildung 11B). Die in Kcv-Oocyten auftretende neue Leitfähigkeit wurde auch quantitativ ausgewertet. Die Stromantworten auf die angelegten Spannungspulse waren bei $+60 \mathrm{mV}$ um den Faktor 8,6 und bei $-140 \mathrm{mV}$ um den Faktor 8,2 höher als die Stromantworten der Wasserkontrollen (Tabelle 5).

Tabelle 5: Ströme in Kcv- und KcvF66A-Oocyten und Wasserkontrollen

\begin{tabular}{c|c|c|c|} 
& $\mathbf{+ 6 0} \mathbf{~ m V}$ & $\mathbf{- 1 4 0} \mathbf{~ m V}$ & $\mathbf{n}$ \\
\hline $\mathbf{H}_{\mathbf{2}} \mathbf{O}$ & $0,2 \pm 0,05 \mu \mathrm{A}$ & $-0,27 \pm 0,08 \mu \mathrm{A}$ & 9 \\
\hline $\mathbf{K c v}$ & $1,63 \pm 0,37 \mu \mathrm{A}$ & $-1,89 \pm 0,44 \mu \mathrm{A}$ & 17 \\
\hline KcvF66A & $0,39 \pm 0,27 \mu \mathrm{A}$ & $-0,48 \pm 0,35 \mu \mathrm{A}$ & 8
\end{tabular}

Mittelwerte und Standardabweichungen der stationären Ströme bei zwei exemplarischen Testspannungen; n, Anzahl der Oocyten.

Abbildung 11C zeigt die Strom-Spannungskurven einer Kcv-Oocyte (instantaner Strom $\mathrm{I}_{\mathrm{i}}$ und stationärer Strom $\mathrm{I}_{\mathrm{st}}$ ) und einerWasserkontrolle (nur $\mathrm{I}_{\mathrm{st}}$ ) im Vergleich. Die charakteristische Strom-Spannungskurve von Kcv-Oocyten hat zwischen $-60 \mathrm{mV}$ und $+20 \mathrm{mV}$ einen weitgehend linearen Verlauf, und $\mathrm{I}_{\mathrm{i}}$ sowie $\mathrm{I}_{\mathrm{st}}$ sind annähernd gleich groß. Bei negativeren bzw. positiveren Spannungen sind jedoch Veränderungen der Stromantworten zu beobachten:

1) die Strom-Spannungskurven nähern sich der X-Achse an (Abbildung 11C);

2) bei positiveren Spannungen wird der Strom träge inaktiviert: $I_{s t}$ ist kleiner als $I_{i}$ (Abbildung 11B, C); 3) bei stärkerer Hyperpolarisation wird träge eine weitere Stromkomponente aktiviert: $\mathrm{I}_{\mathrm{st}}$ ist größer als $\mathrm{I}_{\mathrm{i}}$ (Abbildung 11B, C). Die träge Komponente kann bis zu $15 \%$ des Gesamtstroms betragen. Demnach ist die Kcvinduzierte Leitfähigkeit in geringem Maße spannungsempfindlich. 
A $50 \mathrm{mM} \mathrm{K}$

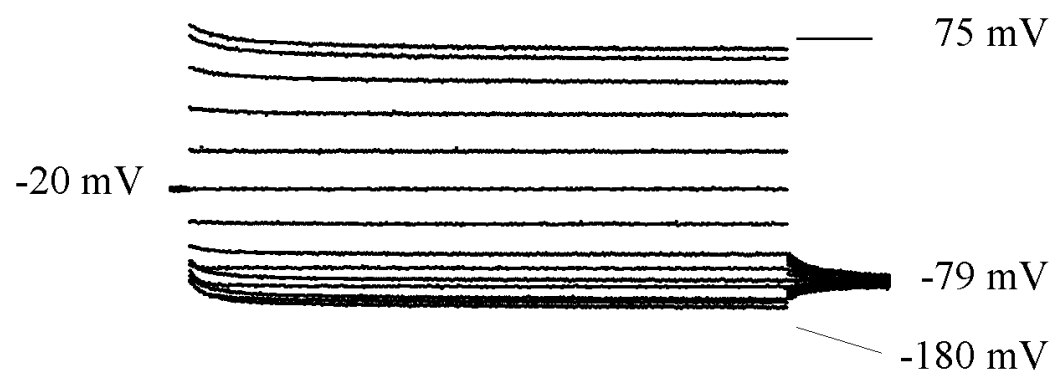

B + 6 mM Amantadin

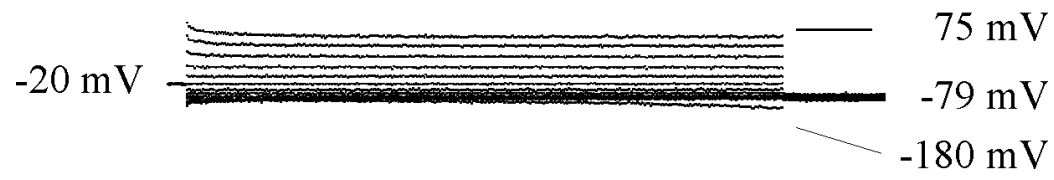

C Differenz A-B

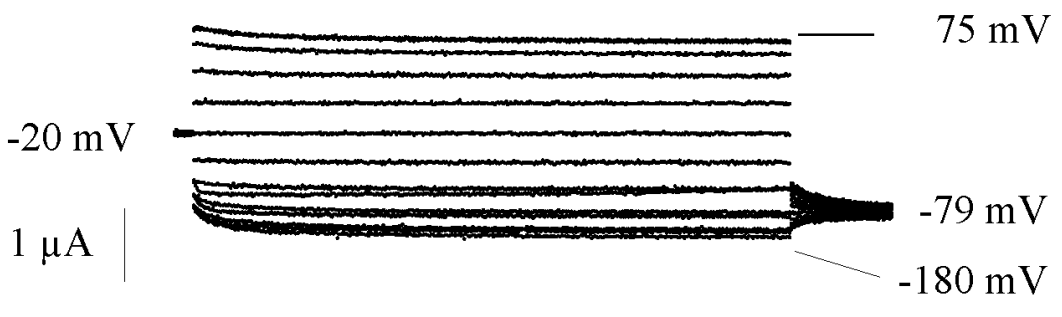

$100 \mathrm{~ms}$

D

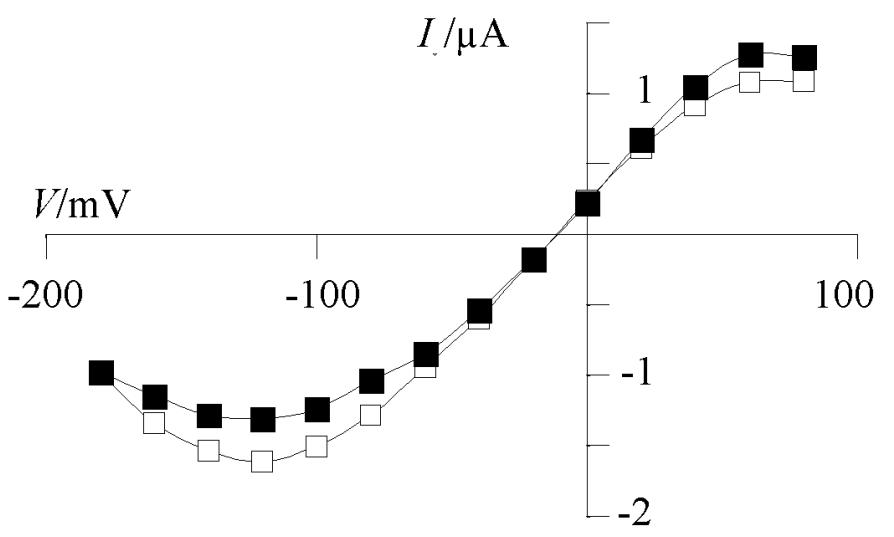

Abbildung 12: Amantadin inhibiert die Kcv-induzierte Leitfähigkeit.

(A) Messung in $50 \mathrm{mM} \mathrm{KCl}$ (Protokoll wie in Abbildung 11). (B) Messung nach Zugabe von $6 \mathrm{mM}$ Amantadin. Die Leitfähigkeit ist bis auf ca. $25 \%$ gehemmt. (C) Differenz der Ströme aus A und B. Die Differenzströme zeigen die gleiche Kinetik wie die Ganzzellströme in A, d.h. Amantadin hemmt spezifisch die Kcvinduzierte Leitfähigkeit. (D) Strom-Spannungskurven ( $\mathrm{I}_{\mathrm{i}}$ und $\mathrm{I}_{\mathrm{st}} \square$ ) aus C. 
Die neue Leitfähigkeit, die in den Kcv-Oocyten beobachtet wurde, könnte auch auf erhöhte Leckströme zurückzuführen sein, wie sie gelegentlich beim Einstechen der Elektrode auftreten. Als Indiz dafür, daß diese großen instantanen Ströme nicht nur Artefakte sind, soll an dieser Stelle auf ihre spezifische Hemmbarkeit (3.2.4.3) hingewiesen werden. Nach Zugabe von 6 mM Amantadin zur Badlösung wird der Strom bis auf einen zeitinvarianten Rest von ca. $25 \%$ gehemmt (Abbildung 12). Subtrahiert man diesen Reststrom (

Abbildung 12B) von der Kontrolle (Abbildung 12A), so zeigen die Differenzkurven (Abbildung 12C) die gleichen Eigenschaften wie die ursprünglich charakterisierte Leitfähigkeit: einen instantanen Strom plus eine träge Komponente. Dies zeigen auch die Differenz-Strom-Spannungskurven aus instantanem und stationärem Strom (Abbildung 12D). Die Leitfähigkeit der Wasserkontrollen wurden durch Amantadin nicht gehemmt. Dies zeigt, daß nach der Injektion von Kcv-mRNA tatsächlich eine neue, spezifisch hemmbare Leitfähigkeit auftritt.

\subsubsection{Selektivität}

In ersten Experimenten zur Bestimmung der Selektivität von Kcv wurden StromSpannungsbeziehungen bei verschiedenen Kaliumkonzentrationen in der Badlösung ermittelt. Bei niedrigeren Kaliumkonzentrationen war das Umkehrpotential $\mathrm{E}_{\mathrm{rev}}$ des instantanen Stroms $I_{i}$ negativer und der Einwärtsstrom nahm ab (Abbildung 13A). Der Einwärtsstrom bei $-140 \mathrm{mV}$ wird in $20 \mathrm{mM} \mathrm{KCl} \mathrm{um} 50 \%$, in $2 \mathrm{mM} \mathrm{KCl} \mathrm{um}$ $92 \%$ reduziert (Abbildung 13A). Der Auswärtsstrom war dagegen unbeeinträchtigt.

Nächste Seite:

\section{Abbildung 13: Selektivität für $\mathrm{K}^{+}$gegenüber $\mathrm{Cl}^{-}$}

(A) Instantaner Strom bei verschiedenen Kaliumkonzentrationen ( $\boldsymbol{0}, 2 \mathrm{mM} /$ $\diamond, 20 \mathrm{mM} / \bullet, 50 \mathrm{mM}$ ) als Funktion der Spannung. (B) Tailcurrent-Messungen in $50 \mathrm{mM} \mathrm{KCl}$. Ausgehend von einer aktivierenden Konditionierungsspannung von $-160 \mathrm{mV}$ wurden in $10 \mathrm{mV}$-Abständen Stufen in dem angegebenen Spannungsbereich angelegt, um die Inaktivierung der Ströme zu verfolgen. Die mV-Angaben bezeichnen die tatsächliche Membranspannung der Oocyte, die parallel zum Strom aufgezeichnet wurde. (C) Nernst-Plot der Umkehrpotentiale aus Ganzzellmessungen wie in A $(O)$ und Tailcurrent Analysen $(\checkmark)$. Die Gerade verläuft durch die Mittelwerte der Umkehrpotentiale mit einer Steigung von $60,0 \mathrm{mV}$ pro zehnfacher Erhöhung der Kaliumkonzentration ( $\mathrm{n}=8$ Oocyten) 
A

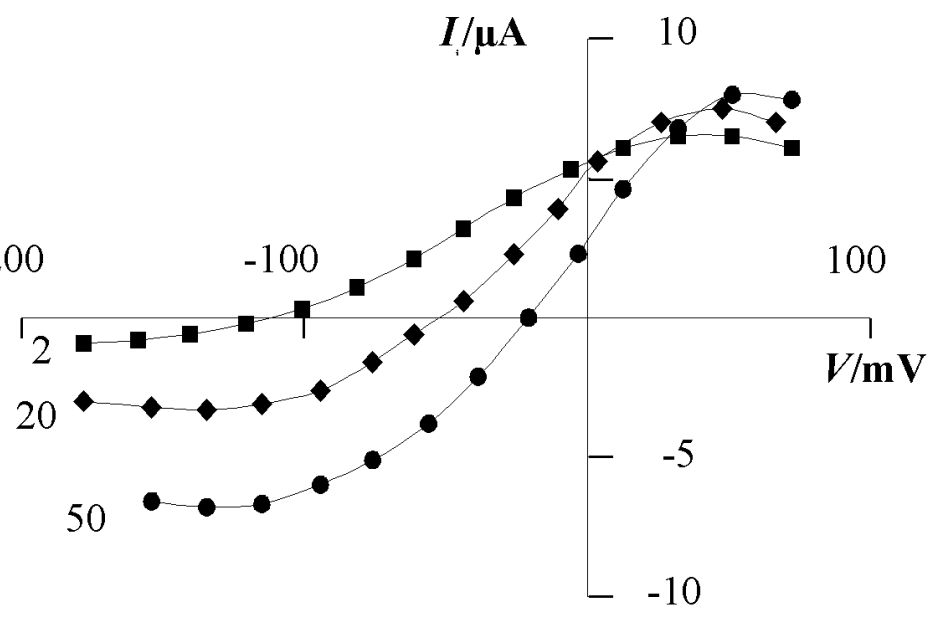

B

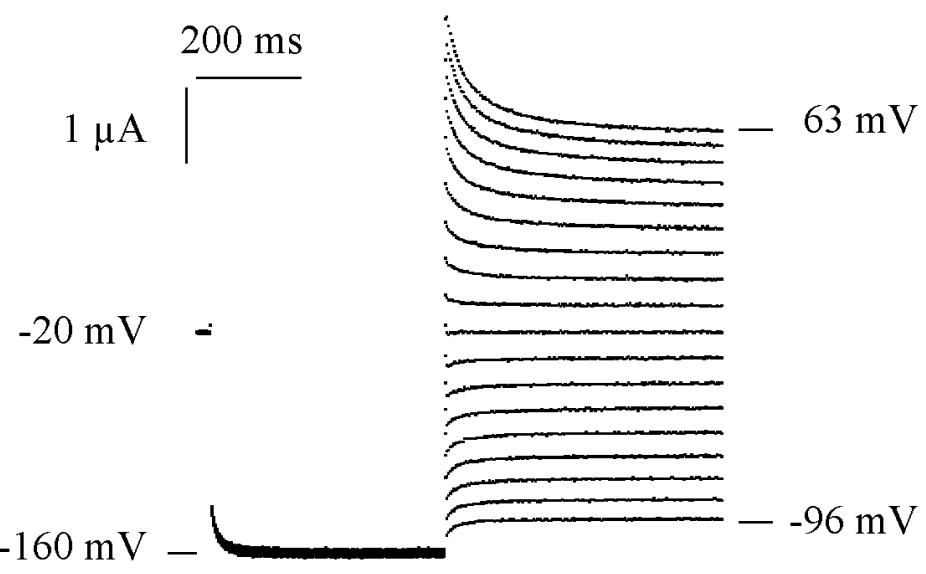

C $\quad \log [\mathrm{K} / \mathrm{mM}]$

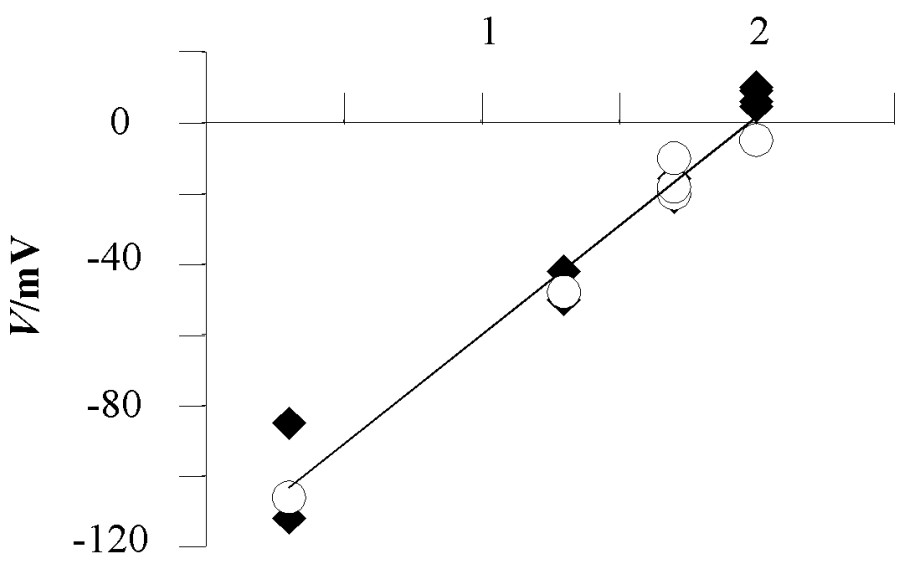


Trägt man die Umkehrpotentiale aus Abbildung 13A gegen $\log \left[\mathrm{K}^{+} / \mathrm{mM}\right]$ auf, so ergibt sich eine Gerade mit der Steigung $60 \mathrm{mV}$ pro 10facher Erhöhung der Kaliumkonzentration (Abbildung 13C). Dies ist annähernd der Wert, der nach der Nernst'schen Gleichung für Kaliumströme erwartet wird (58 mV). Aus dem Schnittpunkt der Geraden mit der X-Achse kann eine intrazelluläre Kaliumkonzentration von $100 \mathrm{mM}$ abgelesen werden.

In den Wasserkontrollen wurde bei entsprechenden Messungen nur eine Verschiebung von $15 \mathrm{mV}$ pro 10facher Erhöhung der Kaliumkonzentration festgestellt $(\mathrm{n}=5)$.

Um die Umkehrpotentiale ohne den störenden Einfluß endogener Hintergrundströme bestimmen zu können, wurde die träge Komponente der Leitfähigkeit für Tailcurrent-Analysen ausgenutzt (Abbildung 13B). Ausgehend von einer Konditionierungsspannung von -160 mV (bei der viele Kanäle geöffnet sind), wurden weniger negative Testspannungen angelegt. Die Differenz zwischen instantanem und stationärem Strom entspricht der trägen Komponente. Diese Differenz wurde gegen die Testspannungen aufgetragen. Die daraus ermittelten Umkehrpotentiale der Ströme zeigen die gleiche Abhängigkeit von der Kaliumkonzentration wie zuvor (Abbildung 13C). Diese Ergebnisse zeigen, daß die Kcv-induzierte Leitfähigkeit selektiv für $\mathrm{K}^{+}$gegenüber $\mathrm{Cl}^{-}$ist.

In einem weiteren Experiment wurde $\mathrm{KCl}$ in der Badlösung gegen $\mathrm{NaCl}$ ausgetauscht. Die Ströme wurden daraufhin deutlich kleiner (Abbildung 14A, B). Abbildung 14C zeigt Strom-Spannungsbeziehungen von zwei Messungen mit $50 \mathrm{mM} \mathrm{KCl}$ und $50 \mathrm{mM} \mathrm{NaCl}$ in der Badlösung. Beim Austausch von $\mathrm{KCl}$ gegen $\mathrm{NaCl}$ wird das Umkehrpotential im Mittel um $52 \pm 11 \mathrm{mV}$ kleiner ( $\mathrm{n}=5$ Oocyten). Der Einwärtsstrom bei $-140 \mathrm{mV}$ wird um $90 \%$ reduziert (Abbildung 14C). Der Austausch von $\mathrm{Na}^{+}$gegen $\mathrm{K}^{+}$wirkt also ähnlich wie die Verringerung der $\mathrm{K}^{+}-$ Konzentration. Das bedeutet, daß $\mathrm{Na}^{+}$nicht oder nur wenig transportiert wird - die Kcv-induzierte Leitfähigkeit ist also selektiv für $\mathrm{K}^{+}$gegenüber $\mathrm{Na}^{+}$. (Endogene Hintergrundströme tragen zum Umkehrpotential bei, so daß der Effekt lediglich qualitativ zu bewerten ist). Die Reduktion des Auswärtsstroms (bei $60 \mathrm{mV}$ auf $54 \%$ des Ausgangswertes) läßt darüber hinaus vermuten, daß $\mathrm{Na}^{+}$die Kanalaktivität hemmt (Abbildung 14C). 


\section{A $50 \mathrm{mMK}$}

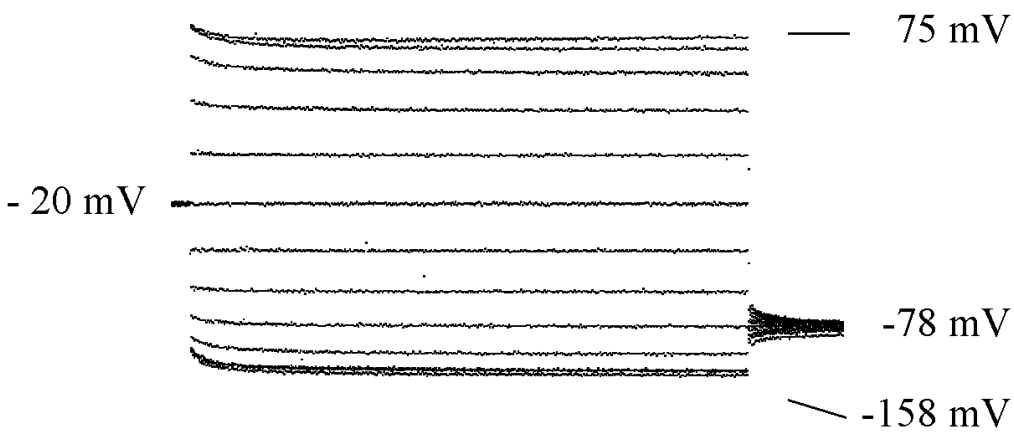

\section{B $50 \mathrm{mM}$ Na}
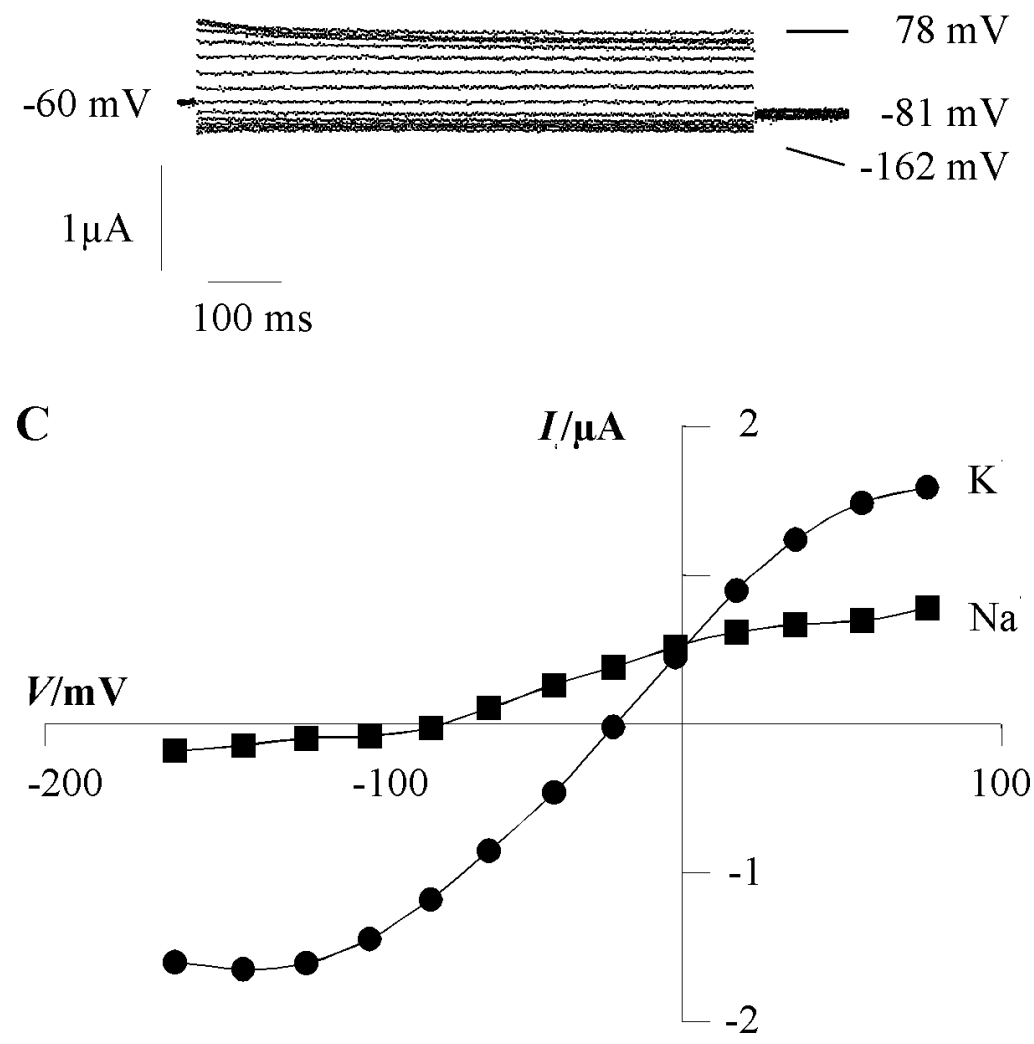

\section{Abbildung 14: Selektivität für $\mathrm{K}^{+}$gegenüber $\mathrm{Na}^{+}$}

(A, B) Ganzzellströme einer Oocyte in $50 \mathrm{mM} \mathrm{KCl} \mathrm{bzw.} 50 \mathrm{mM} \mathrm{NaCl}$ (Protokoll wie in Abbildung 11). Nach Austausch von $\mathrm{K}^{+}$gegen $\mathrm{Na}^{+}$in der Badlösung kommt es zu einer starken Verringerung des Einwärtsstroms mit einer vollständigen Unterdrückung der trägen Stromkomponente und einer schwächeren Verringerung des Auswärtsstroms. (C) Die Strom-Spannungskurven aus A und B zeigen die Veränderung der instantanen Ströme und die Verschiebung des Umkehrpotentials. 


\subsubsection{Hemmbarkeit}

Um die Hemmbarkeit der Kcv-induzierten Leitfähigkeit zu ermitteln, wurde der Badlösung entweder 0,1-40 $\mathrm{mM}$ des antiviralen Therapeutikums Amantadin (Abbildung 15A), 2-20 mM BaCl 2 , oder $10 \mathrm{mM} \mathrm{CsCl}$ zugegeben.

1) Abbildung 12 zeigt, daß $6 \mathrm{mM}$ Amantadin die Kcv-induzierte Leitfähigkeit bis auf ca. $25 \%$ des Ausgangswertes hemmt (3.2.4.1). Abbildung 15B zeigt die zunehmende Hemmung der Ein- und Auswärtsströme bei Amantadinkonzentrationen von 0,1$6 \mathrm{mM}$. Die Amantadinhemmung konnte durch Waschen innerhalb weniger Minuten vollständig rückgängig gemacht werden.

Abbildung 15C zeigt die relative Inhibierung des instantanen Stroms und der trägen Komponente durch $1 \mathrm{mM}$ Amantadin in der Badlösung. Sie beträgt bei allen Testspannungen ca. $80 \%$ der Kontrolle, d.h. die Amantadinhemmung ist kaum spannungsabhängig. Außerdem werden die instantanen Ströme und die träge Komponente gleichmäßig inhibiert - ein Indiz dafür, daß beide Stromkomponenten Resultat der gleichen Leitfähigkeit sind.

Um die Konzentration für die halbmaximale Inhibierung des Kanals $\left(\mathrm{K}_{\mathrm{i}}\right)$ zu ermitteln, wurde die relative Inhibierung der physiologisch relevanten stationären Ströme gegen die Amanadinkonzentration aufgetragen (Abbildung 15D, Testspannung +60 mV bzw. -140 mV). Die resultierenden Sättigungskurven wurden mit einer Michaelis-Menten-Gleichung beschrieben. Die Konzentrationen für halbmaximale Inhibierung $\left(\mathrm{K}_{\mathrm{i}}\right)$ waren $2 \mathrm{mM}$ (bei $+60 \mathrm{mV}$ ) bzw. 0,8 $\mathrm{mM}$ (bei $-140 \mathrm{mV}$ ).

Nächste Seite:

\section{Abbildung 15: Konzentrations- und Spannungsabhängigkeit der Amantadin- hemmung.}

(A) Amantadinhydrochlorid. (B) Strom-Spannungskurven der instantanen Ströme vor $(\bullet)$ und nach Zugaben von $1 \mathrm{mM}(\diamond)$ und $6 \mathrm{mM}(5)$ Amantadin). (C) relative Hemmung der Kcv-induzierten Leitfähigkeit einer weiteren Oocyte nach Zugabe von $1 \mathrm{mM}$ Amantadin als Funktion der Spannung. Instantane $(\diamond)$ und träge Komponente $(\diamond)$ des Stroms werden gleichmäßig gehemmt. (D) Die konzentrationsabhängige Hemmung des stationären Kcv-induzierten Stroms $(\bullet$, bei $60 \mathrm{mV} / 5$, bei $-140 \mathrm{mV}$ ) und der Virusreplikation von PBCV-1 $\diamond$ ) hat einen ähnlichen Verlauf. Konzentrationen für halbmaximale Inhibierung: $2 \mathrm{mM}(60 \mathrm{mV}) ; 0,8 \mathrm{mM}(-140 \mathrm{mV}) ; 2,8 \mathrm{mM}$ (Virusreplikation). Die Werte $\diamond$ ) bezeichnen die relative Reduktion der Virusplaques in einem Plattentest (Plugge et al. 2000). $\mathrm{n}=4$ Oocyten bzw. 4 Plattentests. 

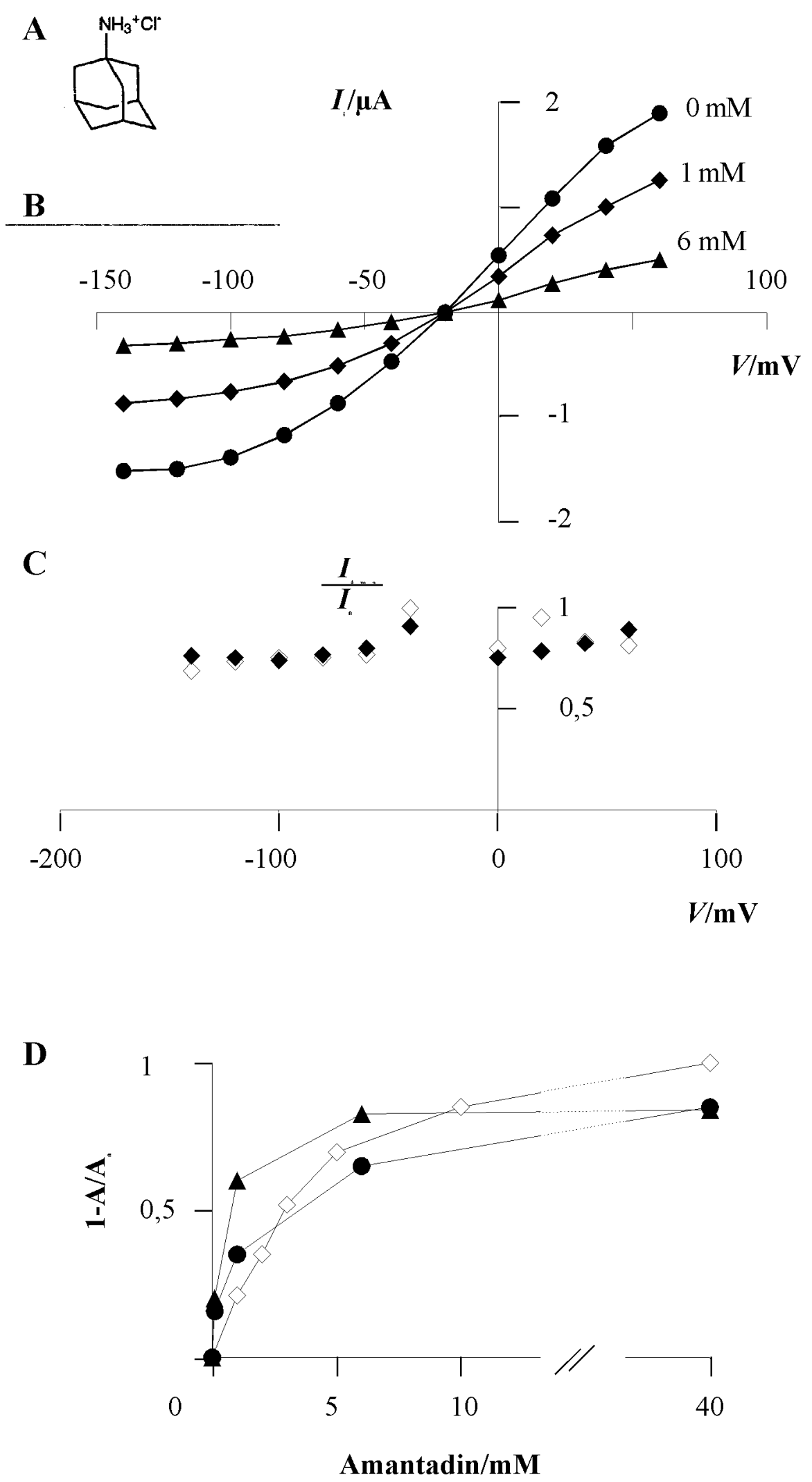
Diese $\mathrm{K}_{\mathrm{i}}$-Werte liegen um drei Größenordnungen höher als der für die Amantadinhemmung des Influenza-Protonenkanals M2 (Wang et al. 1993b). In Abbildung 15D ist zusätzlich die relative Inhibierung der Replikation des Virus PBCV-1 durch Amantadin aufgetragen. Die Abhängigkeit der Virusreplikation von der Amantadinkonzentration verläuft parallel zur Hemmung der Kcv-iduzierten Leitfähigkeit. Das weist darauf hin, daß der Kanal im Lebenszyklus des Virus eine wichtige Rolle spielt.

2) Barium hemmt den Kcv-induzierten Einwärtsstrom bereits in der kleinsten eingesetzten Konzentration von $1 \mathrm{mM}$ (bei -140 mV auf $12 \%$ des Stroms, Abbildung 16). Der Auswärtsstrom wurde nicht gehemmt. Wahrscheinlich wird $\mathrm{Ba}^{2+}$ durch negative Spannungen in die Kanalpore gezogen und blockiert so den Einwärtsstrom der Kaliumionen. Ähnliche Mechanismen wurden bereits für die einwärtsgleichrichtenden Eigenschaften der Kir-Kanäle nachgewiesen (Sabirov et al. 1997, Shieh et al. 1998, Owen et al. 1999).

3) Bei $10 \mathrm{mM} \mathrm{CsCl}$ im Badmedium wird die Kcv-induzierte Leitfähigkeit nur wenig gehemmt. Der Einwärtsstrom bei $-140 \mathrm{mV}$ wurde lediglich um $9 \pm 4 \%$, der Auswärtsstrom bei $+60 \mathrm{mV}$ wurde gar nicht reduziert ( $\mathrm{n}=4$ Oocyten).

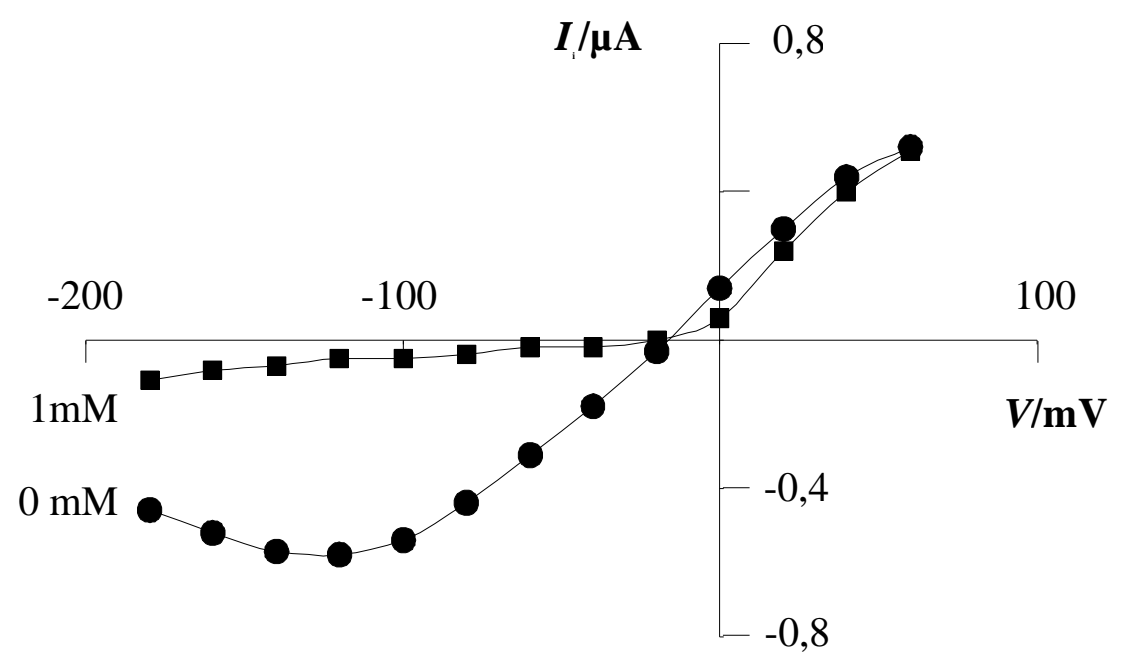

Abbildung 16: Effekt von $\mathrm{Ba}^{2+}$ auf die Kcv-induzierte Leitfähigkeit.

Strom-Spannungskurven der instantanen Ströme vor $(\bullet)$ und nach (ם) Zugabe von $1 \mathrm{mM} \mathrm{BaCl} 2$ zur Badlösung. Hier werden lediglich die Einwärtsströme gehemmt. 
A $\mathrm{HO}$

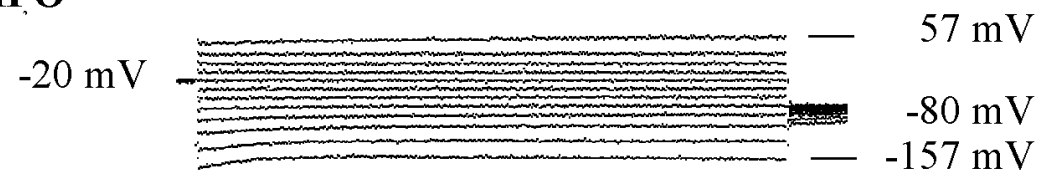

B KevF66A

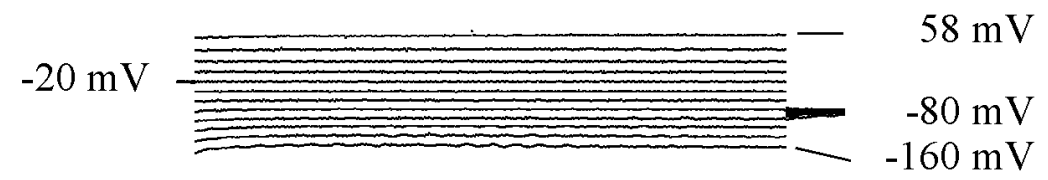

$$
0,5 \mu \mathrm{A}
$$

$200 \mathrm{~ms}$

C

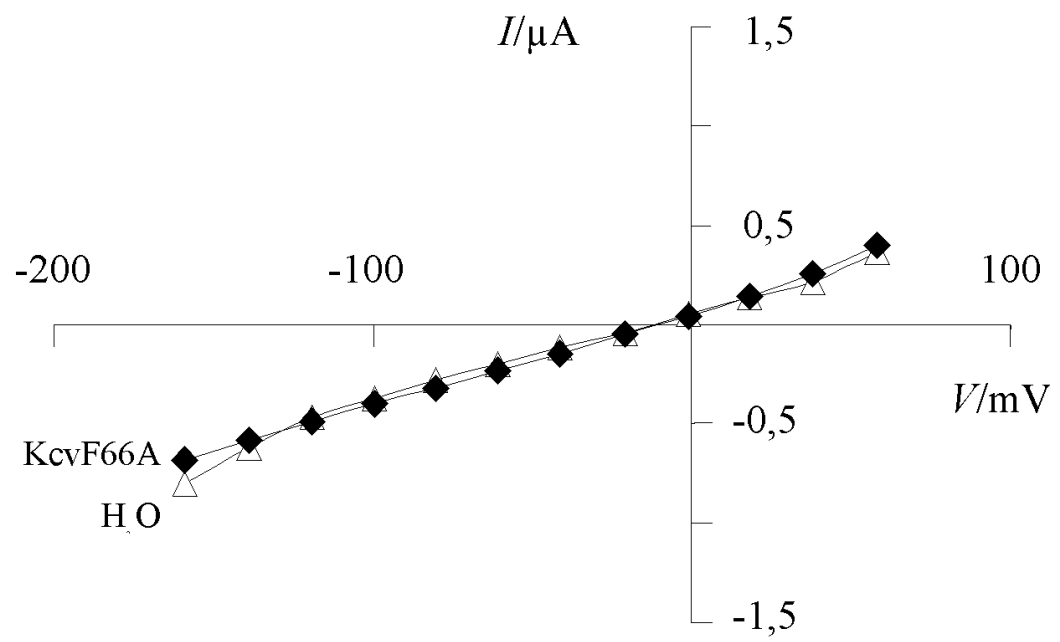

Abbildung 17: Die Mutante KcvF66A induziert keine Leitfähigkeit in Oocyten (A, B) Ganzzellströme einer Wasserkontrolle und einer KcvF66A-Oocyte. Die sonst häufig auftretenden, träge aktivierenden Chloridströme (Dascal et al. 1987) fehlen beiden Oocyten. (C) Die Strom-Spannungskurven der stationären Ströme aus A und B decken sich. 


\subsubsection{Konstruktion einer nicht-funktionalen Mutante}

Heterolog exprimierte Proteine können endogene Kanäle der Oocyten aktivieren (Shimbo et al. 1995, Barhanin et al. 1996). Um die Möglichkeit zu prüfen, daß die beobachtete Leitfähigkeit auf einer solchen Aktivierung endogener Leitfähigkeiten durch Kcv beruht, wurde eine nicht-funktionale Kcv-Mutante konstruiert. In Analogie zu Mutationen in der Konsensus-Sequenz des Shaker-Kanals (Heginbotham et al. 1994) wurde der Phenylalaninrest (F66) im Selektivitätsfilter-Motiv von Kcv gegen die kleine, hydrophobe Aminosäure Alanin (A) ausgetauscht (KcvF66A). Diese Mutation führt im Shaker-Kanal zum Verlust der stationären Leitfähigkeit (Heginbotham et al. 1994).

Mit Hilfe der overlap extension PCR (4.6.5) wurde das Codon von F66 durch ein Alanin-Codon ersetzt. Das mutierte Gen wurde in den Oocyten-Expressionsvektor pSGEM kloniert, transkribiert und die mRNA in Xenopus Oocyten injiziert.

In den KcvF66A-Oocyten trat die durch wt Kcv induzierte Leitfähigkeit nicht auf (Abbildung 17A, B). Die Leitfähigkeit war genauso gering wie die der Wasserkontrollen (Tabelle 5). Auch die Strom-Spannungskurve deckt sich mit der StromSpannungskurve der Wasserkontrolle (Abbildung 17C). Daraus ist zu schließen, daß die von wt Kcv induzierte Leitfähigkeit auf einen funktionalen Kcv-Kanal zurückzuführen ist und nicht auf die Aktivierung oder Rekrutierung von endogenen Kanälen der Oocyten. 


\subsection{Diskussion}

Chlorellavirus PBCV-1 codiert für ein kurzes Protein von 94 Aminosäuren, Kcv, mit dem Kaliumkanal-typischen Selektivitätsfilter-Motiv GFG und weiteren strukturellen Merkmalen von Kaliumkanälen. Das GFG-Motiv liegt in einer Domäne zwischen zwei Transmembransegmenten, die signifikante Ähnlichkeit mit den P-Regionen eukaryotischer Kaliumkanäle hat. Über die allgemeine Ähnlichkeit hinaus sind in dieser Domäne mehrere Aminosäuren mit struktureller Funktion konserviert. Diese Aminosäuren stehen sowohl bei Kcv als auch bei den zum Vergleich herangezogenen, funktionalen Kaliumkanälen stets an äquivalenten Positionen innerhalb der PRegion.

Allen bisher untersuchten Kaliumkanäle ist eine solche Poren-Struktur gemeinsam (Doyle et al. 1998). Daher wird aus der Summe der strukturellen Analogien postuliert, daß Kcv ebenfalls funktionale Kaliumkanäle bilden kann.

Um diese Funktion zu prüfen, wurde das Gen heterolog in Xenopus laevis Oocyten exprimiert. Tatsächlich wurde nach Injektion von Kcv-mRNA reproduzierbar das Auftreten einer neuen, Kalium-selektiven Leitfähigkeit beobachtet, die über die Leitfähigkeit der Wasserkontrollen hinausging und u.a. durch ihre spezifische Pharmakologie zu charakterisieren war. Die Hemmbarkeit und Versuche mit einer nichtfunktionalen Kcv-Mutante sind Indizien dafür, daß die beobachtete Leitfähigkeit auf die Aktivität eines neuen Kanals, nämlich Kcv zurückzuführen ist.

\subsubsection{Gemeinsamkeiten von Kcv mit anderen Kanälen}

Die Primärstruktur von Kcv wurde mit typischen Vertretern aus mehreren Kaliumkanalfamilien verglichen (Tabelle 4). Aus der Prämisse, daß Kcv wie diese Proteine funktionale Kaliumkanäle bilden kann, ergeben sich weitere Kriterien, die Kcv erfüllen müßte:

Ein funktionaler Kaliumkanal setzt sich aus vier $\alpha$-Untereinheiten zusammen, die entweder gleiche (Homotetramere) oder kompatible Kaliumkanalproteine sind (Heterotetramere; MacKinnon 1991, Doyle et al. 1998). Zusätzlich können $\beta$-Untereinheiten vorkommen. Die Zusammensetzung der Untereinheiten findet im ER wäh- 
rend der Faltung der Untereinheiten statt (Papazian 1999). Beim Shaker-Kanal wird die Zusammensetzung durch eine spezielle Domäne am N-Terminus vermittelt ( $\mathrm{Li}$ et al. 1992, Papazian 1999).

Auch ein funktionaler Kcv-Kanal müßte aus vier Untereinheiten aufgebaut sein. Da $\mathrm{N}$ - und C-Terminus des Proteins sehr kurz sind, müssen für die Zusammensetzung des Tetramers allerdings Protein-Protein-Interaktionen zwischen den Transmembranregionen angenommen werden. Solche Interaktionen sind z.B. für Kir 2.1-Tetramere beschrieben worden (Minor et al. 1999).

\subsubsection{Zwei Transmembrandomänen: Kir Kanäle}

Die 2 TM-Struktur von Kcv ist charakteristisch für die Kir-Kanäle (Übersicht in Karschin et al. 1997). Auch diese Kanäle besitzen - wie Kcv - keine Transmembrandomäne mit Ähnlichkeit zum Spannungssensor der Kv-Kanäle (3.3.2). Die Sequenzen von drei Kir-Vertretern, Kir 1.1, Kir 3.2 und $\mu$ KATP1 zeigen allerdings selbst in der Porenregion nur moderate Ähnlichkeit mit Kcv (Abbildung 9).

Trotz ihrer vergleichsweise einfachen Architektur sind Kir-Kanäle komplexe Proteine mit Domänen, die mit G-Proteinen (Kir3) oder verschiedenen Rezeptoren (Kir6) interagieren (s. Karschin et al. 1997). Viele Interaktionen mit zellulären Regulatoren finden an den N- und C-Termini der Kir-Untereinheiten statt. Die Sequenz von Kcv läßt für derartige Interaktionen wenig Spielraum, da der N-Terminus des Proteins nur ca. 12 Aminosäuren umfaßt. Allerdings enthält die Domäne eine mögliche Phosphorylierungsstelle (TRTE), die für eine Regulation der Kanalaktivität in Frage käme. Ein cytoplasmatischer C-Terminus ist nicht vorhanden. Denkbar ist allerdings auch, daß das Kcv-Protein durch Spleißen mit anderen N- oder C-terminalen Domänen versehen wird. Dafür sprechen Northern Blot-Analysen, in denen das Kcv-Gen mit vier sehr viel größeren mRNA-Banden hybridisiert (J.L. Van Etten, pers. Mitteilung).

\subsubsection{Das GFG-Motif: ether-a gogo-Kanäle}

Der seltene Austausch von Tyrosin (Y) im Selektivitätsfilter-Motiv gegen Phenylalanin (F) ist ein strukturelles Merkmal der EAG-Kanäle (Abbildung 8). EAG-Kanäle gehören zur Strukturklasse der 6-TM-Kanäle (Abbildung 5). 
Zu den Vertretern zählen u.a. EAG (D. melanogaster) und hERG (Homo sapiens, Trudeau et al. 1995, Ganetzky et al. 1999).

Über das GFG-Motif hinaus sind sowohl bei EAG, hERG als auch bei Kcv die beiden strukturell bedeutsamen Tryptophanreste (W) in der Porenregion (molecular spring-Hypothese, Doyle et al. 1998) durch Y und F ersetzt (Tabelle 6). Da diese drei aromatischen Aminosäuren keine Wasserstoffbrückenbindungen miteinander ausbilden, wird für hERG ein kleinerer Durchmesser der äußeren Pore postuliert (Fan et al. 1999). Dieses Postulat könnte aufgrund der gleichen Sequenzmerkmale auch auf die Pore von Kcv übertragen werden. Eventuell hätte dies Auswirkungen auf die Bindungsstellen von Kanalblockern wie z.B. $\mathrm{Cs}^{+}$(3.2.4.3).

Tabelle 6: molecular spring: Interagierende Aminosäuren in der P-Region

\begin{tabular}{|c|c|c|c|}
\hline SliKch & hERG & Kev & Die Aminosäuren in jeder Zeile ste- \\
\hline W67 & Y616 & F55 & $\begin{array}{l}\text { hen in der Porenregion der genannten } \\
\text { Proteine an äquivalenten Positionen. }\end{array}$ \\
\hline W68 & F617 & F56 & Die Aminosäuren der letzten Zeile \\
\hline Y78 & F627 & F66 & $\begin{array}{l}\text { sind Teil des Selektivitätsfilter- } \\
\text { Motivs GY/FG }\end{array}$ \\
\hline
\end{tabular}

\subsubsection{Kaliumkanal-Gene aus prokaryotischen Organismen}

Prokaryotische Gene mit Homologien zu eukaryotischen Kaliumkanälen wurden zunächst in E. coli (Milkman 1994) und S. lividans (Schrempf et al. 1995) identifiziert (s. auch Tabelle 4). Mitttlerweise sind 20 weitere Kaliumkanalhomologe mit ein bis sechs Transmembrandomänen und konservierten P-Regionen bekannt (Derst \& Karschin 1998). Wie Kcv sind die prokaryotischen Kaliumkanalkandidaten zunächst aufgrund ihrer Ähnlichkeit mit P-Regionen eukaryotischer Kaliumkanäle gefunden worden.

Von diesen Kanalkandidaten ist nur sliKch aus S. lividans elektrophysiologisch untersucht (Schrempf et al. 1995). Die Expression von sliKch und anderen prokaryotischen Sequenzen in Oocyten ist allerdings bisher nicht gelungen (Schrempf et al. 1995 und C. Derst, pers. Mitteilung). 
Obwohl nur im planaren Film als rekonstituiertes Protein untersucht, gilt sliKch inzwischen als Modellkanal, weil es der erste Kaliumkanal ist, dessen dreidimensionale Struktur durch eine Röntgenstrukturanalyse aufgeklärt werden konnte (Doyle $e t$ al. 1998). Die strukturell wichtigen Aminosäuren in der Porenregion, die in dieser Studie identifiziert wurden, sind in allen Kanälen hochkonserviert.

Zusätzlich zur hohen Sequenzähnlichkeit in der Porenregion haben sowohl Kcv als auch sliKch sehr hydrophobe N-Termini (Abbildung 5A und Abbildung 7), die positiv geladene Aminosäuren enthalten und möglicherweise membranständig sind. Auch der Größenunterschied zwischen diesen beiden Domänen ist gering. Der N-Terminus von sliKch ist mit 20 Aminosäuren nicht viel länger als der von Kcv (12 Aminosäuren). Der Größenunterschied der beiden Proteine (66 Aminosäuren) beruht v.a. auf der Länge der C-Termini (vgl. Abbildung 5A und Abbildung 7).

\subsubsection{Die Kcv-induzierte Leitfähigkeit}

Die Strom-Spannungskurve der Kcv-induzierten Leitfähigkeit nähert sich zu beiden Spannungsextremen der X-Achse an, d.h.der Kanal ist schwach spannungsabhängig. Die beobachteten Merkmale können folgendermaßen interpretiert werden:

Bei Spannungen um $0 \mathrm{mV}$ sind fast alle Kanäle offen. Bei stärker negativen Membranspannungen werden weitere Kanäle träge aktiviert. Gleichzeitig werden die Poren der Kanäle zunehmend kationisch blockiert, so daß die StromSpannungsbeziehung vom linearen Verlauf abweicht. Bei positiven Spannungen werden dagegen die Kanäle träge inaktiviert. Zusätzlich wird auch hier die Leitfähigkeit durch eine Blockade der Poren verringert.

Bei Kaliumkanälen vom 6TM-Typ (wie z.B. Shaker) fungiert die S4-Region als Spannungssensor. Ihre Sequenz ist durch ein Muster aus positiv geladenenen Aminosäuren (Lys und Arg) an jeder dritten Position gekennzeichnet (Liman et al. 1991). Zwar findet sich dieses Muster in keiner der beiden TM-Domänen von Kcv, jedoch enthält der hydrophobe N-Terminus des Proteins zwei positiv geladene Aminosäurereste (Abbildung 7). Sollte dieser Teil des Proteins ebenfalls membranständig sein, könnten diese Ladungsträger als Spannungssensoren fungieren und die schwache Spannungsabhängigkeit der Kcv-induzierten Ströme erklären. 


\subsubsection{Hemmbarkeit}

Von den drei getesteten Stoffen inhibieren $\mathrm{Ba}^{2+}$ und Amantadin die KcvKanalaktivität, $\mathrm{Cs}^{+}$dagegen nicht. Interessanterweise spiegelt dieses pharmakologische Profil die Hemmbarkeit der Virusreplikation wider. $\mathrm{Ba}^{2+}$ und Amantadin hemmen die Replikation von PBCV-1 im gleichen Konzentrationsbereich wie die KcvKanalaktivität. $\mathrm{Cs}^{+}$beeinflußt die Virusreplikation dagegen nicht (Plugge et al. 2000). Diese Ergebnisse lassen die Vermutung zu, daß die Aktivität von Kcv Einfluß auf die Replikation von Chlorellavirus PBCV-1 hat.

Amantadin wird zur Bekämpfung von Virusinfektionen und der Parkinson'schen Krankheit eingesetzt wird (Übersicht in Kornhuber et al. 1994). Es handelt sich um ein relativ kleines, organisches Kation (Abbildung 15A), dessen Struktur vermuten läßt, daß es die Kcv-Pore - und evtl. die Poren anderer Kanäle - auch unspezifisch blockieren kann. Tatsächlich inhibiert Amantadin reversibel sowohl den pflanzlichen Kaliumkanal KAT1 (S. Gazzarrini, pers. Mitteilung) als auch eine ganze Reihe rezeptorgekoppelter Kanäle (Ashcroft et al. 1991, Kornhuber et al. 1994, Matsubayashi et al. 1997) und KAch-Kanäle aus der Kir3-Familie (Mészáros et al. 1982, Freeman et al. 1985). In Kontrolloocyten war allerdings kein Amantadin-Effekt festzustellen. Nur die Leitfähigkeit der Kcv-Oocyten wurde reversibel gehemmt. Dies ist ein weiteres Indiz dafür, daß die Hemmung der Virusreplikation durch Amantadin auf eine Inhibierung der Kcv-Aktivität zurückzuführen ist.

Auch im Fall von Influenzavirus A beruht die antivirale Wirkung von Amantadin auf der Inhibierung eines Ionenkanals, nämlich des M2-Proteins. Die Primärstrukturen von M2 und Kcv haben allerdings - abgesehen von der Länge der Peptide - keine signifikante Ähnlichkeit. Insbesondere fehlt M2 die zweite Transmembranregion und die typische Kaliumkanal-Konsensussequenz. M2 transportiert vor allem Protonen, aber auch $\mathrm{K}^{+}, \mathrm{Na}^{+}$und andere Kationen (Pinto et al. 1992, Tosteson et al. 1994).

Auf den ersten Blick interessant schien allerdings die Tatsache, daß es sich bei beiden Proteinen um viral codierte Ionenkanäle handelt, die durch Amantadin hemmbar sind. Die Aktivität der M2-Kanäle wird durch Zugabe von $<1 \mu \mathrm{M}$ Amantadin komplett und nahezu irreversibel gehemmt (Wang et al. 1993b, Gandhi et al. 1999). Auf den zweiten Blick ist jedoch die Hemmung von Kcv durch Amantadin anderer Art als die von M2: 
Sie ist durch Auswaschen von Amantadin aufzuheben und die Konzentrationen, durch die der Kcv-induzierte Strom halbmaximal gehemmt wird, sind um drei GröBenordnungen höher als beim M2-Protein.

Ein molekulares Modell des M2-Kanals läßt den Schluß zu, daß Amantadin mit einem Histidinrest in der Transmembranregion von M2 (H37) interagiert (Gandhi et al. 1999). Histidinreste finden sich auch in beiden TM-Regionen von Kcv (H17 und H83). Insbesondere wäre eine Interaktion von Amantadin mit H83 denkbar, da die zweite TM-Region bei Kaliumkanälen Teil der Pore ist (Doyle et al. 1998). Die Unterschiede in der Amantadinsensitivität zwischen M2 und Kcv lassen jedoch eher eine andere Wirkung von Amantadin auf Kcv vermuten.

Es überrascht, daß $10 \mathrm{mM} \mathrm{CsCl}$ die Kcv-induzierte Leitfähigkeit nur wenig hemmt. $\mathrm{Cs}^{+}$wird neben Tetraethylammonium und $\mathrm{Ba}^{2+}$ häufig als Inhibitor für Kaliumkanäle eingesetzt. Die $\mathrm{Cs}^{+}$-Sensitivität eines Kanals kann durch Mutationen in der P-Region und der angrenzenden, porenbildenden Transmembrandomäne erhöht werden, so z.B. im pflanzlichen Kaliumkanal KAT1 durch die Mutation T259S (Serin statt Threonin) nahe des Selektivitätsfilters (Becker et al. 1996). Kcv besitzt an äquivalenter Position ebenfalls ein Serin (S62) statt eines Threonins (Abbildung 8). Da in den meisten Kaliumkanälen an dieser Position das $\mathrm{T}$ konserviert ist (Abbildung 8 und Abbildung 9), wäre zu prüfen, ob eine KcvS62T-Mutante $\mathrm{Cs}^{+}$-sensitiv ist.

Die Ladungsverteilung in der Pore sowie der Porendurchmesser können bei der $\mathrm{Cs}^{+}-$ Sensitivität ebenfalls eine Rolle spielen. Beim Kir-Kanal IRK1 ist es der Austausch einer negativ geladenen gegen eine ungeladene Aminosäure zu Beginn der zweiten Transmembransequenz (D172N), der den Kanal unempfindlich gegenüber $\mathrm{Cs}^{+}$werden läßt (Abrams et al. 1996).

Auch könnte - in Analogie zum hERG-Kanal - der äußere Porenbereich von Kcv enger sein als der von anderen Kaliumkanälen (3.3.1.2), so daß $\mathrm{Cs}^{+}$nicht tief in die Pore gelangen kann. In einer engen Pore steigt die Wahrscheinlichkeit, daß sterische Hindernisse auftauchen. So könnten auch die Seitenketten von ungeladenen Aminosäuren wie S62 größere Bedeutung erlangen. Auch diese Hypothese könnte anhand der KcvS62T- und ähnlicher Mutanten geprüft werden. 


\subsubsection{Aktivierung endogener Ströme}

Bei der Expression artfremder Proteine in Xenopus Oocyten muß in Betracht gezogen werden, daß die Überexpression von Fremdproteinen zu Veränderungen in der Aktivität endogener Oocyten-Kanäle führen kann. So werden nach Injektion von minK-mRNA (Takumi et al. 1988) in Oocyten endogene $\mathrm{Cl}^{-}$-Kanäle aktiviert (Shimbo et al. 1995). Diesen Effekt hat auch die Injektion von mRNA des Influenzavirus B NB-Proteins und einer nicht-funktionalen Variante des Influenzavirus A M2Ionenkanals (Shimbo et al. 1995). Das NB-Protein ist ebenfalls ein potentieller Ionenkanal (Sunstrom et al. 1996), dessen Transporteigenschaften aber nicht schlüssig bewiesen werden konnten (Lamb \& Pinto 1997). Die Aktivierung der $\mathrm{Cl}^{-}$-Kanäle wurde erst durch einen Schwellenwert ausgelöst und nahm mit der Menge des exprimierten Proteins zu (Shimbo et al. 1995).

Nach Injektion von Kcv-mRNA in Xenopus Oocyten konnte eine solche Aktivierung endogener $\mathrm{Cl}^{-}$-Leitfähigkeiten nicht beobachtet werden. Dies kann darauf zurückgeführt werden, daß den Oocyten nur $1 \mathrm{ng}$ Kcv-mRNA injiziert wurde. Bei Shimbo et al. (1995 und Referenzen darin) wird dagegen die mRNA-Menge mit 20 ng pro Oocyte angegeben (die Moleküle sind ähnlich groß wie Kcv).

Das Protein minK (Tabelle 4) wurde lange für einen "minimalen" Kaliumkanal" gehalten, weil es in Oocyten eine Kalium-Leitfähigkeit induzierte (Takumi et al. 1988, Hausdorf et al. 1991). Es besitzt aber nur eine Transmembrandomäne und die typische P-Region fehlt. Nachdem in anderen Zellinien keine derartigen Ströme gemessen werden konnten (Lesage et al. 1993), zeigte sich, daß minK heteromultimere Komplexe mit anderen Kanaluntereinheiten bildet. Es konnte eine Assoziation von minK sowohl mit KvLQT1 (Barhanin et al. 1996, Sanguinetti et al. 1996) als auch mit hERG (MacDonald et al. 1997) nachgewiesen werden. Auch in Oocyten wurde ein KvLQT1-Homolog gefunden, dessen Assoziation mit minK wahrscheinlich die gemessenen Ströme induziert (Sanguinetti et al. 1996).

Die Möglichkeit, daß Kcv - ähnlich wie minK - endogene Kanäle rekrutiert, kann nicht ausgeschlossen, aber durch Versuche mit einer nicht-funktionalen Mutante zumindest eingeschränkt werden. In Oocyten, die mit der Mutante KcvF66A injiziert wurden, trat die zuvor charakterisierte Kcv-induzierte Leitfähigkeit nicht auf. Sollte diese Leitfähigkeit also auf die Aktivität eines heteromultimeren Komplexes aus Kcv 
und einem endogenen Kanal zurückzuführen sein, so wären für dessen Funktion anders als bei minK - Kcv-Untereinheiten mit intaktem Selektivitätsfilter Voraussetzung.

\subsubsection{Letalität von Kcv}

Die Injektion größerer Mengen Kcv-mRNA (5-15 ng), wie sie zur Expression z.B. des KAT1 Kaliumkanals in Oocyten eingesetzt werden (Véry et al. 1994) sowie längere Inkubationszeiten führten zum Tod der Zellen. Wurden deutlich geringere Mengen injiziert (1 ng), so blieben die Oocyten vital.

Eine Erklärung für diesen Effekt liefert die geringe Größe von Kcv: Die Länge der Kcv-mRNA beträgt nur etwa 1/7 der KAT1-mRNA, so daß eine absolute Menge von 15 ng einer überproportional großen Zahl von Kcv-mRNA-Molekülen entspricht. Nach Injektion von 15 ng Kcv-mRNA wurde das Protein also übermäßig exprimiert. Dazu kommt, daß das Ruhepotential der Oocyten mit -20 mV in einem Spannungsbereich liegt, in dem die Kcv-Leitfähigkeit aktiv, d.h. der Kanal offen ist. Das könnte bei starker Überexpression des Kanals einen letalen $\mathrm{K}^{+}$-Verlust zur Folge haben.

\subsubsection{Die Rolle von Kcv im viralen Lebenszyklus}

Das hier charakterisierte Protein Kcv ist der erste bekannte Kalium-selektive Ionenkanal aus einem Virus. Eine Suche nach Proteinen mit Homologie zu Kcv in verschiedenen Virusgenomen blieb erfolglos. Somit ist dieser Kaliumkanal aus Chlorellavirus PBCV-1 bislang einmalig.

Nur für das virale Protein M2 aus Influenzavirus A ist bisher überhaupt eine Kanalaktivität zweifelsfrei nachgewiesen worden (Pinto et al. 1992, Lamb \& Pinto 1997). Diese Ionenkanäle sorgen zum einen für die Äquilibrierung der Ladungsverteilung zwischen dem membranumhüllten Viruspartikel und der Umgebung (Tosteson et al. 1994) und tragen zum anderen durch Ansäuerung des Virusinneren zur Entlassung des Nucleocapsids in das Cytoplasma der infizierten Wirtszelle bei (Sugrue \& Hay 1991, Ciampor et al. 1992). 
Drei Indizien sprechen dafür, daß auch der Kaliumkanal Kcv im viralen Lebenszyklus eine Rolle spielt: 1) Die A/T-reiche 5'-untranslatierte Region des codierenden offenen Leserahmens weist darauf hin, daß ORF A250R ein Protein-codierendes Gen ist; 2) in Northern Blot-Analysen wurden drei frühe und ein spätes mRNA-Transkript identifiziert, die mit A250R hybridisieren (M.Graves \& J.L. Van Etten, pers. Mitteilung); 3) Virusreplikation und Kcv-Aktivität haben die gleiche Pharmakologie.

Aufschluß darüber, wann und wo Kcv im Infektionsprozeß eine Rolle spielt, könnte sicherlich eine Lokalisation des Proteins mit Hilfe von Antikörpern geben. Zu klären wäre dabei als erstes, ob Kcv im Capsid oder nur in infizierten Zellen lokalisiert ist. Das Capsid von PBCV-1 mit seiner internen Lipidschicht (Skrdla et al. 1984, Van Etten \& Meints 1999) muß sicherlich mit der Umgebung äquilibriert werden, um in hypotonischem Medium nicht zu platzen. Eine solche Funktion übernimmt beispielsweise bei den membranumhüllten Influenzaviren das M2-Protein, das neben Protonen auch andere Kationen passieren läßt (3.3.2.1). Auch ist denkbar, daß Kcv bei Überexpression in der Wirtszelle die membranösen Organellen (die während der späten Infektionsphase abgebaut werden) osmotisch destabilisiert oder auf ähnliche Weise an der abschließenden Lysis der Zelle beteiligt ist. Ein Indiz dafür ist, daß die Überexpression von Kcv-mRNA für Xenopus Oocyten vermutlich wegen einer solchen osmotischen Destabilisierung letal war (3.3.2.3).

Das Genom von Chlorellavirus PBCV-1 enthält Gene eukaryotischen und prokaryotischen Ursprungs (Van Etten \& Meints 1999). Die phylogenetische Analyse ordnet Kcv keiner der bekannten Kaliumkanalfamilien aus Pro- oder Eukaryoten zu. Denkbar ist, daß das Kcv-Gen aus einer Wirtszelle stammt. Leider sind jedoch bisher keine Kaliumkanal-Gene aus Chlorella, der Wirtsspezies von PBCV-1, beschrieben worden. Der eigene, ursprüngliche Ast von Kcv im phylogenetischen Baum könnte jedoch auch bedeuten, daß der primitive Kaliumkanal Kcv evolutionär sehr alt ist und ein Bindeglied zwischen prokaryotischen und eukaryotischen Kanälen darstellt. Unterstützt wird diese Annahme durch die Tatsache, daß die P-Region von Kcv mit dem prokaryotischen ecoKch und zwei eukaryotischen Tandemkanälen die größte Ähnlichkeit aufweist. 


\subsubsection{Weiterführende Experimente}

Aus der anscheinenden Abhängigkeit der Virusreplikation von der KcvKanalaktivität ergeben sich Ansatzpunkte für weitere Studien. Vordringliche Aufgabe ist dabei die Lokalisation des Kcv-Proteins in infizierten Zellen bzw. im Viruscapsid.

Physiologisch ist auch interessant, daß das Genom von PBCV-1 zwei funktionale Gene für Polyamin-Biosyntheseenzyme enthält (Tabelle 1, A270R \& A237L) und die Polyaminzusammensetzung virusinfizierter Zellen verändert ist (Kaiser et al. 1999). Polyamine kommen in millimolaren Konzentrationen im Kern von Eukaryoten vor und können DNA vor der Zersetzung durch freie Radikale schützen (Ha et al. 1998). Intrazelluläre Polyamine blockieren aber auch spannungsabhängig Kir-Kanäle (Lopatin et al. 1994, Karschin et al. 1997). Möglicherweise haben sie einen ähnlichen Effekt auf die Kcv-Kanalaktivität oder auf Kanäle der Wirtszelle, so daß die Polyamin-Biosynthese während der Infektion von PBCV-1 auch hinsichtlich der Funktion von Kcv bedeutsam sein könnte.

Die beobachtete leichte Spannungsempfindlicheit des Kanals könnte zur Aufklärung einfacher Sensor-Mechanismen beitragen, da ihre Ursache in der kurzen Proteinsequenz zu finden sein müßte. Zu diesem Zweck könnten beispielsweise Kcv-Mutanten eingesetzt werden, in denen die positiv geladenen Aminosäuren am N-Terminus gegen neutrale Aminosäuren ausgetauscht sind.

Auch wäre es interessant, Kcv auf einen möglichen pH-Regulationsmechanismus zu untersuchen, da beide Transmembranregionen und die Porenregion Histidinreste enthalten. Sollte eine pH-Sensitivität festgestellt werden, könnten auch hier Mutanten konstruiert werden, um die Beteiligung der Histidinreste H17 und H83 in den TMDomänen, sowie des H61 und ggf. des Aspartatrestes D68 in der Porenregion zu prüfen. 


\subsection{Zusammenfassung}

Kcv ist ein virales Protein von 94 Aminosäuren Länge, das die typischen Merkmale eines Kaliumkanals besitzt. Kcv induziert in Xenopus laevis Oocyten eine schwach spannungsabhängige, Kalium-selektive Leitfähigkeit, die durch $\mathrm{Ba}^{2+}$ und Amantadin, nicht aber durch $\mathrm{Cs}^{+}$hemmbar ist. Die Virusreplikation ist auf ebensolche Art hemmbar, was auf eine Rolle von Kcv im viralen Lebenszyklus hinweist. Damit ist erstmals ein Kaliumkanal beschrieben, der von einem Virus codiert wird. Proteine mit struktureller Analogie zu Kcv wurden in anderen Virusgenomen bisher nicht gefunden. Darüber hinaus ist das Protein der kürzeste bis dato beschriebene funktionale Kaliumkanal. Die strukturellen und elektrophysiologischen Besonderheiten von Kcv rechtfertigen eine Einordnung als eigenständiger Kaliumkanaltyp. 


\section{MATERIAL \& METHODEN}

\subsection{EDV}

Macintosh Performa 450

Software ABI PRISM ${ }^{\mathrm{TM}}$ Sequencing Analysis 3.0 (PE Applied Biosystems)

Software Canvas 3.0 (Deneba Systems)

Software EndNote 2.2 (Niles \& Associates Inc.)

Software MacVector und Assembly Lign (IBI)

Software Netscape Navigator 4.05 (Netscape Communications Corporation)

Software Nisus Writer 5.0 (Nisus)

Pentium 2, $200 \mathrm{MHz}, 32 \mathrm{MB}$ RAM

Software Clampfit (Axon Instruments)

Software Windows 95, Excel 4.0, Word 7.0, CorelDraw 8 (Microsoft)

\subsection{Chemikalien}

Chemikalien wurden über die Firmen Biomol (Ilvesheim), Bio-Rad (München), Gibco BRL (Eggenstein), DIFCO-Laboratories (Detroit, U.S.A.), Boehringer (Mannheim), Invitrogen (San Diego, U.S.A.), Merck (Darmstadt), Pharmacia (Freiburg), Qiagen (Hilden), Serva (Heidelberg) und Sigma-Aldrich GmbH (München) bezogen.

Die Radiochemikalien ( $\alpha^{32}$ P-Nucleotide) lieferte die Firma Hartmann Analytic (Braunschweig).

\section{$\underline{4.2 .1 \quad \text { Reaktionssysteme (Kits) }}$}

Wenn nicht anders angegeben, wurden bei der Verwendung von Reaktionssystemen stets die Angaben des Herstellers befolgt. 


\subsection{Organismen \& Plasmide}

\subsubsection{Escherichia coli (E. coli)}

Zur Vermehrung von Plasmiden und Bakteriophagen wurden E. coli K12 Derivate eingesetzt. Der Stamm DH5 $\alpha$ F' (Hanahan 1985) wurde bei der Transformation mit Plasmiden verwendet, der Stamm XL1-Blue MRA (Stratagene, USA) bei der Vermehrung von EMBL3-Phagen. Die Genotypen sind im folgenden aufgelistet.

DH5 $\alpha$ F':

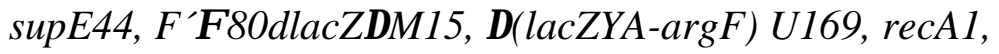
endAl, $h s d R 17\left(r_{K} \cdot m_{K+}\right)$

XL1-Blue MRA (P2): $\Delta(m c r A) 183, \Delta(m c r C B-h s d S M R-m r r) 173$, endA1, supE44, thi-1, gyrA96, relA1, lac

\subsubsection{Bakteriophagen}

Die DNA-Genbibliothek von Chlorellavirus Göttingen 1 (CVG-1) wurde in EMBL3 Bakteriophagen (Stratagene, USA) kloniert. Die Vermehrung erfolgte im E. coliStamm XL1-Blue MRA (P2-Lysogen).

\subsubsection{Plasmide}

\subsubsection{1 pBluescript $K S(+)$}

In dieser Arbeit erhaltene Restriktionsfragmente wurden in den Vektor pBluescript $\mathrm{KS}(+)$ (Stratagene, USA) kloniert, in dem vorher mit verschiedenen Restriktionsendonucleasen überhängende Enden erzeugt worden waren. Die durch Ligation erzeugten Konstrukte wurden in den E. coli-Stamm DH5 $\alpha \mathrm{F}^{\prime}$ transformiert.

pBluescript:

- $\beta$-Lactamase-Gen (Ampicillin-Resistenz)

- lacZ-Gen ( $\alpha$-Komplementation für Blau-Weiß-Selektion)

- Zugangsnummer GenBank X52327 


\subsubsection{2 pUC18}

Das hier verwendeten SureClone Ligation Kit enthält pUC18 DNA, die bereits mit der Restriktionsendonuclease Sma I linearisiert ist. Der lineare Vektor hat stumpfe Enden, die mit ungeschnittenen PCR-Fragmenten ligiert werden können. Die erzeugten Konstrukte wurden in den E. coli-Stamm DH5 $\alpha \mathrm{F}^{\prime}$ transformiert.

pUC18

- $\quad \beta$-Lactamase-Gen (Ampicillin-Resistenz)

- lacZ-Gen ( $\alpha$-Komplementation für Blau-Weiß-Selektion)

- Zugangsnummer GenBank L08752

\subsubsection{3 pSGEM}

Der Vektor ist ein Konstrukt von Michael Hollmann (MPI für experimentelle Medizin, Göttingen) und wurde von ihm freundlicherweise zur Verfügung gestellt. Für das Konstrukt wurde der Vektor pGEMHE (Liman et al. 1992) um die multiple Klonierungsstelle von pBluescript erweitert. Grundlage des Konstruktes pGEMHE ist der Vektor pGEM-3Z (Promega, Mannheim), in den die 5'- und 3'-untranslatierte Region des $\beta$-Globingens aus Xenopus laevis eingefügt wurden.

pGEM-3Z:

- $\beta$-Lactamase-Gen (Ampicillin-Resistenz)

- lacZ-Gen ( $\alpha$-Komplementation für Blau-Weiß-Selektion)

- T7 RNA-Polymerase-Promotor

- Zugangsnummer: Genbank X65304

\subsection{Oligonucleotide}

Die folgenden Oligonucleotide wurden als Primer für die PCR eingesetzt (Amplifikation von DNA-Fragmenten und Sequenzierungen). Spezielle Primer wurden von den Firmen NAPS (Göttingen) und Roth (Karlsruhe) synthetisiert.

Standardprimer für pUC18, pBluescript und pSGEM:

$\begin{array}{llllllll}\text { SK } & \text { TCT } & \text { AGA } & \text { ACT } & \text { AGT } & \text { GGA } & \text { TC } & \\ \text { KS } & \text { TCG } & \text { AGG } & \text { TCG } & \text { ACG } & \text { GTA } & \text { TC } & \\ \text { M13 } & \text { GTA } & \text { AAA } & \text { CGA } & \text { CGG } & \text { CCA } & \text { GT } & \text { (Primer A in 4.6.5) } \\ \text { M13 rev } & \text { AAC } & \text { AGC } & \text { TAT } & \text { GAC } & \text { CAT } & \text { G } & \text { (Primer D in 4.6.5) }\end{array}$


degenerierte Primer zur Isolation der Hüllproteingene von CVG-1 (Abbildung 18)

deg1 GTI GCI TAY GGI GCI CAR GAY GTI TA

deg2 AGR TAY TTI GTI GGR TGR TTR AAR

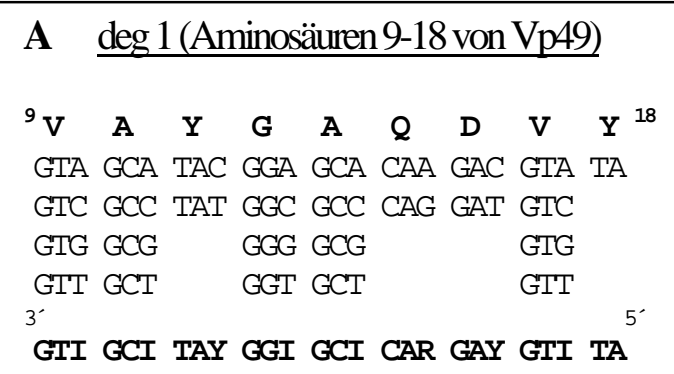

GII GCI TAY GGI GCI CAR GAY GTI TA

B deg 2(Aminosäuren 254-262 von Vp54)
$\begin{array}{lllllllll}{ }^{254} \mathbf{N} & \mathbf{F} & \mathbf{N} & \mathbf{H} & \mathbf{P} & \mathbf{T} & \mathbf{K} & \mathbf{Y} & \text { L }^{262}\end{array}$
C TTC AAC CAC CCA ACA AAA TAC CT
T TTT AAT CAT CCC ACC AAG TAT
CCG ACG
CCT ACT
5.

Y TTY AAY CAY CCI ACI AAR TAY CT

\section{Abbildung 18: Degenerierte PCR-Primer zur Isolation des Haupthüllprotein- Gens von CVG-1}

Die Aminosäuresequenzen (1. Zeile) wurden unter Berücksichtigung der Degeneration des genetischen Codes in Basentripletts übersetzt (Zeilen 2-4). Die KonsensusSequenz der Primer ist in der jeweils letzten Zeile angegeben. Auf der Grundlage dieser Konsensussequenzen wurde ein Gemisch von Primern mit den verschiedenen möglichen Codon-Kombinationen synthetisiert (für den Primer deg1 gibt es acht, für den Primer deg2 64 verschiedenen Kombinationen). Aminosäuren und Nucleotide wurden nach dem internationalen Einbuchstabencode abgekürzt (s. Anhang A).

Primer für die Amplifikation von ORF A250R aus genomischer DNA

pGEX 5' GTA TAG GAT CCG TAT GTT AGT GT

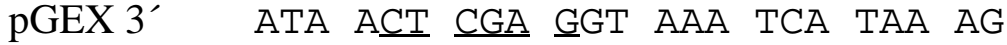

Unterstrichen sind die eingefügten Erkennungssequenzen für die Restriktionsendonucleasen Bam HI (pGEX 5') und Xho I (pGEX 3')

Primer für die in vitro Mutagenese von ORF A250R (Abbildung 19)

mtF66A CT GTC GGA GCC GGA GAT ATA CTG C (Primer C in 4.6.5)

mtF66Arev TAT CTC CGG CTC CGA CAG TAG AG (Primer B in 4.6.5) 


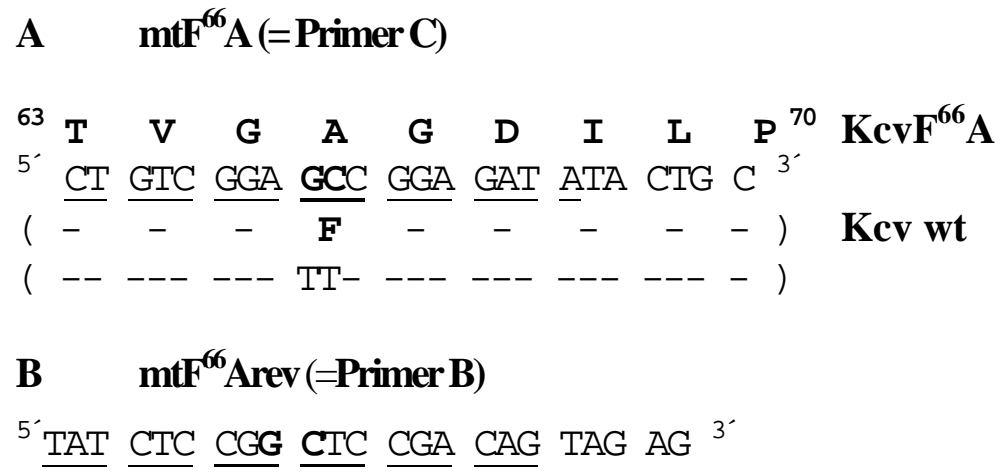

\section{Abbildung 19: Primer $B$ und $C$ für die in vitro-Mutagenese von A250R}

Die fett gedruckten Nucleotide markieren die eingefügten Mutationen. Die in Klammern gesetzten Buchstaben entsprechen der Wildtypsequenz (Kcv wt). Die überlappenden Basen der beiden Primer sind unterstrichen (15 nt).

\subsection{Kultivierung von $E$. coli}

Bakterienkulturen wurden in Vollmedium (NZY oder LB bzw. Variationen davon) angezogen wie unten angegeben. Die Zelldichte einer Kultur wurde photometrisch anhand der Absorption von Licht mit 600 nm Wellenlänge ermittelt (Schichtdicke $1 \mathrm{~cm})$. Eine optische Dichte $\left(\mathrm{OD}_{600}\right)$ von 1 entspricht einer Zahl von 8x $10^{8}$ Zellen pro ml (Sambrook et al. 1989).

\subsubsection{E. coli Stamm DH5 $\alpha \mathrm{F}^{\prime}$}

Bakterien-Stammkulturen wurden als Glycerinsuspensionen (40\%) über Jahre bei $-70{ }^{\circ} \mathrm{C}$ gelagert und bei Bedarf auf Agarplatten ausgestrichen (1,5\% Agar in NZYMedium, Sambrook et al. 1989). Übernachtkulturen von E. coli DH5 $\alpha \mathrm{F}^{\prime}$ wurden in autoklavierten Reagenzgläsern mit Aluminiumkappe gezogen. Dazu wurden in der Regel $2 \mathrm{ml} \mathrm{NZY-Medium,} \mathrm{bei} \mathrm{Bedarf} \mathrm{mit} \mathrm{Ampicillin}(75 \mu \mathrm{g} / \mathrm{ml})$ versetzt und mit einer einzelnen Bakterienkolonie beimpft. Die Kulturen wurden 12-16 h bei $37 \mathrm{C}$ und $250 \mathrm{Upm}$ in einem Schüttelinkubator herangezogen. 


\subsubsection{E. coli Stamm XL1-Blue MRA}

Stamm- und Übernachtkulturen von E. coli XL1-Blue MRA (Stratagene, USA) wurden angelegt wie oben beschrieben. Vor Infektion mit Bakteriophagen wurden die Zellen in $50 \mathrm{ml}$ LBM-Medium mit 0,2 \% Maltose angezogen. Nach Erreichen einer $\mathrm{OD}_{600}$ von 0,9-1 wurde die Kultur zentrifugiert und das Pellet in $10 \mathrm{mM} \mathrm{MgSO} 4$ resuspendiert. Die OD der Zellsuspension wurde auf 0,5 eingestellt $\left(4 \times 10^{8}\right.$ Zellen pro $\mathrm{ml})$.

LBM-Medium:

$$
\begin{aligned}
& 1 \% \text { (w/v) Bactotrypton } \\
& 1 \% \quad(\mathrm{w} / \mathrm{v}) \mathrm{NaCl} \\
& 0,5 \% \quad(\mathrm{w} / \mathrm{v}) \text { Hefeextrakt } \\
& 0,25 \% \quad(\mathrm{w} / \mathrm{v}) \mathrm{MgSO}_{4}
\end{aligned}
$$

\subsection{Polymerasekettenreaktion (PCR)}

Die PCR wurde u.a. zur Amplifikation genomischer Sequenzen, zur DNA-Sequenzierung und für die in vitro Mutagenese eingesetzt. Die Reaktionen wurden in 0,5 ml Reaktionsgefäßen durchgeführt.

\subsubsection{Amplifikation von Fragmenten aus genomischer DNA}

Die Ansätze enthielten $0,1 \mathrm{ng} / \mu \mathrm{l}$ genomischer DNA, je $1 \mu \mathrm{M}$ spezifische Primer (4.4), $200 \mu \mathrm{M}$ Desoxyribonucleotide (dNTP), 0,5 U/ $\mu 1$ taq-Polymerase und 1:10 verdünntes Pufferkonzentrat in einem Volumen von $100 \mu$ l. Reaktionsansätze wurden mit Mineralöl überschichtet. Die thermostabile Polymerase wurde erst nach anfänglicher Denaturierung $\left(5 \mathrm{~min}\right.$ bei $94^{\circ} \mathrm{C}$ ) durch die Ölschicht hindurch zum Reaktionsgemisch pipettiert.

PCR-Protokoll für die Amplifikation der Hüllprotein-Genfamilie:

$\begin{array}{lll}\text { Denaturierung: } & 2 \mathrm{~min} & 98{ }^{\circ} \mathrm{C} \\ \text { annealing: } & 1 \mathrm{~min} & 50{ }^{\circ} \mathrm{C} \\ \text { Polymerisation: } & 1 \mathrm{~min} & 72{ }^{\circ} \mathrm{C}\end{array}$

25 Zyklen 
PCR-Protokoll für die Amplifikation von ORF A250R:

$\begin{array}{lll}\text { Denaturierung: } & 2 \mathrm{~min} & 96{ }^{\circ} \mathrm{C} \\ \text { annealing: } & 1 \mathrm{~min} & 48{ }^{\circ} \mathrm{C} \\ \text { Polymerisation: } & 1 \mathrm{~min} & 72{ }^{\circ} \mathrm{C}\end{array}$

25 Zyklen

\subsubsection{Amplifikation von Plasmidinserts als Sondenmatritze}

Die Ansätze enthielten $1 \mathrm{ng} / \mu \mathrm{l}$ Plasmid-DNA und $1 \mu \mathrm{M}$ Standardprimer (4.4). Alle anderen Reagenzien wurden in Konzentrationen wie in 4.6.1 eingesetzt.

PCR-Protokoll:

Denaturierung: $\quad 2 \mathrm{~min} \quad 96{ }^{\circ} \mathrm{C}$

annealing: $\quad 1 \mathrm{~min} \quad 55^{\circ} \mathrm{C}$

Polymerisation: $\quad 3 \mathrm{~min} \quad 72{ }^{\circ} \mathrm{C}$

25 Zyklen

finale Polymerisation: $\quad 5 \mathrm{~min} \quad 72{ }^{\circ} \mathrm{C}$

\section{$\underline{\text { 4.6.3 Analyse von Plasmiden aus Bakterienkolonien }}$}

Nach der Transformation kann das klonierte Fragment in Ampicillin-resistenten Bakterienkolonien durch PCR nachgewiesen werden. Zellen aus Kolonien wurden in $50 \mu \mathrm{l}$ sterilem Wasser resuspendiert und $10 \mathrm{~min}$ bei $95{ }^{\circ} \mathrm{C}$ aufgekocht. $3 \mu \mathrm{l}$ dieser Suspension wurden mit $3 \mu$ l PCR-Mastermix versetzt ( $2 \mu \mathrm{M}$ Standardprimer (4.4), $400 \mu \mathrm{M}$ dNTP, 2x PCR-Puffer und 0,5 U/ $\mu$ l taq-Polymerase ) und mit Mineralöl überschichtet. Die Ansätze wurden in den heißen Thermocycler gestellt (simplified hot start).

PCR-Protokoll:

Denaturierung: $\quad 1 \mathrm{~min} \quad 96{ }^{\circ} \mathrm{C}$

annealing: $\quad 1 \mathrm{~min} \quad 50{ }^{\circ} \mathrm{C}$

Polymerisation: $\quad 1 \mathrm{~min} \quad 72{ }^{\circ} \mathrm{C}$

35 Zyklen

finale Polymerisation: $\quad 10 \mathrm{~min} \quad 72{ }^{\circ} \mathrm{C}$ 


\subsubsection{Sequenzierungsreaktionen}

Zur Sequenzierung von Phagen- und Plasmid-DNA wurde das ABI PRISM ${ }^{\mathrm{TM}}$ dRhodamine Terminator Cycle Sequencing Ready Reaction Kit (Perkin Elmer Applied Biosystems, Weiterstadt) eingesetzt. Die verwendeten Didesoxynucleotide sind mit fluoreszierenden dRhodamine-Farbstoffen gekoppelt. So konnten für die Sequenzierungsreaktionen unmarkierte Primer eingesetzt werden. Für die Reaktionen wurden 200 ng Plasmid- eingesetzt. Die Primer-Konzentrationen betrugen 160 nM. Das Reaktionsvolumen wurde auf die Hälfte, der Reaktionsmix auf ein Viertel des im Herstellerprotokoll angegebenen Volumens reduziert (10 $\mu$ l Gesamtvolumen, davon $2 \mu 1$ Reaktionsmix).

Standard-PCR-Protokoll:

$\begin{array}{lll}\text { Denaturierung: } & 1 \mathrm{~min} & 96{ }^{\circ} \mathrm{C} \\ \text { annealing: } & 30 \mathrm{~s} & 50{ }^{\circ} \mathrm{C} \\ \text { Polymerisation: } & 4 \mathrm{~min} & 60{ }^{\circ} \mathrm{C}\end{array}$

25 Zyklen

Aufreinigung und Präparation der DNA für die Elektrophorese (4.12) erfolgten wie im Herstellerprotokoll unter "Vereinfachte Ethanolfällung" angegeben. 


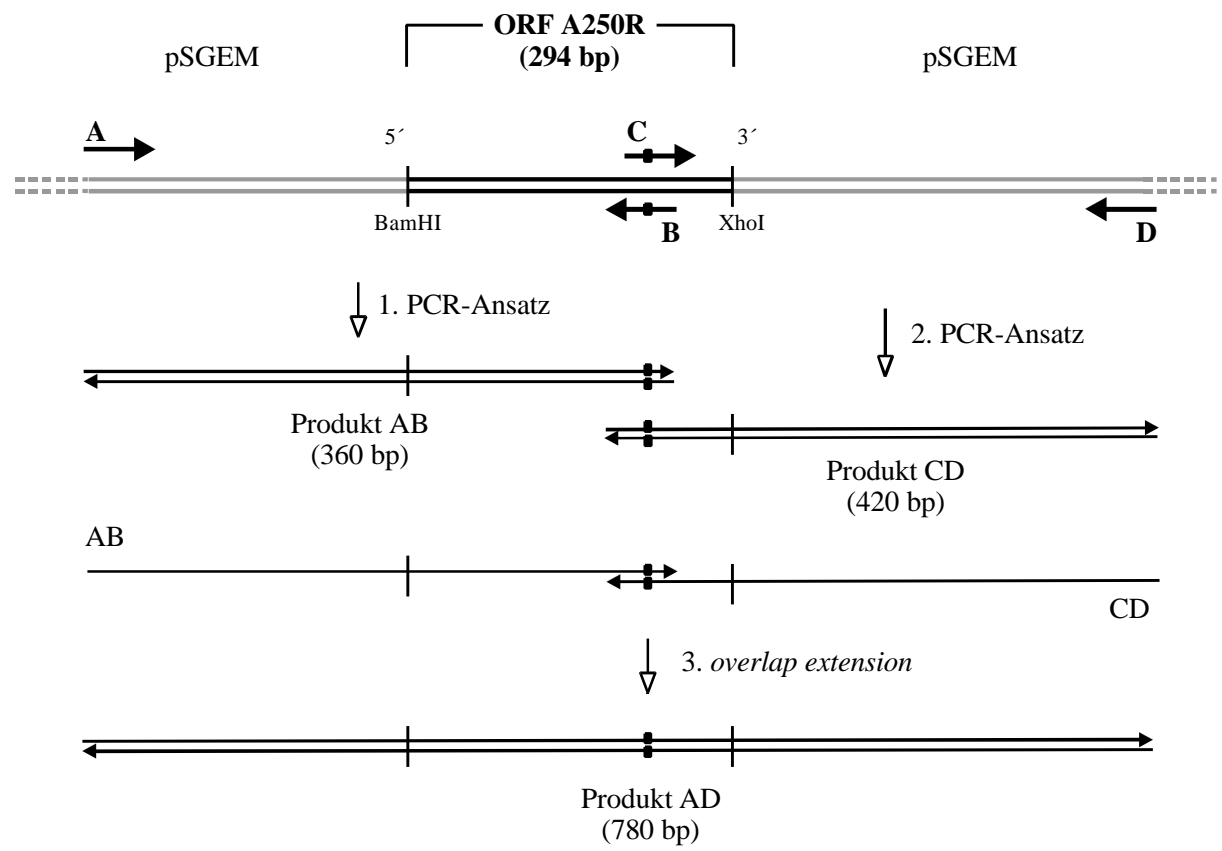

Abbildung 20: Mutagenese von ORF A250R durch overlap extension PCR

Die Mutation F66A (schwarzes Kästchen) wurde in die Sequenz der überlappenden Primer B und C eingefügt (Abbildung 19). Die Produkte der ersten Amplifikationsrunde, $\mathrm{AB}$ und $\mathrm{CD}$, bestehen aus Teilen von A250R und den angrenzenden Vektorsequenzen. In der zweiten Amplifikationsrunde lagern sich die überlappenden Enden der Zwischenprodukte $\mathrm{AB}$ und $\mathrm{CD}$ aneinander und fungieren als Primer. Beide Stränge werden von der Polymerase verlängert, so daß das Produkt AD entsteht. Die Balken am 5'- und 3'-Ende von ORF A250R markieren die Erkennungssequenzen zweier Restriktionsendonucleasen (Bam HI und Xhol), die zur gerichteten Klonierung des Gens eingefügt wurden. Abbildung modifiziert nach Horton (1997).

\subsubsection{In vitro Mutagenese von ORF A250R}

Die Methode des overlap extension (Ho et al. 1989) wurde nach einem Protokoll von (Horton 1997) durchgeführt. Alle Ansätze enthielten $1 \mu \mathrm{M}$ Primer und $200 \mu \mathrm{M}$ Desoxyribonucleotide $(\mathrm{dNTP})$ in einem Volumen von $100 \mu \mathrm{l}$. Als Matrize wurde pro Reaktion 0,5 $\mu \mathrm{g}$ Plasmid pSKcv eingesetzt (3.2.4). Zunächst wurden in zwei getrennten PCR-Reaktionen die überlappenden Fragmente AB und CD amplifiziert (Abbildung 20). Die Sequenz der Primer B und C enthält die einzuführende Mutation (Abbildung 19). Als Primer A und D wurden die Standardprimer m13 und m13 rev eingesetzt (4.4). Die amplifizierten Fragmente wurden durch Gelelektrophorese aufgetrennt, aus dem Gel eluiert (4.7.6) und für die dritte PCR-Reaktion, die eigentliche overlap-extension, eingesetzt (Abbildung 20). 
PCR-Protokoll für die Amplifikation von AB, CD, und AD:

$\begin{array}{lll}\text { Denaturierung: } & 2 \mathrm{~min} & 94{ }^{\circ} \mathrm{C} \\ \text { annealing: } & 1 \mathrm{~min} & 50{ }^{\circ} \mathrm{C} \\ \text { Polymerisation: } & 1 \mathrm{~min} & 72{ }^{\circ} \mathrm{C} \\ \text { 25 Zyklen } & & \\ \text { finale Polymerisation: } & 5 \mathrm{~min} & 72{ }^{\circ} \mathrm{C}\end{array}$

\subsection{Reinigung und Konzentrierung von Nucleinsäuren}

Folgende Methoden wurden bei der Isolation von Plasmid-, Phagen- und genomischer DNA, sowie zur Reinigung von PCR- oder Restriktionsfragmenten eingesetzt.

\subsubsection{Phenol-Chloroform-Extraktion}

Phenol-Chloroform-Extraktionen wurden bei allen DNA-Präparationen (außer der Plasmidisolation mit dem QIAfilter Plasmid Midi Kit) eingesetzt, um Proteine und andere organische Komponenten aus der Lösung zu entfernen.

Wassergesättigtes Phenol (P) wurde mit dem Antioxidationsmittel Hydroxychinolin versetzt und mit Tris-Base auf $\mathrm{pH}$ 8,0 eingestellt. Chloroform (C) wurde im Verhältnis 24:1 mit Isoamylalkohol (I) versetzt, um Schaumbildung bei der Phasentrennung zu vermeiden. Die Extraktion erfolgte entweder durch 1 Vol PCI-Gemisch (25:24:1 Volumenverhältnis) oder durch Zugabe von Phenol und Chloroform bzw. CI. Eine Durchmischung von organischer und wäßriger Phase wurde durch Schütteln erreicht, die Trennung durch kurze Zentrifugation beschleunigt. Nach der Extraktion wurden die Nucleinsäuren gefällt (4.7.4), um Reste organischer Lösungsmittel zu entfernen.

\subsubsection{Schleudersäulen-Chromatographie}

Alternativ zur Fällung wurden kleine Volumina von DNA-Suspensionen (50-100 $\mu 1)$ über Microspin Schleudersäulen (S-200, S-300, oder S-400, Pharmacia, Freiburg) gereinigt. Diese Methode wurde zum Pufferwechsel, zum Entfernen von Nucleotiden und Primern nach der PCR und als zusätzliche Reinigung nach der PhenolChloroform-Extraktion eingesetzt. 


\subsubsection{Ultrafiltration}

Durch Ultrafiltration wurden Salz und Saccharose aus den Fraktionen des Saccharosegradienten entfernt und DNA-Lösungen konzentriert.

Dazu wurden Microconcentrator-Röhrchen (Centricon-30, Amicon, Witten) verwendet. Das eingesetzte Volumen betrug $1 \mathrm{ml}$. Die Zentrifugation erfolgte in einem $34^{\circ}$ Festwinkelrotor 30 min bei 4300x g und RT (SS-34 Rotor, Sorvall RC-5B Kühlzentrifuge, DuPont, Bad Homburg). Anschließend wurde das Retentat durch zweiminütige Zentrifugation bei $2.500 \mathrm{Upm}$ aufgefangen.

\subsubsection{Fällung}

Die Fällung dient der Abscheidung von Proteinen und niedermolekularen Substanzen aus wäßrigen Lösungen von DNA. Sie ermöglicht außerdem die Aufnahme der gefällten Nucleinsäuren in definierten Volumina Puffer oder Wasser.

Standardprozedur war die Fällung mit 0,1 Vol 3 M Natriumacetat $(\mathrm{pH} 5,3)$ und 3 Vol Ethanol p.a.. Die Dauer betrug zwischen 30 min und 3 h, die Temperatur war entweder RT (Fällung genomischer Phagen-DNA) oder $-20^{\circ} \mathrm{C}$ (Fällung von Plasmiden). Alternativ wurde DNA bei RT mit 0,7 Vol Isopropanol präzipitiert, wenn das Gesamtvolumen gering gehalten werden mußte. Die gefällte DNA wurde durch Zentrifugation (Eppendorf-Zentrifuge 5402 oder 5415C, Eppendorf, Hamburg) am Boden des Reaktionsgefäßes gesammelt, der Überstand dann verworfen. Das Pellet wurde anschließend mit 70 \%igem Ethanol gewaschen und 5-10 min bei gleicher Umdrehungszahl zentrifugiert.

DNA aus kleinen Volumina wurde in 1,5 ml Reaktionsgefäßen gefällt (Zentrifugation $30 \mathrm{~min}$ bei $14.000 \mathrm{Upm}$ und $4{ }^{\circ} \mathrm{C}$, Eppendorf-Zentrifuge 5402). Größere Volumina wurden in $15 \mathrm{ml}$ Corex-Zentrifugenröhrchen gefällt (Zentrifugation $30 \mathrm{~min}$ bei 10.000 Upm, HB4-Rotor, Sorvall RC-5B). 


\subsubsection{Konzentrationsbestimmung}

Die Konzentrationen wäßriger DNA-Lösungen wurden photometrisch anhand der Absorption von Licht mit 260 nm Wellenlänge ermittelt (Gene Quant II Photometer, Pharmacia, Freiburg). Dabei wurde eine optische Dichte $\left(\mathrm{OD}_{260}\right)$ von 1 einer Konzentration von $50 \mu \mathrm{g}$ doppelsträngiger DNA gleichgesetzt (Schichtdicke $1 \mathrm{~cm}$ ).

Die Reinheit der Lösungen wurde durch das Verhältnis der Absorption bei $260 \mathrm{~nm}$ und $280 \mathrm{~nm}$ abgeschätzt (Warburg \& Christian 1942). Ein Verhältnis von >1,8 gilt als geringes Maß an Verunreinigung durch Proteine (Sambrook et al. 1989).

\subsubsection{Isolation von DNA-Fragmenten aus Agarose-Gelen}

Nach dem Auftrennen der Fragmente in 2,5\% Agarosegelen (4.12) wurden die gwünschten DNA-Banden unter UV-Licht ausgeschnitten und mit dem DNA Extraction Kit (MBI Fermentas, St. Leon-Rot) eluiert.

\subsection{Erstellen einer Genbibliothek von Chlorellavirus CVG-1}

Die verwendete genomische DNA aus CVG-1 wurde freundlicherweise von Dr. A. Wolf (Albrecht-von Haller-Institut, Abteilung Biophysik) zur Verfügung gestellt. Durch partielle Spaltung mit der Restriktionsendonuclease Sau 3AI und Größenselektion wurde eine Sammlung von ca. $20 \mathrm{~kb}$ großen Genomfragmenten erhalten. Nach Ligation dieser Fragmente mit Phagen-Vektoren wurde eine Population von rekombinanten Bakteriophagen erhalten, die das gesamte CVG-1-Genom beinhaltet.

\subsubsection{Partielle Restriktion mit Sau 3AI}

Die optimale Reaktionszeit wurde in Vorversuche bestimmt. $50 \mu \mathrm{g}$ genomische DNA wurden in einem Volumen von $600 \mu 1$ mit 30 Units Sau 3AI geschnitten. Nach 5 min wurden $300 \mu \mathrm{l}$ abgenommen und die Reaktion durch 15 min Inkubation bei $65^{\circ} \mathrm{C}$ und Zugaben von $12 \mu 1$ 0,5 M EDTA-Lösung beendet. Die restliche Reaktion wurde nach insgesamt 10 min auf die gleiche Weise beendet. Anschließend wurde zweimal mit PCI extrahiert (4.7.1), die Überstände vereinigt und die Nucleinsäuren gefällt (4.7.4). Zur Trennung der Fragmente nach Größe wurde das gelöste Pellet in einem Saccharosegradienten fraktioniert. 


\subsubsection{Fraktionierung im Saccharosegradienten}

Die Gradienten wurden nach einem Protokoll von Sambrook et al. 1989 (Reinigung von Bakteriophage $\lambda$-Vektorarmen) in Zentrifugengefäßen aus Polyallomer (34 ml Vol, Beckmann, München) gemischt. Die verwendeten Lösungen (10\% und $40 \%$ (w/v) Saccharose) und die Ultrazentrifugengefäße wurden auf Eis gekühlt. Die Durchflußrate des Gradientenmischers betrug bei 10\%iger Saccharoselösung ca. $1,7 \mathrm{ml} / \mathrm{min}$. Nach Auftragen der Restriktionsansätze wurden die Gradienten $20 \mathrm{~h}$ bei 24.000 Upm und $4{ }^{\circ} \mathrm{C}$ zentrifugiert (TST 28.38-Rotor, Centrikon T-1065 Ultrazentrifuge, Kontron, Eching).

Mit einer Glaskapillare, die an die Peristaltikpumpe P-1 (Pharmacia, Freiburg) angeschlossen war, wurden die Gradienten in 0,5 ml Fraktionen aufgeteilt und in 1,5 mlReaktionsgefäße überführt.

\subsubsection{Größenselektion}

Stichproben der aus dem Saccharosegradienten erhaltenen Fraktionen wurden in einem 0,5 \%igen Agarosegel aufgetrennt, um zu ermitteln, welche Fraktionen DNAFragmente der gewünschten Größe enthalten. Die betreffenden Fraktionen wurden vereinigt und durch Ultrafiltration (4.7.3) gereinigt.

\subsubsection{Ligation in EMBL3}

Zur Ligation in den Klonierungsvektor EMBL3 wurden $1 \mu \mathrm{g}$ Vektorarme und $300 \mathrm{ng}$ der gereinigten DNA-Fragmente eingesetzt. Das Volumen des Ansatzes betrug 5,5 $\mu$ l. Für die Ligation der Vektorarme mit den DNA-Fragmenten aus dem Genom von Chlorellavirus CVG-1 wurde das Lambda EMBL3/BamH I Vector Kit (Stratagene, USA) eingesetzt.

\subsubsection{In vitro Verpackung}

Die rekombinanten Vektoren aus 4.8.4 wurden in vitro in Phagenpartikel verpackt (Gigapack ${ }^{\circledR}$ II Gold, Stratagene, USA) und bei $4{ }^{\circ} \mathrm{C}$ gelagert. 


\section{$\underline{4.8 .6}$ Titerbestimmung}

$200 \mu \mathrm{l}$ E. coli Zellen (4.5) wurden a) mit $1 \mu \mathrm{l}$ unverdünnter und b) mit $1 \mu 1$ 1:10 verdünnter Verpackungsreaktion vermischt und $15 \min$ bei $37^{\circ} \mathrm{C}$ inkubiert.

Nach Ablauf der Inkubationszeit wurde der Ansatz mit $3 \mathrm{ml}$ flüssigem Agar (0,75\% in NZYM, auf $45^{\circ} \mathrm{C}$ abgekühlt) versetzt und sofort auf vorgewärmten Agarplatten $\left(1,5 \%\right.$ in NZYM, $\left.37^{\circ} \mathrm{C}\right)$ verteilt. Nach Erstarren des Oberflächenagars wurden die Platten umgedreht und über Nacht bei $37^{\circ} \mathrm{C}$ inkubiert.

Der Phagentiter ließ sich anschließend aus der Anzahl der hellen Höfe im Bakterienrasen (Plaques) unter Berücksichtigung der Verdünnungsstufe in plaque-forming units (pfu) pro ml bestimmen. Bei späteren Titerbestimmungen wurden größtenteils mehrere Verdünnungsstufen hergestellt, um eine zählbare Anzahl von Plaques zu erhalten. Die Verdünnungen erfolgten jeweils in Schritten von $10^{-2}(10 \mu$ l Phagensuspension, $990 \mu$ l SM-Puffer).

NZYM-Medium:

$$
\begin{array}{lll} 
& \text { NZY-Medium } \\
0,2 \% & (\mathrm{w} / \mathrm{v}) \mathrm{MgSO}_{4}
\end{array}
$$

SM-Puffer:

$1 \mathrm{M} \quad \mathrm{NaCl}$

$50 \mathrm{mM}$ Tris/ $\mathrm{HCl}(\mathrm{pH} 7,5)$

$0,2 \% \quad(\mathrm{w} / \mathrm{v}) \mathrm{MgSO}_{4}$

$0,01 \% \quad(\mathrm{w} / \mathrm{v})$ Gelatine 


\subsection{Durchmustern der Genbibliothek}

Für Nucleinsäure-Hybridisierungen von immobilisierter Phagen-DNA wurden DNASonden synthetisiert (4.9.1) und zur späteren Detektion mit $\alpha^{32} \mathrm{P}$ - oder Biotingekoppelten Nucleotiden markiert.

Die Anzahl unabhängiger Klone N, die durchmustert werden müssen, um das gesuchte Gen mit 99,9\%iger Wahrscheinlichkeit $\mathrm{zu}$ finden, wurde nach folgender Formel berechnet (Sambrook et al. 1989):

$$
\mathrm{N}=\quad \frac{\ln (1-\mathrm{P})}{\ln (1-(\mathrm{F} / \mathrm{G}))}
$$

$\mathrm{P}=0,999$ (Wahrscheinlichkeit)

$\mathrm{F}=20.000$ (maximale Länge eines klonierten Fragmentes in bp)

$\mathrm{G}=330.000$ (Genomgröße von CVG-1 in bp)

Die Zahl N der zu plattierenden Klone beträgt demnach mindestens 110. Für das Durchmustern der CVG-1 Genbibliothek wurden nach Standardprotokoll 8000 Phagen plattiert.

\subsubsection{Radioaktiv markierte Sonden}

Für die radioaktive Markierung von DNA-Fragmenten wurde radioaktives $\alpha^{32} \mathrm{P}$ dCTP (3000 Ci/mmol) benutzt. Die doppelsträngige Matritze wurde durch 10 minütiges Aufkochen und anschließendes Abkühlen auf Eis in Einzelstränge aufgetrennt.

Die verwendeten fertigen Reaktionsansätze für die Markierung (Ready-to-go DNA Labelling Beads, Pharmacia, Freiburg) enthielten das Klenow-Fragment der E. coli DNA-Polymerase I und als Primer Gemische von Nonadesoxyribonucleotiden mit permutierter Basenabfolge (random priming). Nach Zugabe der denaturierten Matritze (50-100 ng) und des radioaktiven Nucleotids (2 MBq $\left.\alpha^{32} \mathrm{P}-\mathrm{dCTP}\right)$ wurde die Markierungsreaktion bei $37^{\circ} \mathrm{C} 15$ min inkubiert.

Die Ansätze wurden nach Ablauf der Inkubation denaturiert (10 min bei $100{ }^{\circ} \mathrm{C}$ ), auf Eis abgekühlt und ohne weitere Aufreinigung zur Hybridisierung verwendet. 


\subsubsection{Plattieren}

Für das Durchmustern der Genbibliothek wurden die Phagen aus der Verpackungsreaktion (4.8.5) mit einer Dichte von 8000 Phagen pro Platte auf $150 \mathrm{~mm}$ Agarplatten plattiert. Dazu wurden $400 \mu 1$ Bakteriensupension (4.5.2) mit $50 \mu 1$ des Reaktionsansatzes aus 4.8.5 vermischt und 15 min bei $37^{\circ} \mathrm{C}$ inkubiert. Nach Ablauf der Inkubationszeit wurde der Ansatz mit $12 \mathrm{ml}$ flüssiger Agarose (0,75\% in NZYM, auf $45^{\circ} \mathrm{C}$ abgekühlt) versetzt und sofort auf vorgewärmten Agarplatten (1,5\% in NZYM) verteilt. Nach Erstarren der Oberfläche wurden die Platten umgedreht und über Nacht bei $37^{\circ} \mathrm{C}$ inkubiert.

\subsection{3 Übertragen der Phagen-DNA auf Nylonmembranen}

Nach der Inkubation wurden die Platten auf Plaquebildung überprüft und anschließend $2 \mathrm{~h}$ bei $4{ }^{\circ} \mathrm{C}$ gekühlt. Die Phagen-DNA wurde auf Qiabrane Rundfilter (132 mm Durchmesser, Diagen Düsseldorf) übertragen, und ihre Lage markiert (plaquelift). Um nach der Hybridisierung falsch positive Signale ausschließen zu können, wurden jeweils zwei plaquelifts angefertigt. Die Dauer der ersten Übertragung war $5 \mathrm{~min}$, die der zweiten $10 \mathrm{~min}$. Die Membranen wurden nach der Übertragung jeweils 5 min mit Denaturierungs- und Neutralisierungslösung behandelt. Nach Äquilibrierung mit 2x SSC und Lufttrocknen wurde die DNA durch Bestrahlung mit UV-Licht (1 min) und Erhitzen auf $80{ }^{\circ} \mathrm{C}(90 \mathrm{~min})$ fixiert.

$\begin{array}{lrll}\text { Denaturierungslösung: } & 1,5 & \mathrm{M} & \mathrm{NaCl} \\ & 0,5 & \mathrm{M} & \mathrm{NaOH} \\ & & & \\ \text { Neutralisierungslösung: } & 0,5 & \mathrm{M} & \mathrm{Tris} / \mathrm{HCl}(\mathrm{pH} 8,0) \\ & 1,5 & \mathrm{M} & \mathrm{NaCl} \\ & & & \\ \text { 20x SSC: } & 3 & \mathrm{M} & \mathrm{NaCl} \\ & 0,3 & \mathrm{M} & \mathrm{NaCitrat}\end{array}$




\subsubsection{Hybridisierung mit $\alpha^{32} \mathrm{P}$-markierten Sonden}

Die Membranen wurden nach Äquilibrierung in 1x TBS (20 mM TrisBase, pH 7,5; $500 \mathrm{mM} \mathrm{NaCl}) 1 \mathrm{~h}$ bei $37{ }^{\circ} \mathrm{C}$ mit Proteinase K $(75 \mu \mathrm{g} / \mathrm{ml})$ behandelt. Nach kurzem Waschen in TBS folgte eine zweistündige Prähybridisierung bei $65^{\circ} \mathrm{C}$ in $30 \mathrm{ml}$ vorgewärmtem Phosphatpuffer (Church \& Gilbert 1984). Die Sonde (4.9.1) wurde dem Ansatz denaturiert zugegeben. Die Inkubation erfolgte über Nacht bei $65^{\circ} \mathrm{C}$.

Um nicht oder unspezifisch gebundene DNA zu entfernen, wurden die Membranen in je 2x 15 min in Salzlösungen mit steigender Stringenz (d.h. abnehmender Salzkonzentration) bei RT gewaschen: 6x SSC, 2x SSC, 0,2x SSC. Der letzte Waschschritt war 10 min mit $0,1 \times \operatorname{SSC}+0,1 \% \operatorname{SDS}\left(65^{\circ} \mathrm{C}\right)$.

Nach Lufttrocknen wurden die Membranen blasenfrei eingeschweißt und $48 \mathrm{~h}$ bei $-70{ }^{\circ} \mathrm{C}$ in einer Kassette mit Signalverstärker (Intensifying Screen von DuPont Cronex) einem Röntgenfilm exponiert (KODAK X-OMAT AR Filme, Sigma-Aldrich GmbH, München).

\subsubsection{Isolation positiver Plaques}

Nach Entwicklung des Röntgenfilmes wurden die erhaltenen Signale auf die Originalplatten übertragen und die positiven Plaques identifiziert. Sie wurden ausgestochen und mit $200 \mu 1$ SM-Puffer und einem Tropfen Chloroform überschichtet. Für ein sekundäres Durchmustern wurden die erhaltenen Phagenisolate in SM-Puffer verdünnt und mit geringer Plaquedichte erneut plattiert. Von diesen Platten wurden plaquelifts angefertigt und wie in 4.9.4 mit der Sonde hybridisiert. Von den identifizierten positiven Plaques wurden dann 1-3 deutlich separiert liegende Plaques ohne Kontamination durch andere Phagenklone ausgestochen und mit $200 \mu 1$ SM-Puffer und einem Tropfen Chloroform überschichtet. Die Aufbewahrung dieser „PhagenStammsuspensionen“ erfolgte bei $4-8{ }^{\circ} \mathrm{C}$.

\subsubsection{Amplifikation positiver Phagenklone}

Zur Titerbestimmung wurde eine Verdünnungsreihe der Phagen-Stammsuspensionen angesetzt ( 1 bis $10^{-3}$ ), auf $90 \mathrm{~mm}$-Platten plattiert und $16 \mathrm{~h}$ inkubiert. Bei hoher Plaquedichte (Konfluenz), wurden die Platten direkt zur Amplifikation verwendet 
und mit 3-5 ml SM-Puffer überschichtet. Es folgte eine mehrstündige Inkubation auf einem Schüttler bei RT und schwacher Rotation, nach deren Ablauf der Puffer mit den darin gelösten Phagen abgesaugt und die Platten mit 1-2 ml SM-Puffer nachgespült wurden. Zellreste wurden durch Zugabe von 4 Tropfen Chloroform und anschließende Zentrifugation sedimentiert ( $5 \mathrm{~min}$ bei $4^{\circ} \mathrm{C}, 6.000 \mathrm{Upm}$, SS-34-Rotor, Sorvall RC-5B). Die so erhaltenen hochkonzentrierten Phagensuspensionen (high titer stocks) wurden bei $4-8^{\circ} \mathrm{C}$ in $15 \mathrm{ml}$ Polypropylen-Röhrchen (Falcon, Becton Dickinson, Heidelberg) aufbewahrt.

\subsection{DNA-Extraktion aus Phagen}

Zur genauen Bestimmung des Phagentiters wurden Doppelansätze mit Verdünnungen von $10^{-4}$ bis $10^{-12}$ plattiert (4.8.6). Phagen und Wirtsbakterien sollten im Verhältnis 1:200 eingesetzt werden (multiplicity of infection m.o.i. $=0,005$ ), um die vollständige Lyse zu erreichen (Sambrook et al. 1982). Durch zusätzliche Ansätze mit zehnfach erhöhter oder erniedrigter m.o.i. wurde das tatsächlich zur vollständigen Lyse nötigen Phagen-Bakterienverhältnis ermittelt.

\section{$\underline{4.10 .1 \text { Infektion der Wirtsbakterien }}$}

Aliquots mit $5 \times 10^{9}-10^{10}$ Wirtszellen in $10 \mathrm{mM} \mathrm{MgSO}_{4}$ (4.5.2) wurden kurz zentrifugiert und in $3 \mathrm{ml}$ SM-Puffer resuspendiert. Nach Zugabe der Phagen wurde der Ansatz $15 \mathrm{~min}$ bei $37^{\circ} \mathrm{C}$ im Schüttler vorinkubiert und dann in $500 \mathrm{ml}$ NZYMMedium überführt. Die anschließende Inkubationszeit betrug $11-14 \mathrm{~h}$ bei $37^{\circ} \mathrm{C}$ und 200 Upm.

\subsubsection{Isolation der Phagenpartikel}

Bis zur Polyethylenglykolfällung folgte das Isolationsprotokoll dem von Sambrook et al. 1982. Die Phagensuspension wurde zusätzlich mit $10 \mathrm{mM} \mathrm{MgCl}{ }_{2}$ versetzt. Das Polyethylenglykol (PEG 6.000) wurde bei RT zugegeben und auf dem Magnetrührer gelöst. Die Inkubation erfolgte $3 \mathrm{~h}$ bei $4{ }^{\circ} \mathrm{C}$.

Präzipitierte Phagen wurden durch Zentrifugation pelletiert (15 min bei $10.000 \mathrm{Upm}$ und $4{ }^{\circ} \mathrm{C}$, GSA-Rotor, Sorvall RC-5B) und anschließend in $10 \mathrm{ml}$ SM-Puffer gelöst. PEG und Zellreste wurden durch Extraktion mit 1 Vol Chloroform und Zentrifugati- 
on entfernt (15 min bei 10.000 Upm, SS-34-Rotor, Sorvall RC-5B). Die obere Phase (ca. $10 \mathrm{ml}$ ) wurde zur weiteren Aufreinigung im Glyceringradienten abgenommen.

Durch Unterschichtung von $1 \mathrm{ml} 5$ \%iger Glycerinlösung mit $1 \mathrm{ml} 40$ \%iger Glycerinlösung wurde in dünnwandigen Polyallomerröhrchen ein Zwei-Stufen-Gradient hergestellt (Prozentangaben v/v). Die Lösungen waren vorgekühlt und wurden auf Eis gehalten, um Diffusion zu verlangsamen.

Nach Überschichtung mit je $2 \mathrm{ml}$ Phagensuspension wurde $1 \mathrm{~h}$ bei $43.000 \mathrm{Upm}$ und $4{ }^{\circ} \mathrm{C}$ zentrifugiert (TST 60.4-Rotor, Centrikon T-1065). Der Überstand wurde bis zur Phasengrenze abpipettiert, der Rest ausgegossen. Das Phagenpellet erschien milchigbläulich.

\section{$\underline{4.10 .3 \text { DNA-Extraktion }}$}

Nach Resuspension in SM-Puffer wurde die DNA durch Proteinase-K-Behandlung freigesetzt und durch Phenol-Chloroform-Extraktion gereinigt (4.7.1).

Bei Zugabe von Natriumacetat und Ethanol fiel die DNA als fädige, weiße Substanz aus und konnte mit Hilfe eines kleinen gläsernen Hakens aufgewickelt werden. Nach Waschen mit $70 \%$ Ethanol wurde sie in $\mathrm{H}_{2} \mathrm{O}$ gelöst. Die restliche DNA im Fällungsansatz wurde durch Zentrifugation pelletiert und in $\mathrm{H}_{2} \mathrm{O}$ aufgenommen. Die Konzentration der DNA-Suspensionen wurden photometrisch bestimmt (4.7.5).

\subsection{Restriktionsanalysen}

Für die Restriktionsanalysen wurden Restriktionsendonucleasen und Puffer verschiedener Hersteller einzeln und in Kombination eingesetzt.

\section{$\underline{4.11 .1 \text { Plasmid DNA }}$}

0,5 $\mu \mathrm{g}$ DNA wurden mit $5 \mathrm{U}$ Enzym in einem Volumen von $20 \mu \mathrm{l}$ für $1 \mathrm{~h}$ bei $37^{\circ} \mathrm{C}$ inkubiert. Wenn nötig, wurden die Enzyme durch 10 min Inkubation bei $70{ }^{\circ} \mathrm{C}$ inaktiviert. $10 \mu \mathrm{l}$ Aliquots der Ansätze wurden zur analytischen Gelelektrophorese (4.12) eingesetzt. 


\subsubsection{Phagen-DNA}

Für die Restriktion der Phagen-DNA wurden ausschließlich Enzyme verwendet, die nicht in den Vektorarmen schneiden. Die Ansätze enthielten jeweils $10 \mu \mathrm{g}$ DNA, sowie 30-40 U Enzym. Die Inkubationszeiten betrugen 6-12 h.

Die Reaktionen wurden durch mindestens 10minütiges Erhitzen auf $70{ }^{\circ} \mathrm{C}$ beendet. Durch die Hitzebehandlung werden gleichzeitig die Vektorarme voneinander gelöst und die hochmolekularen DNA-Fragmente während der präparativen Gelelektrophorese (4.12) besser aufgetrennt. (Bei der Verpackung der Phagengenome in die Capside entstehen kohäsive Enden. Isoliert man die lineare DNA aus dem Capsid, können sich diese Enden verbinden, so daß entweder ringförmige Strukturen oder TandemAnordnungen entstehen).

\subsection{Gelelektrophorese}

Analytische Gelelektrophoresen von Aliquots der Versuchsansätze wurden routinemäßig zur Erfolgskontrolle eingesetzt. Präparative Gelelektrophoresen wurden für Southern Blot-Analysen (4.13) und zur Isolation bestimmter DNA-Fragmente (4.7.6) durchgeführt. Vor dem Auftragen wurden die Proben mit Probenpuffer versetzt (180 mM Tris Base, 180 mM Borsäure, 5 mM EDTA, $40 \%$ (w/v) Saccharose, 0,25\% (w/v) Bromphenolblau, 0,25\% (w/v) Xylencyanol FF).

Für die Gele wurde die entsprechende Menge Agarose mit TBE-Puffer (90 mM Tris Base, $90 \mathrm{mM}$ Borsäure, 2,5 mM EDTA) aufgekocht und auf ca. $40{ }^{\circ} \mathrm{C}$ abgekühlt. 1-2 \%ige Gele wurden in Plexiglaskammern (K. Unger, Pflanzenphysiologie) gegossen. Die elektrophoretische Trennung der DNA-Fragmente erfolgte 1-2 $\mathrm{h}$ bei Feldstärken von $5 \mathrm{~V} / \mathrm{cm}$ (Elektrophoresekammer Eigenbau, K. Unger, Albrecht-vonHaller-Institut). Zur Auftrennung größerer Fragmente aus Restriktionsanalysen von Phagen-DNA wurden 0,8 \%ige Gele verwendet. Die Elektrophorese lief dann über Nacht bei Feldstärken von 1-2 V/cm (Elektrophoresekammer Modell Horizon ${ }^{\mathrm{TM}}$ $11 \cdot 14$ oder 20·25, Gibco BRL, Eggenstein). 
Zur Bestimmung der Fragmentgrößen wurden DNA-Längenstandards aufgetragen. Neben kommerziell erhältlichen DNA-Längenstandards wurden selbsterstellte Plasmid-Standards von Dr. A. Wolf und Dr. M. Giersberg zur Verfügung gestellt (Längen in $b p)$ :

A-Standard: $\quad 6.991,5.086,3.992,2.999,2.357,1.652,1.389,1.077,516$

BaP-Standard: $32.710,10.630,4.000$

M-Standard: $\quad 710,498,404,367,242,190,147,118,110,67,57$

Nach dem Gellauf wurde die DNA mit Ethidiumbromid gefärbt, unter UV-Licht kontrolliert (UV-Leuchttisch LKB 2011 MACP Transillumin, Pharmacia, Freiburg) und fotografisch dokumentiert (Polaroid DS-34 Direct Screen Instant Camera).

\subsection{Southern Blot}

Hybridisierungsanalysen nach Southern (1975) wurden durchgeführt, um Restriktionsfragmente mit speziellen Gensequenzen zu identifizieren. Dazu wurde genomische Phagen-DNA mit Restriktionsendonucleasen fragmentiert (4.11.2) und in 0,8\% Agarosegelen elektrophoretisch aufgetrennt (4.12).

\subsubsection{Gelvorbehandlung}

Vor der Übertragung wurde die DNA im Gel fragmentiert und denaturiert. Dazu wurde das Gel erst 20 min unter leichtem Schwenken mit 0,25 N HCl behandelt, danach kurz mit $\mathrm{H}_{2} \mathrm{O}$ gespült und in Denaturierungslösung überführt. Nach Erneuern der Denaturierungslösung und insgesamt 50 min Inkubation wurde das Gel nach erneutem Waschen 30 min in Neutralisierungslösung inkubiert.

\subsection{2 Übertragung der DNA}

Die Phagen-DNA-Fragmente wurden über Nacht durch Kapillarkräfte auf Nytranmembranen (Nytran 12 N Membranen, Schleicher \& Schüll, Göttingen) übertragen (Sambrook et al. 1989). Als Träger diente 20x SSC, das über eine Brücke aus Fließpapier (Fließpapier 003 oder 004, Schleicher \& Schüll, Göttingen) durch das Gel zur Membran gelangte. Die Membran wurde durch Erhitzen bei $80^{\circ} \mathrm{C}$ für 90 min fixiert. Die Vollständigkeit der Übertragung wurde durch UV-Licht überprüft. 


\section{$\underline{\text { 4.13.3 Biotin-markierte Sonden }}$}

Die Markierung mit Biotin-gekoppelten Nucleotiden erfolgte analog zur radioaktiven Markierung (4.9.1) mit random priming durch Oligonucleotide. Dazu wurden Readyto-go DNA Labelling Beads (Pharmacia, Freiburg) mit Biotin-14-dCTP (Gibco BRL, Eggenstein) eingesetzt.

\subsubsection{Hybridisierung mit Biotin-markierten Sonden}

Die Membran wurde in 6x SSC angefeuchtet und in 100 ml Prähybridisierungslösung $1 \mathrm{~h}$ bei $65^{\circ} \mathrm{C}$ inkubiert. Nach Überführung in $75 \mathrm{ml}$ Hybridisierungslösung wurde erneut $1 \mathrm{~h}$ bei $65^{\circ} \mathrm{C}$ inkubiert. Auf die Zugabe der denaturierten Sonde folgte Inkubation über Nacht bei $50{ }^{\circ} \mathrm{C}$.

Wurde die Hybridisierung mit gleichen Sonden wiederholt, erfolgte nach der Vorinkubation in Hybridisierungslösung alternativ ein weiterer Lösungswechsel: Eingefrorene Hybridisierungslösung mit Sonde wurde denaturiert und erneut zur Hybridisierung eingesetzt. Die Nachbehandlung der Membran wurde nach Anleitung des Biotin-Blot Clone Detection Manuals (Bio-Rad, München) durchgeführt. Die Farbreaktion erfolgte mit Reagenzien von Sigma nach Angaben des Herstellers. Hybridisierungen mit radioaktiv markierten Sonden wurden durchgeführt wie unter 4.9.4 für Plaquelifts beschrieben.

$\begin{array}{lrll}\text { Prähybridisierungslösung: } & 4 \mathrm{x} & \begin{array}{l}\text { SSC } \\ (\mathrm{v} / \mathrm{v}) \text { SDS-Stammlösung (10\%) }\end{array} \\ 1 & & & \\ \text { Hybridisierungslösung: } & 4 \mathrm{x} & \text { SSC } \\ & 5 \mathrm{x} & \begin{array}{l}\text { Denhardts Reagenz } \\ (\mathrm{v} / \mathrm{v}) \text { SDS-Stammlösung }(10 \%)\end{array} \\ & 0,1 \% & \\ & 2 \% & (\mathrm{w} / \mathrm{v}) \text { Ficoll } 400 \\ \text { Denhardts Reagenz: } & 2 \% & (\mathrm{w} / \mathrm{v}) \text { Polyvinylpyrollidon-360 }\end{array}$




\subsection{Ligation von DNA-Fragmenten}

Um Fragmente mit kohäsiven Enden zu erzeugen, wurden PCR-Produkte und Vektor pBluescript KS durch Behandlung mit einer oder zwei Restriktionsendonucleasen gespalten (4.11). Die Reinigung der Ansätze erfolgte durch Phenol-ChloroformExtraktion (4.7.1) und Sephacryl S-200 Schleudersäulen (4.7.2). PCR-Produkte, die mit stumpfen Enden in Vektor pUC 18 kloniert werden sollten, wurden ohne vorherige Restriktion in gleicher Weise gereinigt.

Für PCR-Produkte und Vektoren mit kohäsiven Enden wurde Ready-To-Go T4 DNA Ligase (Pharmacia, Freiburg) eingesetzt, für PCR-Produkte mit stumpfen Enden das SureClone Ligation Kit (Pharmacia, Freiburg). Das molare Verhältnis von Fragment$\mathrm{zu}$ Vektor-DNA betrug bei der Ligation von Fragmenten mit kohäsiven Enden 2-3 : 1, bei stumpfen Enden 4-8 : 1 .

\subsection{Transformation von $E$. coli}

Für Standard-Transformationen wurden E. coli DH5 $\alpha$-Zellen (4.3.1) mit Calciumchlorid für die Aufnahme von Plasmid-DNA kompetent gemacht (Cohen et al. 1972), Protokoll nach Sambrook et al. 1989). Zur Transformation wurden bis zu $5 \mu 1$ Plasmid-DNA mit $200 \mu \mathrm{l}$ kompetenten Zellen vermischt und 30 min auf Eis inkubiert. Nach kurzem Erhitzen auf $42^{\circ} \mathrm{C}$ (90 s), wurde anschließend auf Eis gekühlt und die Zellen zur Expression der Antibiotikaresistenz mit $800 \mu 1$ NZY-Medium $30 \mathrm{~min}$ bei $37^{\circ} \mathrm{C}$ geschüttelt.

Nach der Inkubation wurden die Zellen durch kurze Zentrifugation im unteren Bereich des Reaktionsgefäßes konzentriert, in ca $100 \mu \mathrm{l}$ NZY resuspendiert und auf NZY-Agarplatten mit 75 mg/ml Ampicillin plattiert. Zur schnellen Analyse Ampicillin-resistenter Kolonien wurde PCR eingesetzt (4.6.3). 


\subsection{Plasmidisolierung}

Die Plasmidisolierung erfolgte mit dem Nucleobond AX Plasmidisolierungskit (Macherey \& Nagel, Düren) oder QIAfilter Plasmid Midi/Mini Kit (Qiagen, Hilden). Die isolierten Plasmide wurden mit Restriktionsendonucleasen inkubiert, um die enthaltenen Fragmente zu analysieren (4.11.1).

\subsection{DNA-Sequenzierung}

Für Plasmidsequenzierungen (4.6.4) wurden zunächst die Standardprimer m13 und m13 reverse (4.4) eingesetzt, deren Sequenzen in den multiplen Klonierungsstellen der verwendeten Vektoren liegen. Anhand der eingelesenen Sequenzen wurden dann fortlaufend neue Oligonucleotide synthetisiert und zur weiteren Sequenzanalyse eingesetzt (primer walking).

Die Sequenzierungsreaktionen aus 4.6.4 wurden in dem computergesteuerten Elektrophorese- und Fluoreszenzdetektions-System ABI PRISM ${ }^{\mathrm{TM}} 310$ (Perkin Elmer Applied Biosystems, Weiterstadt) aufgetrennt. Die erzielten Leseweiten betrugen 400-500 bp.

\subsection{Computergestützte Sequenzanalysen}

Zur Analyse von Nucleotid- und Aminosäuresequenzen wurden zunächst die Rohdaten (Chromatogramme) des Elektrophoreselaufes mit dem Programm ABI PRISM ${ }^{\text {TM }}$ Sequencing Analysis 3.0 editiert. Anschließend wurden die Sequenzen mit der DNAAnalyse Software MacVector (IBI) analysiert (Suche nach offenen Leserastern zur Translation, coding probability Berechnungen, codon usage Bestimmungen, Sekundärstrukturvorhersagen etc.). Zur Vorhersage von Transmembransequenzen wurde außerdem das Programm TMpred (Hofmann \& Stoffel 1993) eingesetzt. Dieses Programm identifiziert Transmembranregionen und versucht, ihre Orientierung vorherzusagen. Die Vorhersagen stützen sich auf die statistische Analyse der Datenbank TMbase, eine Sammlung aller bekannten Transmembranproteine der Sequenzdatenbank Swissprot. 
Während der fortschreitenden Sequenzierung eines bestimmten Klones wurden überlappende Sequenzdaten mit dem Programm AssemblyLign (IBI) lokalisiert und zusammengesetzt.

Parallele Mehrfachabgleiche (multiple Alignments) wurden mit den Programmen Clustal V (Higgins \& Sharp 1988) und Clustal W (Thompson et al. 1994, OnlineVersion) durchgeführt. Zur Bestimmung des prozentualen Anteils identischer bzw. ähnlicher Aminosäuren in zwei Sequenzen wurde die Online-Version des Programms BLAST benutzt (Altschul et al. 1990; Zhang \& Madden 1997).

\subsection{Analysen von voltage clamp-Daten}

Die Messungen an Xenopus laevis Oocyten wurden von Sabrina Gazzarrini (Universität Mailand, Italien) durchgeführt.

Die Plasmide pSKcv bzw. pSKcvF66A wurden mit dem Enzym NsiI linearisiert und mit T7 RNA Polymerase (Promega Riboprobe II Core System) in vitro transkribiert. Die so gewonnene mRNA wurde $X$. laevis Oocyten injiziert (maximal 1ng/50 nl).

Für Ganzzellableitungen wurde das herkömmliche voltage clamp-Verfahren mit zwei intrazellulären Elektroden angewendet (Gene Clamp 500 Verstärker und pCLAMP5.5 Software, beides Axon Instruments, USA). Beide Elektroden waren mit $3 \mathrm{M} \mathrm{KCl}$ gefüllt. Die Oocyten wurden kontinuierlich mit Badlösung umspült.

$\begin{array}{rlll}50 & \mathrm{mM} & \mathrm{KCl} \\ 1,8 & \mathrm{mM} & \mathrm{CaCl}_{2} \\ 1 & \mathrm{mM} & \mathrm{MgCl}_{2} \\ 5 & \mathrm{mM} & \text { Hepes/LiOH, pH 7,4 }\end{array}$

Die Osmolarität der Lösung wurde mit Mannitol auf 215 mM eingestellt.

Die gewonnenen Daten wurden mit den Programmen Clampfit (Axon Instruments) und Ecxel 4.0 (Microsoft) analysiert (4.1). 


\section{LITERATURVERZEICHNIS}

\subsection{Artikel \& Bücher}

Abrams, C.J., Davies, N.W., Shelton, P.A. \& Stanfield, P.R. (1996) The role of a single aspartate residue in ionic selectivity and block of a murine inward rectifier $\mathrm{K}^{+}$channel Kir2.1. Journal of Physiology 493, 643-49

Altschul, S.F., Gish, W., Miller, W., Myers, E.W. \& Lipman, D.J. (1990) Basic local alignment tool. Journal of Molecular Biology 215, 403-10

Anderson, J.A., Huprikar, S.S., Kochian, L.V., Lucas, W.J. \& Gaber, R.F. (1992) Functional expression of a probable Arabidopsis thaliana potassium channel in Saccharomyces cerevisiae. Proceedings of the National Academy of Sciences USA 89, 3736-40

Andersson, S.G.E., Zomorodipour, A., Andersson, J.O., Sicheritz-Pontén, T., Alsmark, U.C.M., Podowski, R.M., Nöslund, K., Eriksson, A.S., Winkler, H.H. \& Kurland, C.G. (1998) The genome sequence of Rickettsia prowazekii and the origin of mitochondria. Nature 396, 133-40

Ashcroft, F.M., Kerr, A.J., Gibson, J.S. \& Williams, B.A. (1991) Amantadine and sparteine inhibit ATP-regulated $\mathrm{K}^{+}$-currents in the insulin-secreting beta-cell line HIT-T15. British Journal of Pharmacology 104, 579-84

Bamford, D.H., Caldenty, J. \& Bamford, J.K.H. (1995) Bacteriophage PRD1: a broad host range dsDNA tectivirus with an internal membrane. Advances in Virus Research 45, 281-319

Barhanin, J., Lesage, F., Guillemare, E., Fink, M., Lazdunski, M. \& Romey, G. (1996) KvLQT1 and IsK (minK) proteins associate to form the $\mathrm{I}_{(\mathrm{Ks})}$ cardiac potassium current. Nature 384, 78-80

Bauer, C.K., Falk, T. \& Schwarz, J.R. (1996) An endogenous inactivating inwardrectifying potassium current in oocytes of Xenopus laevis. Pflugers Archive 432, 812-20

Becker, B.E. (1991) Untersuchungen zur Charakterisierung von Chlorellaviren. Göttinger Dissertationen 15, Hartung-Gorre Verlag, Konstanz

Becker, D., Dreyer, I., Hoth, S., Reid, J.D., Busch, H., Lehnen, M., Palme, K. \& Hedrich, R. (1996) Changes in voltage activation, $\mathrm{Cs}^{+}$sensitivity and ion permeability in $\mathrm{H} 5$ mutants of the plant $\mathrm{K}^{+}$channel KAT1. Proceedings of the National Academy of Sciences USA 93, 8123-28 
Benson, S.D., Bamford, J.K.H., Bamford, D.H. \& Burnett, R.M. (1999): Viral evolution revealed by bacteriophage PRD1 and human adenovirus coat protein structures. Cell 98, 825-33

Brendel, V., Bucher, P., Nourbakhsh, I., Blaisdell, B.E. \& Karlin, S. (1992) Methods and algorithms for statistical analysis of protein sequences. Proceedings of the $\mathrm{Na}$ tional Academy of Sciences USA 89, 2002-6

Chen, F. \& Suttle, C.A. (1996) Evolutionary relationships among large doublestranded DNA viruses that infect microalgae and other organisms as inferred from DNA polymerase genes. Virology 219, 170-78

Church, G.M. \& Gilbert, W. (1984) Genomic sequencing. Proceedings of the National Academy of Sciences USA 81, 1991-95

Ciampor, F., Bayley, P.M., Nermut, M.V., Hirst, A., Sugrue, R.J. \& Hay, A.J. (1992) Regulation of $\mathrm{pH}$ by the M2 Protein of influenza A viruses. Virus Research 22, 247-58

Cohen, S.N., Chang, A.C.Y. \& Hsu, L. (1972) Nonchromosomal antibiotic resistance in bacteria: Genetic transformation of Escherichia coli by R-factor DNA. Proceedings of the National Academy of Sciences USA 69, 2110

Dascal, N. (1987) The use of Xenopus oocytes for the study of ion channels. Critical Reviews in Biochemistry 22, 317-87

Derst, C. \& Karschin, A. (1998) Evolutionary link between prokaryotic and eukaryotic $\mathrm{K}^{+}$channels. Journal of Experimental Biology 201, 2791-99

Doyle, D.A., Cabral, J.M., Pfuetzner, R.A., Kuo, A., Gulbis, J.M., Cohen, S.L., Chait, B.T. \& MacKinnon, R. (1998) The structure of the potassium channel: Molecular basis of $\mathrm{K}^{+}$conduction and selectivity. Science 280, 69-77

Engelman, D.M., Steitz, T.A. \& Goldman, A. (1986) Identifying nonpolar transbilayer helices in amino acid sequences of membrane proteins. Annual Review of Biophysics and Biophysical Chemistry 15, 321-53

Fan, J.S., Jiang, M., Dun, W., McDonald, T.V. \& Tseng, G.N. (1999) Effects of outer mouth mutations on hERG channel function: a comparison with similar mutations in the Shaker channel. Biophysical Journal 76, 3128-40

Francki, R.I.B., Fauquet, C.M., Knudson, D.L. \& Brown, F. (1991) Classification and Nomenclature of Viruses. Fifth Report of the International Committee on Taxonomy of Viruses. Springer Verlag, Wien, New York

Freeman, S.E., Dawson, R.M., Culvenor, A.J. \& Keeghan, A.M. (1985) Interactions of amantadine with the cardiac muscarinic receptor. Journal of Molecular and Cellular Cardiology 17, 9-21 
Gandhi, C.S., Shuck, K., Lear, J.D., Dieckmann, G.R., DeGrado, W.F., Lamb, R.A. \& Pinto, L.H. (1999) $\mathrm{Cu}$ (II) inhibition of the proton translocation machinery of the influenza A virus M2 protein. Journal of Biological Chemistry 274, 5474-82

Ganetzky, B., Robertson, G.A., Wilson, G.F., Trudeau, M.C. \& Titus, S.A. (1999) The EAG family of $\mathrm{K}^{+}$channels in Drosophila and mammals. Annals of the New York Academy of Sciences 868, 356-69

Goldstein, S.A., Price, L.A., Rosenthal, D.N. \& Pausch, M.H. (1996) ORK1, a potassium-selective leak channel with two pore domains cloned from Drosophila melanogaster by expression in Saccharomyces cerevisiae. Proceedings of the National Academy of Sciences USA 93, 13256-61

Graves, M.V. \& Meints, R.H. (1992) Characterization of the major capsid protein and cloning of its gene from algal virus PBCV-1. Virology 188, 198-207

Ha, H.C., Sirisoma, N.S., Kuppusamy, P., Zweier, J.L., Woster, P.M. \& Casero, R.A.J. (1998) The natural polyamine spermine functions directly as a free radical scavenger. Proceedings of the National Academy of Sciences USA 95, $11140-45$

Hanahan, D.J. (1985) Techniques for transformation of E.coli. In: DNA cloning. (D.M. Glover, ed.) pp. 109-135, IRL Press, Oxford

Hausdorf, S.F., Goldstein, S.A.N., Rushin, E.E. \& Miller, C. (1991) Functional characterization of a minimal $\mathrm{K}^{+}$channel expressed from a synthetic gene. Biochemistry 30, 3341-46

Heginbotham, L., Lu, Z., Abramson, T. \& MacKinnon, R. (1994) Mutations in the $\mathrm{K}^{+}$channel signature sequence. Biophysical Journal 66, 1061-67

Henry, E.C. \& Meints, R.H. (1992) A persistent virus infection in Feldmannia (Phaeophyceae). Journal of Phycology 28, 517-26

Higgins, D.G. \& Sharp, P.M. (1988) CLUSTAL: a package for performing multiple alignments on a microcomputer. Gene $\mathbf{7 3}, 237-44$

Hille, B. (1992) Ionic channels of excitable membranes. Sinauer, Sunderland, MA

Ho, S.N., Hunt, H.D., Horton, R.M., Pullen, J.K. \& Pease, L.R. (1989) Site-directed mutagenesis by overlap extension using the polymerase chain reaction. Gene 77, 51-59

Hofmann, K. \& Stoffel, W. (1993) TMbase - A database of membrane spanning protein segments. Biological Chemistry 374, 166-70

Holsinger, L.J. \& Lamb, R.A. (1991) Influenza virus M2 integral membrane protein is a homotetramer stabilized by formation of disulfide bonds. Virology 183, 32-43 
Horton, R.M. (1997) In vitro recombination and mutagenesis of DNA. In: PCR Cloning Protocols: From molecular cloning to genetic engineering (B.A. White, ed.) S. 141-49, Humana Press Inc., Totowa, N.J.

Hoth, S. \& Hedrich, R. (1999) Distinct molecular bases for pH sensitivity of the guard cell $\mathrm{K}^{+}$channels KST1 and KAT1. Journal of Biological Chemistry 274, $11599-603$

Kaiser, A., Vollmert, M., Tholl, D., Graves, M.V., Gurnon, J.R., Xing, W., Lisec, A., Nickerson, K.W. \& Van Etten, J.L. (1999) Chlorella virus PBCV-1 encodes a functional homospermidine synthase. Virology 263, 254-62

Karschin, A., Wischmeyer, E., Döring, F. \& Karschin, C. (1997) Kaliumeinwärtsgleichrichter - ursprüngliche Kanalstrukturen als Basis funktioneller Vielfalt. Neuroforum 4, 127-32

Kawakami, H. \& Kawakami, N. (1978) Behaviour of a virus in a symbiotic system, Paramecium bursaria Zoochlorella. Journal of Protozoology 25, 217-25

Ketchum, K.A., Joiner, W.J., Sellers, A.J., Kaczmarek, L.K. \& Goldstein, S.A. (1995) A new family of outwardly rectifying potassium channel proteins with two pore domains in tandem. Nature 376, 690-95

Kornhuber, J., Weller, M., Schoppmeyer, K. \& Riederer, P. (1994) Amantadine and memantine are NMDA receptor antagonists with neuroprotective properties. Journal Of Neural Transmission. Supplementum 43, 91-104

Kubo, Y., Baldwin, T.J., Jan, Y.N. \& Jan, L.Y. (1992) Primary structure and function of a mouse inward rectifier potassium channel. Nature 362, 127-33

Kutish, G.F., Li, Y., Lu, Z., Furuta, M., Rock, D.L. \& Van Etten, J.L. (1996) Analysis of $76 \mathrm{~kb}$ of the chlorella virus PBCV-1 330-kb genome: Map positions 182 to 258. Virology 223, 303-17

Kyte, J. \& Doolittle, R.F. (1982) A simple method for displaying the hydropathic character of a protein. Journal of Molecular Biology 157, 105-32

Lamb, R.A. \& Pinto, L.H. (1997) Do Vpu and Vpr of Human Immunodeficiency Virus type 1 and NB of Influenza B Virus have an ion channel activity?

Virology 229, 1-11

Lesage, F., Attali, B., Lakey, J., Honore, E., Romey, G., Faurobert, E., Lazdunski, M. \& Barhanin, J. (1993) Are Xenopus ocytes unique in displaying functional IsK channel heterologous expression? Receptors and Channels 1, 143-52

Lesage, F., Reyes, R., Fink, M., Duprat, F., Guillemare, E. \& Lazdunski, M. (1996) Dimerization of TWIK $\mathrm{K}^{+}$channel subunits via a disulfide bridge.

EMBO Journal 15, 6400-07 
Li, M., Jan, Y.N. \& Jan, L.Y. (1992) Specification of subunit assembly by the hydrophilic amino-terminal domain of the shaker potassium channel. Science 257, 1225-30

Li, Y., Lu, Z., Burbank, D.E., Kutish, G.F., Rock, D.L. \& Van Etten, J.L. (1995) Analysis of $43 \mathrm{~kb}$ of the Chlorella virus PBCV-1 330-kb genome: Map positions 45 to 88 . Virology 212, 134-50

Li, Y., Lu, Z., Sun, L., Ropp, S., Kutish, G., Rock, D.L. \& Van Etten, J.L. (1997) Analysis of $76 \mathrm{~kb}$ of DNA located at the right end of the 330-kb Chlorella virus PBCV-1 genome. Virology 237, 360-77

Liman, E.R., Hess, P., Weaver, P. \& Koren, G. (1991) Voltage-sensing residues in the $\mathrm{S} 4$ region of a mammalian $\mathrm{K}^{+}$channel. Nature $353,752-56$

Liman, E.R., Tytgat, J. \& Hess, P. (1992) Subunit stoichiometry of a mammalian $\mathrm{K}^{+}$ channel determined by construction of multimeric cDNAs. Neuron 9, 861-71

Lopatin, A.N., Makhina, E.N. \& Nichols, C.G. (1994) Potassium channel block by cytoplasmic polyamines as the mechanism of intrinsic rectification.

Nature 372, 366-69

Lu, Z.Q., Li, Y., Zhang, Y.P., Kutish, G.F., Rock, D.L. \& Van Etten, J.L. (1995) Analysis of $45 \mathrm{~kb}$ of DNA located at the left end of the Chlorella virus PBCV-1 genome. Virology 206, 339-52

Lu, Z., Li, Y., Que, Q., Kutish, G.F., Rock, D.L. \& Van Etten, J.L. (1996) Analysis of $94 \mathrm{~kb}$ of the chlorella virus PBCV-1 330-kb genome: Map positions 88 to 182. Virology 216, 102-23

Macaulay, C. \& McFadden, G. (1989) Tumorigenic poxviruses: Characterization of an early promotor from Shope fibroma virus. Virology 172, 237-46

MacDonald, T.V., Yu, Z., Ming, Z., Palma, E., Meyers, M.B., Wang, K.W., Goldstein, S.A.N. \& Fishman, G.I. (1997) A minK-hERG complex regulates the cardiac potassium current $\mathrm{I}_{(\mathrm{Kr})}$. Nature 388, 289-92

MacKinnon, R. (1991) Determination of the subunit stoichiometry of a voltageactivated potassium channel. Nature 350, 232-35

Matsubayashi, H., Swanson, K.L. \& Albuquerque, E.X. (1997) Amantadine inhibits nicotinic acetylcholine receptor function in hippocampal neurons. Journal of Pharmacology and Experimental Therapeutics 281, 834-44

Meints, R.H., Van Etten, J.L., Kuczmarski, D., Lee, K. \& Ang, B. (1981) Viral infection of the symbiotic Chlorella-like alga present in Hydra viridis. Virology 113, 698-703

Meints, R.H., Lee, K., Burbank, D.E. \& Van Etten, J.L. (1984) Infection of a Chlorella-like alga with the virus, PBCV-1: Ultrastructural studies. Virology 138, $341-46$ 
Mèszàros, J., Kelemen, K., Mark R., Kecskeméti, V. \& Szegi, J. (1982) Inhibition of myocardial $\mathrm{K}^{+}$channels by bromobenzoyl-methyladamantylamine, an adamantane derivative. European Journal of Pharmacology 84, 151-60

Milkman, R. (1994) An Escherichia coli homologue of eukaryotic potassium channel proteins. Proceedings of the National Academy of Sciences USA 91, 3510-14

Minor, D.L.J., Masseling, S.J., Jan, Y.N. \& Jan, L.Y. (1999) Transmembrane structure of an inwardly rectifying potassium channel. Cell 96, 879-91

Müller, D.G., Kawai, H., Stache, B. \& Lanka, S. (1990) A virus infection in the marine brown alga Ectocarpus siliculosus (Phaeophyceae). Botanica Acta 103, 72-82

Müller, D.G. \& Stache, B. (1992) Worldwide occurrence of virus infections in filamentous marine brown algae. Helgoländer Meeresuntersuchungen 46, 1-8

Müller, D.G. \& Parodi, E. (1993) Transfer of a marine DNA virus from Ectocarpus to Feldmannia (Ectocarpales, Phaeophyceae). Protoplasma 175, 121-25

Müller, D.G., Kapp, M. \& Knippers, R. (1998) Viruses in marine brown algae. Advances in Virus Research 50, 49-67

Nishida, K., Suzuki, S., Kimura, Y., Nomura, N., Fujie, M. \& Yamada, T. (1998)

Group I introns found in Chlorella viruses: Biological implications.

Virology 242,319-26

Numberger, M. \& Draguhn, A. (1996) Patch-Clamp-Technik. Labor im Fokus, Spektrum Akademischer Verlag, Heidelberg, Berlin, Oxford

Owen, J.M., Quinn, C.C., Leach, R., Findlay, J.B. \& Boyett, M.R. (1999) Effect of extracellular cations on the inward rectifying $\mathrm{K}^{+}$channels Kir2.1 and Kir3.1/Kir3.4. Experimental Physiology 84, 471-88

Papazian, D.M. (1999) Potassium channels: some assembly required. Neuron 23, 7-10

Piller, S.C., Ewart, G.D., Premkumar, A., Cox, G.B. \& Gage, P.W. (1996) Vpr protein of human immunodeficiency virus type 1 forms cation-selective channels in planar lipid bilayers. Proceedings of the National Academy of Sciences USA 93, 111-15

Pinto, L.H., Holsinger, L.J. \& Lamb, R.A. (1992) Influenza virus M2 protein has ion channel activity. Cell 69, 517-28

Plugge, B., Becker, B. \& Wolf, A.H. (1999) Several genes in chlorella virus strain CVG-1 encode putative virion components. Journal of General Virology 80, 1067-72

Plugge, B., Gazzarrini, S., Nelson, M., Cerrana, R., Van Etten, J.L., Derst, C., DiFrancesco, D., Moroni, A. \& Thiel, G. (2000) A new potassium channel encoded by chlorella virus PBCV-1. Eingereicht bei Science (10/99) 
Que, Q.D., Li, Y., Wang, I.N., Lane, L.C., Chaney, W.G. \& Van Etten, J.L. (1994) Protein glycosylation and myristylation in chlorella virus PBCV-1 and its antigenic variants. Virology 203, 320-27

Raganathan, R. (1994) Evolutionary origins of ion channels. Proceedings of the National Academy of Sciences USA 91, 3484-86

Reisser, W. (1984) The taxonomy of green algae endosymbiotic in ciliates and a sponge. Bryology and Phycology 19, 309-18

Reisser, W., Becker, B. \& Klein, T. (1986) Studies on ultrastructure and host range of a Chlorella attacking virus. Protoplasma 135, 162-65

Reisser, W., Burbank, D.E., Meints, S.M., Meints, R.H., Becker, B. \& Van Etten, J.L. (1988) A comparison of viruses infecting two different Chlorella-like green algae. Virology 167, 143-49

Reisser, W. \& Widowski, M. (1992) Taxonomy of eukaryotic algae endosymbiotic in freshwater associations. In: Algae and symbioses (W. Reisser, ed.) S. 21-40, Biopress Limited, Bristol, England

Sabirov, R.Z., Tominaga, T., Miwa, A., Okada, Y. \& Oiki, S. (1997) A conserved arginine residue in the pore region of an inward rectifier $\mathrm{K}^{+}$channel (IRK1) as an external barrier for cationic blockers. Journal Of General Physiology 110, 665-77 [published erratum appears in J. Gen. Physiol. (1998) 111, 395].

Saitou, N. \& Nei, M. (1987) The neighbor-joining method: a new method for reconstructing phylogenetic trees. Molecular and Biological Evolution 4, 406-25

Sambrook, J., Fritsch, E.F. \& Maniatis, T. (1989) Molecular Cloning. A Laboratory Manual. Cold Spring Harbour Laboratory, Cold Spring Harbour

Sanger, F., Nicklen, S. \& Coulsen, A.R. (1977) DNA sequencing with chaintermination inhibitors. Proceedings of the National Academy of Sciences USA 74, 5463-67

Sanguinetti, M.C., Curran, M.E., Zou, A., Shen, J., Spector, P.S., Atkinson, D.L. \& Keating, M.T. (1996) Coassembly of KvLQT1 and MinK (Isk) proteins to form

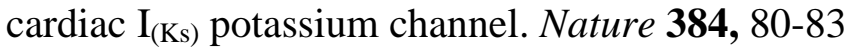

Schlesinger, M.J. \& Schlesinger, S. (1987) Domains of virus glycoproteins. Advances in Virus Research 33, 1-44

Schrempf, H., Schmidt, O., Kümmerlen, R., Hinnah, S.D.M., Betzler, M., Steinkamp, T. \& Wagner, R. (1995) A prokaryotic potassium ion channel with two predicted transmembrane segments from Streptomyces lividans. EMBO Journal 14, 5170-78 
Schubert, U., Ferrer-Montiel, A.V., Oblatt-Montal, M., Henklein, P., Strebel, K. \& Montal, M. (1996) Identification of an ion channel activity of the Vpu transmembrane domain and its involvement in the regulation of virus release from HIV-1infected cells. FEBS Letters 398, 12-18

Schuster, A.M., Graves, M., Korth, K., Ziegelbein, M., Brumbaugh, J., Grone, D. \& Meints, R.H. (1990) Transcription and sequence studies of a 4.3-kbp fragment from a dsDNA eukaryotic algal virus. Virology 176, 515-23

Sengco, M.R., Bräutigam, M., Kapp, M. \& Müller, D.G. (1996) Detection of virus DNA in Ectocarpus siliculosus and Ectocarpus fasciculatus (Phaeophyceae) from various geographic areas. European Journal of Phycology 31, 73-78

Shieh, R.C., Chang, J.C. \& Arreola, J. (1998) Interaction of $\mathrm{Ba}^{2+}$ with the pores of the cloned inward rectifier $\mathrm{K}^{+}$channels Kir2.1 expressed in Xenopus oocytes. Biophysical Journal 75, 2313-22

Shih, T.M. \& Goldin, A.N. (1997) Topology of the Shaker potassium channel probed with hydrophilic epitope insertions. Journal of Cell Biology 136, 1037-45

Shimbo, K., Brassard, D.L., Lamb, R.A. \& Pinto, L.H. (1995) Viral and cellular small integral membrane proteins can modify ion channels endogenous to Xenopus oocytes. Biophysical Journal 69, 1819-29

Skrdla, M.P., Burbank, D.E., Xia, Y., Meints, R.H. \& Van Etten, J.L. (1984) Structural proteins and lipids in a virus, $\mathrm{PBCV}-1$, which replicates in a Chlorella-like alga. Virology 135, 308-15

Songsri, P., Hiramatsu, S., Fujie, M. \& Yamada, T. (1997) Proteolytic processing of chlorella virus CVK2 capsid proteins. Virology 227, 252-54

Southern, E.M. (1975) Detection of specific sequences among DNA fragments separated by gel electrophoresis. Journal of Molecular Biology 98, 503-17

Sugrue, R.J. \& Hay, A.J. (1991) Structural characteristics of the M2 protein of influenza A viruses: Evidence that it forms a tetrameric channel. Virology 180, 617-24

Sunstrom, N.A., Premkumar, L.S., Premkumar, A., Ewart, G., Cox, G.B. \& Gage, P.W. (1996) Ion channels formed by NB, an influenza B virus protein. Journal of Membrane Biology 150, 127-32

Takumi, T., Ohkubo, H. \& Nakanishi, S. (1988) Cloning of a membrane protein that introduces a slow voltage-gated potassium current. Science 242, 1042-45

Thompson, J.D., Higgins, D.G. \& Gibson, T.J. (1994) CLUSTAL W: Improving the sensitivity of progressive multiple sequence alignment through sequence weighting, position specific gap penalties and weight matrix choice.

Nucleic Acids Research 22, 4673-80 
Tosteson, M.T., Pinto, L.H., Holsinger, L.J. \& Lamb, R.A. (1994) Reconstitution of the influenza virus M2 ion channel in lipid bilayers.

Journal of Membrane Biology 142, 117-26

Trudeau, M.C., Warmke, J.W., Ganetzky, B. \& Robertson, G.A. (1995) hERG, a human inward rectifier in the voltage-gated potassium channel family.

Science 269, 92-95

Van Etten, J.L., Meints, R.H., Kuczmarski, D., Burbank, D.E. \& Lee, K. (1982) Viruses of symbiotic Chlorella-like algae isolated from Paramecium bursaria and Hydra viridis. Proceedings of the National Academy of Sciences USA 79, 3867-71

Van Etten, J.L., Burbank, D.E., Xia, Y. \& Meints, R.H. (1983) Growth cycle of a virus, PBCV-1, that infects a Chlorella-like algae. Virology 126, 117-25

Van Etten, J.L., Burbank, D.E., Schuster, A.M. \& Meints, R.H. (1985) Lytic viruses infecting a Chlorella-like alga. Virology 140, 135-43

Van Etten, J.L., Lane, L.C. \& Meints, R.H. (1991) Viruses and viruslike particles of eukaryotic algae. Microbiological Reviews 55, 586-620

Van Etten, J.L. (1995) Phycodnaviridae. In: Virus Taxonomy (F.A. Murphy, C.M. Fauguet, D.H.L Bishop, S.A. Ghabrial, A.W. Jarvis et. al., eds.) S. 100-03, Springer Verlag, New York

Van Etten, J.L. \& Meints, R.H. (1999) Giant viruses infecting algae. Annual Reviews in Microbiology 53, 447-94

Véry, A.A., Bosseux, C., Gaymard, F., Sentenac, H. \& Thibaud, J.B. (1994) Level of expression in Xenopus oocytes affects some characteristics of a plant inward rectifying voltage-gated $\mathrm{K}^{+}$channel. Pflugers Archive 428, 422-24

Wang, I.N., Li, Y., Que, Q., Bhattacharya, M., Lane, L.C., Chaney, W.G. \& Van Etten, J.L. (1993a) Evidence for virus-encoded glycosylation specificity. Proceedings of the National Academy of Sciences USA 90, 3840-44

Wang, C., Takeuchi, K., Pinto, L.H. \& Lamb, R.A. (1993b) Ion channel activity of influenza A virus M2 protein: characterization of the amantadine block.

Journal of Virology 67, 5585-94

Warburg, O. \& Christian, W. (1942) Isolierung und Kristallisation des Gärungsfermentes Enolase. Biochemische Zeitschrift 310, 384-421

Wei, A., Jegla, T. \& Salkoff, L. (1996) Eight potassium channel families revealed by the C. elegans genome project. Neuropharmacology 35, 805-29

Willis, D.C., ed. (1985) Iridoviridae. Current topics in Microbiology and Immunology 116, Springer Verlag, Berlin, New York 
Xia, Y.N. \& Van Etten, J.L. (1986a) DNA methyltransferase induced by PBCV-1 virus infection of a Chlorella-like green alga. Molecular and Cellular Biology 6, $1440-45$

Xia, Y.N., Burbank, D.E., Uher, L., Rabussay, D. \& Van Etten, J.L. (1986b) Restriction endonuclease activity induced by PBCV-1 virus infection of a Chlorella-like green alga. Molecular and Cellular Biology 6, 1430-39

Yamada, T., Shimomae, A., Furukawa, S. \& Takehara, J. (1993) Widespread distribution of chlorella viruses in Japan.

Bioscience, Biotechnology and Biochemistry 57, 733-39

Yan, X., Olson, N.H., Van Etten, J.L. \& Baker, T.S. (1999) Cryoelectron microscopy and image reconstruction of PBCV-1, an algal virus with $\mathrm{T}=169$ lattice symmetry. Electron Microscopy 1, 775-76

Zhang, Y.P., Burbank, D.E. \& Van Etten, J.L. (1988) Chlorella viruses isolated in China. Applied and Environmental Microbiology 54, 2170-73

Zhang, Y., Nelson, M., Nietfeldt, J.W., Burbank, D.E. \& Van Etten, J.L. (1992) Characterization of chlorella virus PBCV-1 CviAII restriction and modification system. Nucleic Acids Research 20, 5351-56

Zhang, J. \& Madden T.L. (1997) PowerBLAST: A new network BLAST application for interactive or autimated sequence analysis and annotation. Genome Research 7 , 649-56

\subsection{Web-Adressen}

BLAST similarity searches at the National Center for Biotechnology Information (NCBI) : http://www.ncbi.nlm.nih.gov/gorf/wblast2/cgi

CLUSTAL W service at the European Bioinformatics Institute (EBI): http://www2.ebi.ac.uk/clustalw

GenBank Sequence Database at the National Center for Biotechnology Information (NCBI): http://www.ncbi.nlm.nih.gov

ICTV (International Committee on Taxonomy of Viruses): http://www.ncbi.nlm.nih.gov/ICTV

TMpred at the Swiss Institute of Cancer Research (ISREC) /Swiss Institute for Bioinformatics (ISB): http://www.isrec.isb-sib.ch/cgi-bin/TMPRED_form_parser

World of Chlorella Viruses (Labor von J.L. Van Etten): http://ianrwww.unl.edu/plantpath/facilities/virology/first.htm 


\section{Anhang A: Abkürzungen für Aminosäuren und Nucleotide}

$\underline{\text { Internationaler Einbuchstabencode für Nucleotide und Aminosäuren }}$

Nucleotide

$\begin{array}{ll}\text { A } & \text { Adenin } \\ \text { B } & \text { nicht A } \\ \text { C } & \text { Cytosin } \\ \text { D } & \text { nicht C } \\ \text { G } & \text { Guanin } \\ \mathrm{H} & \text { nicht } \mathrm{G} \\ \mathrm{K} & \text { G oder T } \\ \mathrm{M} & \text { A oder C } \\ \mathrm{N} & \text { A, C, G, oder T } \\ \mathrm{R} & \text { A oder } \mathrm{G} \\ \mathrm{S} & \text { C oder } \mathrm{G} \\ \mathrm{T} & \text { Thymin } \\ \mathrm{U} & \text { Uracil } \\ \mathrm{V} & \text { nicht T } \\ \mathrm{W} & \text { A oder T } \\ \mathrm{Y} & \text { C oder T } \\ * & \text { Stopcodon }\end{array}$

\section{Aminosäuren}

$\begin{array}{lll}\text { A } & \text { Ala } & \text { Alanin } \\ \text { B } & \text { Asx } & \text { Aspartat oder Asparagin } \\ \text { C } & \text { Cys } & \text { Cystein } \\ \text { D } & \text { Asp } & \text { Aspartat } \\ \text { E } & \text { Glu } & \text { Glutamat } \\ \text { F } & \text { Phe } & \text { Phenylalanin } \\ \text { G } & \text { Gly } & \text { Glycin } \\ \text { H } & \text { His } & \text { Histidin } \\ \text { I } & \text { Ile } & \text { Isoleucin } \\ \text { K } & \text { Lys } & \text { Lysin } \\ \text { L } & \text { Leu } & \text { Leucin } \\ \text { M } & \text { Met } & \text { Methionin } \\ \text { N } & \text { Asn } & \text { Asparagin } \\ \text { P } & \text { Pro } & \text { Prolin } \\ \text { Q } & \text { Gln } & \text { Glutamin } \\ \text { R } & \text { Arg } & \text { Arginin } \\ \text { S } & \text { Ser } & \text { Serin } \\ \text { T } & \text { Thr } & \text { Threonin } \\ \text { V } & \text { Val } & \text { Valin } \\ \text { W } & \text { Trp } & \text { Tryptophan } \\ \text { X } & & \text { beliebige Aminosäure } \\ \text { Y } & \text { Tyr } & \text { Tyrosin } \\ \text { Z } & \text { Glx } & \text { Glutamat oder Glutamin } \\ * & & \text { Ende }\end{array}$

$\underline{\text { Reduziertes 11-Buchstaben-Alphabet der Aminosäuren (Brendel et al. 1992) }}$

$\begin{array}{lll}\text { i } & \text { L; I; V, F } & \text { hydrophobe Seitenketten } \\ + & \text { K, R } & \text { positiv geladene Seitenketten } \\ - & \text { E, D } & \text { negativ geladene Seitenketten } \\ \text { s } & \text { A, G } & \text { kleine Aminosäuren } \\ \text { o } & \text { S, T } & \text { Hydroxylgruppe in der Seitenkette } \\ \text { n } & \text { N, Q } & \text { Amidgruppe in der Seitenkette } \\ \text { a } & \text { Y, W, (F) } & \text { aromatische Seitenketten } \\ \text { h } & \text { H } & \text { Histidin } \\ \text { m } & \text { M } & \text { Methionin } \\ \text { c } & \text { C } & \text { Cystein }\end{array}$




\section{Anhang B: Sequenzen der Hüllprotein-Genfamilie}

\section{Nuclein- und Aminosäuresequenz des Genfragmentes pcr3}

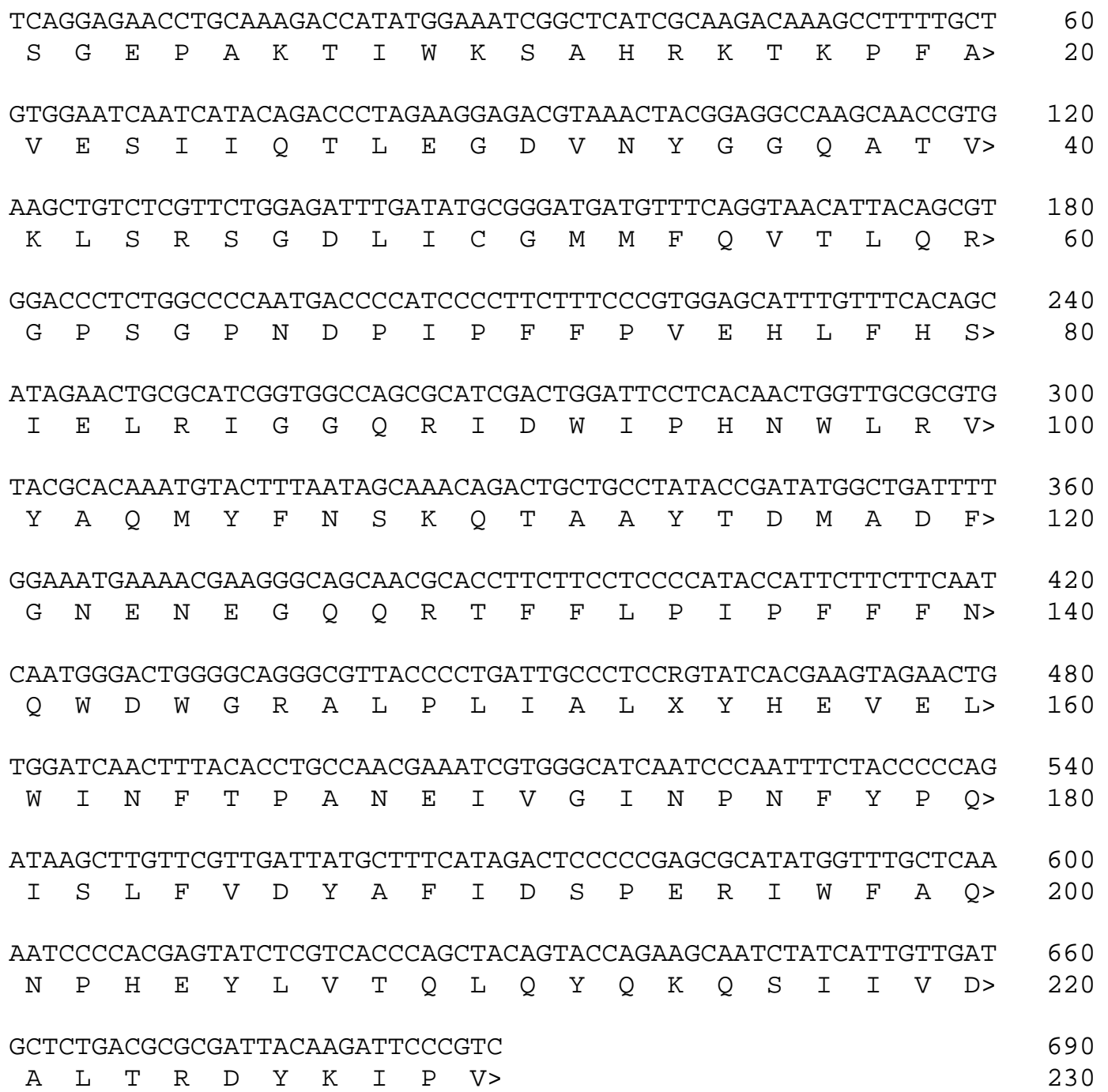

Die Sequenz von pcr3 ist unter der Zugangsnummer GenBank AFO76923 eingetragen. 


\section{Nuclein- und Aminosäuresequenz des HaupthüllproteinGens vcr7 mit 5'- und 3 '-untranslatierten Bereichen}

ACTAGTATGTCTAATTTCACAGGCAATAGGATGAAAGAAATGTGGAATCAATATTTTTCG TATCAATCAATCTGATAAAATGAAAGATATATGGGCAAATGAGATATTCAAGTATAAAAT GTACTCCATTTTTGCCAGCGATGTCTATAGAAGTAAGTTGAGCTTGAAACAAATTTCTAG GTTCTCAACCACGGAAGGGAAAGAAGCTGCGCGCATTTCACATAGTCATATGCGAAAATT TACAGATGAAGAACTGATAATAGCAAATATCAAATGCAATGGAAGTGTTAAAAAGATGAC GGAACTTTTACAATGTGGACATACTGCTATTGATAGAGCAAAGAAACGTCTAGGTCTCTG TAGACCTAGGAAAACTCCGGAAACTTCTGTAAAATCATAGAGAAAGTCTCAGAAAATCAC TAAAAACCATAGAAAAAACTCGACGTGTGTGTAAAAATGCGTTAAAATT TAAAAAAAAA,

GCCCAGGACGTTTACCTCACTGGAAATCCCCAAATCACTTTTTTCAAAACTGTATATCGC 600

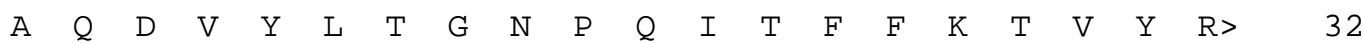

CGCTACACCAACTTCGCTGTGGAGTCCATCCAGCAAACTATTAATGGATCCGTTGGTTTT 660 $\begin{array}{lllllllllllllllllllll}R & Y & T & N & F & A & V & E & S & I & Q & Q & T & I & N & G & S & V & G & F> & \end{array}$

GGAAATAAAGTGTCTACACAAATCTCCCGTAATGGTGACCTGATAACCGACATCGTGGTT . . 720 $\begin{array}{llllllllllllllllllllllll}G & N & K & V & S & T & Q & I & S & R & N & G & D & L & I & T & D & I & V & V> & & 72\end{array}$

GAGTTCGTGCTGACCAAGCAGGGCCCCACTTTCTACTGCGCTGAGCAGCTGCTACAGGAT 780

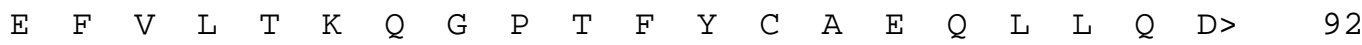

GTTGAGCTGGAGATTGGTGGCCAGCGCATCGACAAGCACTACGCCGACTGGTTCCGCATG 840 $\begin{array}{lllllllllllllllllllll}V & E & L & E & I & G & G & Q & R & I & D & K & H & Y & A & D & W & F & R & M> & 112\end{array}$

TACGACTCCCTGTTCCGCATGGACAACGACCGTCAGAACTACCGCCGCATGACTGACTTC 900 $\begin{array}{lllllllllllllllllllll}Y & D & S & L & F & R & M & D & N & D & R & Q & N & Y & R & R & M & T & D & F> & 132\end{array}$

GTGAACGACGAGCCCGCCACCGCCGTCAAGCGTTTCTACGTGCCCCTGATCTTCTTCTTC 960 \begin{tabular}{lllllllllllllllllllll}
$\mathrm{V}$ & $\mathrm{N}$ & $\mathrm{D}$ & $\mathrm{E}$ & $\mathrm{P}$ & $\mathrm{A}$ & $\mathrm{T}$ & $\mathrm{A}$ & $\mathrm{V}$ & $\mathrm{K}$ & $\mathrm{R}$ & $\mathrm{F}$ & $\mathrm{Y}$ & $\mathrm{V}$ & $\mathrm{P}$ & $\mathrm{L}$ & $\mathrm{I}$ & $\mathrm{F}$ & $\mathrm{F}$ & $\mathrm{F}>$ & \\
\hline
\end{tabular}

AACCAGACCCCCGGCCTGGCCCTCCCCCTGATTGCCCTCCAGTACCACGAGGTGAAGCTT 1020 $\begin{array}{lllllllllllllllllllll}\mathrm{N} & \mathrm{Q} & \mathrm{T} & \mathrm{P} & \mathrm{G} & \mathrm{L} & \mathrm{A} & \mathrm{L} & \mathrm{P} & \mathrm{L} & \mathrm{I} & \mathrm{A} & \mathrm{L} & \mathrm{Q} & \mathrm{Y} & \mathrm{H} & \mathrm{E} & \mathrm{V} & \mathrm{K} & \mathrm{L}> & 172\end{array}$

TACTTCACACTGGCATCCACTGTCAACGGTATCACCGCTGTTGAGGGCGGCGCCGCCGTG 1080 $\begin{array}{lllllllllllllllllllll}Y & \mathrm{~F} & \mathrm{~T} & \mathrm{~L} & \mathrm{~A} & \mathrm{~S} & \mathrm{~T} & \mathrm{~V} & \mathrm{~N} & \mathrm{G} & \mathrm{I} & \mathrm{T} & \mathrm{A} & \mathrm{V} & \mathrm{E} & \mathrm{G} & \mathrm{G} & \mathrm{A} & \mathrm{A} & \mathrm{V}> & 192\end{array}$

ACCGCTGTCGCTCCCCAGATGAGCGTGTGGGTCGACTACATCTTCCTGGACACCCAGGAG 1140 $\begin{array}{lllllllllllllllllllll}\mathrm{T} & \mathrm{A} & \mathrm{V} & \mathrm{A} & \mathrm{P} & \mathrm{Q} & \mathrm{M} & \mathrm{S} & \mathrm{V} & \mathrm{W} & \mathrm{V} & \mathrm{D} & \mathrm{Y} & \mathrm{I} & \mathrm{F} & \mathrm{L} & \mathrm{D} & \mathrm{T} & \mathrm{Q} & \mathrm{E}> & 212\end{array}$

CGCACCCGCTTCGCCCAGCTGCCCCACGAGTACCTGATCGAGCAGCTGCAGTTCACCGGC 1200 $\begin{array}{lllllllllllllllllllll}R & \mathrm{~T} & \mathrm{R} & \mathrm{F} & \mathrm{A} & \mathrm{Q} & \mathrm{L} & \mathrm{P} & \mathrm{H} & \mathrm{E} & \mathrm{Y} & \mathrm{L} & \mathrm{I} & \mathrm{E} & \mathrm{Q} & \mathrm{L} & \mathrm{Q} & \mathrm{F} & \mathrm{T} & \mathrm{G}> & 232\end{array}$ TCCGAGACCGCCACCCCCTCCACCACCTCTCAGTCCACCCAGAACATCCGTCTGAACTTC 1260 $\begin{array}{lllllllllllllllllllll}S & E & T & A & T & P & S & T & T & S & Q & S & T & Q & N & I & R & L & N & F> & 252\end{array}$

AACCACCCCACCAAGTACCTGGCCTGGAACTTCAGCAACCCCAGCCCCCTGGCATACGGC 1320 $\begin{array}{lllllllllllllllllllll}\mathrm{N} & \mathrm{H} & \mathrm{P} & \mathrm{T} & \mathrm{K} & \mathrm{Y} & \mathrm{L} & \mathrm{A} & \mathrm{W} & \mathrm{N} & \mathrm{F} & \mathrm{S} & \mathrm{N} & \mathrm{P} & \mathrm{S} & \mathrm{P} & \mathrm{L} & \mathrm{A} & \mathrm{Y} & \mathrm{G}> & 272\end{array}$

CAGTACACCGCCACCGCCAACCTGACCGCCAGCTCCAACGTGCTGTATGGCGACGTGCCC 1380 $\begin{array}{lllllllllllllllllllll}Q & Y & T & A & \text { T } & \text { A } & \text { N } & \text { L } & \text { T } & \text { A } & \text { S } & \text { S } & \text { N } & \text { V } & \text { L } & \text { Y } & \text { G } & \text { D } & \text { V } & \text { P }> & 292\end{array}$ 


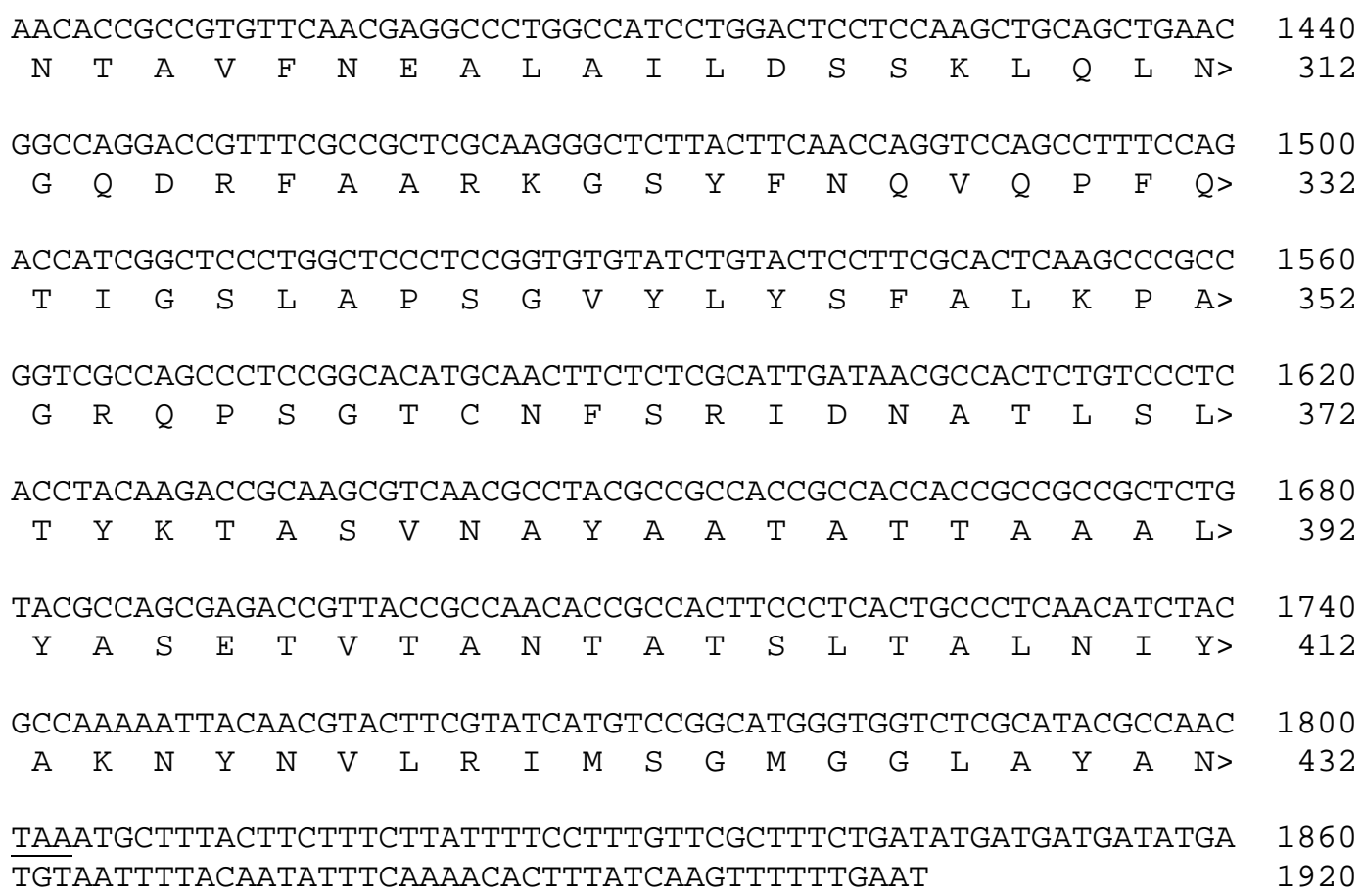

Der Rahmen markiert eine Abfolge von Adenosinnucleotiden in der Promotorregion des Gens. Fett gedruckte Buchstaben markieren die Sequenzen der degenerierten Oligonucleotide. Das Stopcodon ist unterstrichen. Die Sequenz ist unter der $\mathrm{Zu}-$ gangsnummer GenBank AF076921 eingetragen. 


\section{Nuclein- und Aminosäuresequenz von vcr8 mit 5'- und 3'-untranslatierten Bereichen}

TTCTGTCATTTTTCCAAACATCTTCCCCAGCAACCAACCATATCAGAGAAAgTCCAAAG 60 TTAACATAATTGCGCTGCTTTTCAGACCGACGAGTTCATTTTTAATGGTAATATATTTAA 120 ATGTCATTGATTTGTGCGGTGTGTGGTAAACGGGTTGACATGCTTGATTCTCTTGCCCCT 180 GCGACGACAAGAAATCCTTTTGTGCAAAACACAGGCTCCGAGAATACCATGCATGCCCAA 240 CCTTGGAAACCAAGGGAAAGGTTCACCTTGAGAAGATCGTTGCAGATAAAGTTAAGAATA 300 GACTGTGACTATATCGATAGACGTTAAAAATCACATAAA AAAAAAATCATAGTAATAA 360

AAGCAATCATGCCAGGTGCCATTTCTCAGCTTGTGTCATATGGTGCCCAGGATGTATACC 420 $\begin{array}{lllllllllllllllllll}M & P & G & A & I & S & Q & L & V & S & Y & G & A & Q & D & V & Y>\ldots\end{array}$

TCACTGGAAACCCCCAAATCACATTCTTCAAGGCAATCTATAGGAGGTACACAAACTTTG 480 $\begin{array}{llllllllllllllllllllll}\mathrm{L} & \mathrm{T} & \mathrm{G} & \mathrm{N} & \mathrm{P} & \mathrm{Q} & \mathrm{I} & \mathrm{T} & \mathrm{F} & \mathrm{F} & \mathrm{K} & \mathrm{A} & \mathrm{I} & \mathrm{Y} & \mathrm{R} & \mathrm{R} & \mathrm{Y} & \mathrm{T} & \mathrm{N} & \mathrm{F}> & & 37\end{array}$ CAATGGAATCCATCCAGCAgtCCATGgATgGtACAACAgAtTTtGgtAAgtTCCCTACAT 540

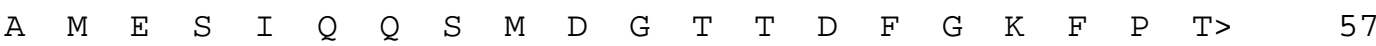
GCACCATATCACGTAATGGAGACCTTGCAGGAGCTATTTGGATCGAGGTAACTTTGCCAT 600

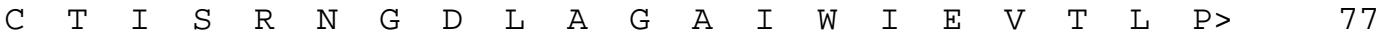

CCCTTCTTGGGTATAACATCACCCCCACTCCCCCCATTTCTCCTGGTTCGTCTACTCTCC. . 660 \begin{tabular}{lllllllllllllllllllll}
$S$ & L & L & G & Y & N & I & T & P & T & P & P & I & S & P & G & S & S & T & L> & \\
\hline
\end{tabular}

AAAACGCATCAAACGTGATGGCAAACACAAGTTTGTTTACAGATACATCTGGTAACTACT 720

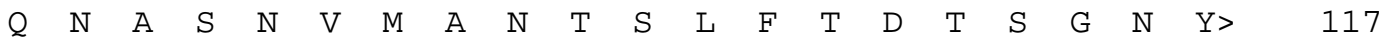

GGCAAACCAGAAATGGCGCGGCATATTCTAACCTTGTTGCTGCCAACCTGAATGGTATTT 780

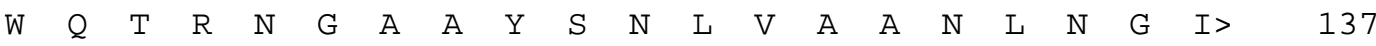

ACTATGCCAGTGCAGACACTGCCAATATGGCAAACACTGCTGCTTATTCTGGCAACATCA 840

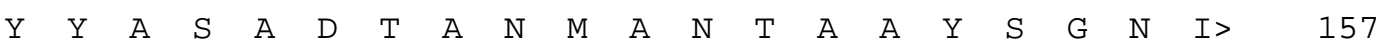
TCACATGGCCTTACATGACATTCACCGGAAATGGGATGCCAAACACCCCTGCAATTTCCA 900

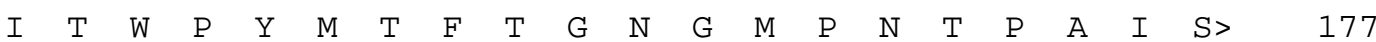
ACGTGAGCATTCCCACTTCAAACCTCCGATATGTGAACGGTGTTGGTCTTGCGCTCTTCA 960 \begin{tabular}{lllllllllllllllllllll}
$\mathrm{N}$ & $\mathrm{V}$ & $\mathrm{S}$ & $\mathrm{I}$ & $\mathrm{P}$ & $\mathrm{T}$ & $\mathrm{S}$ & $\mathrm{N}$ & $\mathrm{L}$ & $\mathrm{R}$ & $\mathrm{Y}$ & $\mathrm{V}$ & $\mathrm{N}$ & $\mathrm{G}$ & $\mathrm{V}$ & $\mathrm{G}$ & $\mathrm{L}$ & $\mathrm{A}$ & $\mathrm{L}$ & $\mathrm{F}>$ & \\
\hline
\end{tabular}

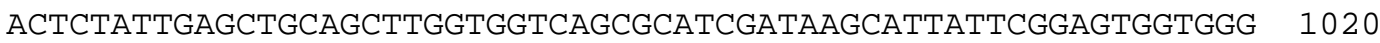
\begin{tabular}{lllllllllllllllllllll}
$\mathrm{N}$ & $\mathrm{S}$ & $\mathrm{I}$ & $\mathrm{E}$ & $\mathrm{L}$ & $\mathrm{Q}$ & $\mathrm{L}$ & $\mathrm{G}$ & $\mathrm{G}$ & $\mathrm{Q}$ & $\mathrm{R}$ & $\mathrm{I}$ & $\mathrm{D}$ & $\mathrm{K}$ & $\mathrm{H}$ & $\mathrm{Y}$ & $\mathrm{S}$ & $\mathrm{E}$ & $\mathrm{W}$ & $\mathrm{W}>$ & \\
\hline
\end{tabular}

ACATTTGGTCGGAGCTCACCGAGACTTCTGAGCATCTGCAAGGCTATAACCAGATGGTTG 1080 $\begin{array}{llllllllllllllllllllll}D & I & W & S & E & L & T & E & T & S & E & H & L & Q & G & Y & N & Q & M & V> & & 237\end{array}$ GCCGGTACGATCCTGCGTACTACAATAACAATTGGGATGTGACTCAAGCAAGGGGTGGGA 1140 \begin{tabular}{lllllllllllllllllllll}
$G$ & $R$ & $Y$ & $D$ & $P$ & $A$ & $Y$ & $Y$ & $N$ & $N$ & $N$ & $W$ & $D$ & $V$ & $T$ & $Q$ & $A$ & $R$ & $G$ & $G>$ & \\
\hline
\end{tabular}

CATACTACATTCCTCTGAAGTTCTGTTACAACCTGAACCCCGGTCAGTACATGCCCCTTG 1200 \begin{tabular}{lllllllllllllllllllll}
$\mathrm{T}$ & $\mathrm{Y}$ & $\mathrm{Y}$ & $\mathrm{I}$ & $\mathrm{P}$ & $\mathrm{L}$ & $\mathrm{K}$ & $\mathrm{F}$ & $\mathrm{C}$ & $\mathrm{Y}$ & $\mathrm{N}$ & $\mathrm{L}$ & $\mathrm{N}$ & $\mathrm{P}$ & $\mathrm{G}$ & $\mathrm{Q}$ & $\mathrm{Y}$ & $\mathrm{M}$ & $\mathrm{P}$ & $\mathrm{L}>$ & \\
\hline
\end{tabular} TGGCTCTGAGTTATCACGATCTCAAGCTCAACTTTGACATCAATAATTATCTCAACTGTG 1260

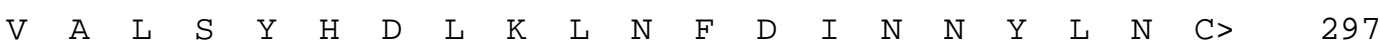


TCCGGTGCAATTATCCCGTGACGAGTCTGACTTCTATGGTTGGTTCCAACCCTCTGAGTA 1320

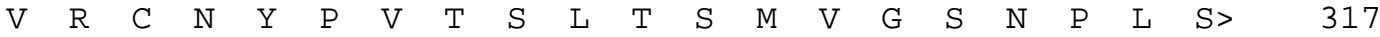

TCTCTAACTTCAAGTTGTACTGCGATTACATTTTCCTTGATGCCCCTGAGCGCATTAGgA 1380

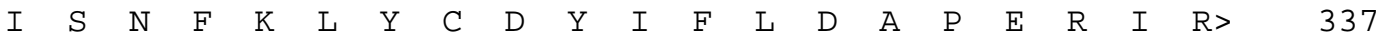

TGTCCGAGATTCAGCATGAATATCTGGTGACACAGCTCCAGTGGCAGGGTTCTGAACCGG 1440

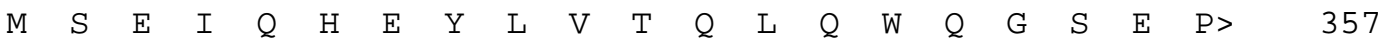

TGACTGCCCCTAGTGCGCCTAATGGCACGACAAACCGGAAATTCACCCTGAATTTCAACC 1500

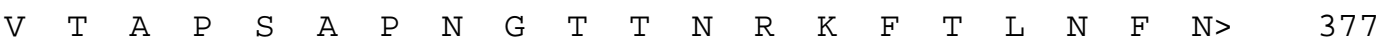

ACCCCGTCAAGTGTCTTATTATAGCATATCAGGCTGCCAGCTCATACGAACAAGGTGATG 1560

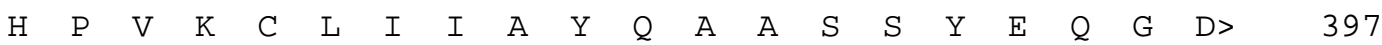

CTGTGAATGGCAACGATATCTTCAACTATCAAATACCAGGGGATGATGACGCTGAGATTA 1620

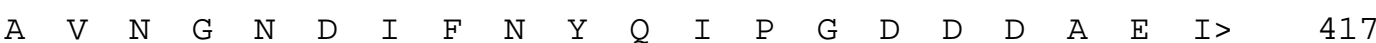

TTGAGTCCATGACTCTGCTCATCAACGGAAGCGAGCGTTTCTCTGCGCGCCCTGGTGCCT 1680

\begin{tabular}{lllllllllllllllllllll}
$I$ & $E$ & $S$ & $M$ & $T$ & $L$ & $L$ & $I$ & $N$ & $G$ & $S$ & $E$ & $R$ & $F$ & $S$ & $A$ & $R$ & $P$ & $G$ & $A>$ & \\
\hline
\end{tabular}

ATtTCCGTCTTGTCCAGCCCTATCAgCACAgTCTGCGCACCCCCTCCAAGAGTATCTATC 1740

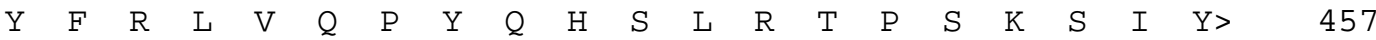

TGTATTCCTTTGCCCTAGAGGACATTGACTCCAAGCAGCCCAATGGCAGTGCCAACTTTA 1800

$\begin{array}{llllllllllllllllllllll}\mathrm{L} & \mathrm{Y} & \mathrm{S} & \mathrm{F} & \mathrm{A} & \mathrm{L} & \mathrm{E} & \mathrm{D} & \mathrm{I} & \mathrm{D} & \mathrm{S} & \mathrm{K} & \mathrm{Q} & \mathrm{P} & \mathrm{N} & \mathrm{G} & \mathrm{S} & \mathrm{A} & \mathrm{N} & \mathrm{F}> & & 477\end{array}$

CCCGTTACGACTCTGCCCAGCTCCAGATGGTTCTCAACCCCAACTTGCCCTCCGGTCGTT 1860

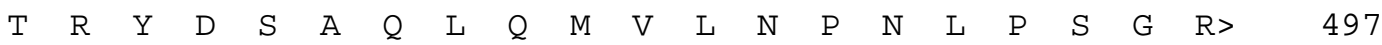

TCCAGATTTATGCGCCCAATTACAACATTCTACGCGTGGCAGCAGGTATAGGCGGTCTCG 1920

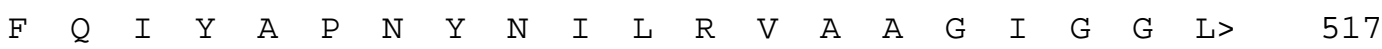

CATTTGCGAACTAATTAATACTCATCCTCGCTGTCAGACACCTCCTCGCCGCGCGCCTT 1980

A $\mathrm{F} A \mathrm{~N}>\quad 521$

CCGCATCTTCCGTGACTTAGCAGCGTTGCTTCTTTTCTTGACGAGTCAACTCCCGCTTCT . . 2040 CTTCCTTTACCTTGTGGGTGTTACCAAGAGCATCAGGGTACTCGGTCTCCCGCTTGAGCT 2160

Der Rahmen markiert eine Abfolge von Adenosinnucleotiden in der Promotorregion des Gens. Fett gedruckte Buchstaben markieren die Sequenzen der degenerierten Oligonucleotide. Das Stopcodon ist unterstrichen. Die Sequenz ist unter der $\mathrm{Zu}-$ gangsnummer GenBank AF076922 eingetragen. 


\section{Danksagung}

Diese Arbeit wurde von Februar 1996 bis Dezember 1999 in der Abteilung „Biophysik der Pflanze“ des Albrecht-von-Haller-Instituts für Pflanzenwissenschaften angefertigt.

Bedanken möchte ich mich

bei Prof. Dr. Dietrich Gradmann für die Möglichkeit, diese Arbeit in seinem Labor anzufertigen. Besonderer Dank gilt PD Dr. Gerhard Thiel für die Betreuung und sein Engagement im Kcv-Projekt;

bei der Abteilung Biophysik für ihre Freundschaft und die Anteilnahme an allen Lebenslagen;

bei Prof. James Van Etten (Universität von Nebraska, USA) und Michael Nelson (Megabase Research Inc., Nebraska, USA) für die Zusammenarbeit im Kcv-Projekt. Besonderen Dank an James Van Etten für die Möglichkeit, am PBCV-1 Genomprojekt mitzuarbeiten und die zur Verfügung gestellte DNA von Chlorellavirus PBCV-1.

Sabrina Gazzarrini (Universität Mailand, Italien) danke ich für die Versorgung mit Daten, Daten, Daten....

Dank auch Dr. Andreas Wolf für Unterstützung in Computerfragen und die CVG-1 DNA; Dr. Christian Derst (Universität Marburg) dafür, daß er Ordnung in die phylogenetischen Analysen gebracht hat; Dr. Michael Hollmann (Max-Planck-Institut für Experimentelle Medizin, Göttingen) für den Vektor pSGEM.

Bei Sandra Schönberg möchte ich mich besonders dafür bedanken, daß wir unsere Arbeiten, uns selbst und unsere Zukunftspläne in den letzten drei Jahren gemeinsam entwickeln konnten.

Finaler Dank an Stefan, den Mann mit dem Verwöhnaroma, und meine Familie, deren Rückhalt das Fundament dieser Arbeit war. 


\section{Lebenslauf}

Barbara Ebert

geb. Plugge

28.12.1970 geboren in Braunschweig

1977-1980 Besuch der Grundschule in Dettum

1980-1982 Besuch der Orientierungsstufe in Sickte

1982-1989 Besuch des Gymnasiums Gaußschule in Braunschweig

08.05.1989 Hochschulreife

1989-1990 Au-Pair in Hanover, New Hampshire (USA)

1990-1996 Studium der Biologie an der Georg-August-Universität Göttingen

03.07.1992 Diplomvorprüfung im Fach Biologie

1995-1996 Diplomarbeit am Pflanzenphysiologischen Institut der Universität Göttingen, Abteilung Biophysik der Pflanze

01.02.1996 Diplom im Fach Biologie

1996-1999 Dissertation am Albrecht-von Haller-Institut für Pflanzenwissenschaften der Universität Göttingen, Abteilung Biophysik der Pflanze 